\title{
The diabetic foot
}

Citation for published version (APA):

Nabuurs-Franssen, M. H. (2005). The diabetic foot. [Doctoral Thesis, Maastricht University]. Maastricht University. https://doi.org/10.26481/dis.20050617mn

Document status and date:

Published: 01/01/2005

DOI:

10.26481/dis.20050617mn

Document Version:

Publisher's PDF, also known as Version of record

\section{Please check the document version of this publication:}

- A submitted manuscript is the version of the article upon submission and before peer-review. There can be important differences between the submitted version and the official published version of record.

People interested in the research are advised to contact the author for the final version of the publication, or visit the DOI to the publisher's website.

- The final author version and the galley proof are versions of the publication after peer review.

- The final published version features the final layout of the paper including the volume, issue and page numbers.

Link to publication

\footnotetext{
General rights rights.

- You may freely distribute the URL identifying the publication in the public portal. please follow below link for the End User Agreement:

www.umlib.nl/taverne-license

Take down policy

If you believe that this document breaches copyright please contact us at:

repository@maastrichtuniversity.nl

providing details and we will investigate your claim.
}

Copyright and moral rights for the publications made accessible in the public portal are retained by the authors and/or other copyright owners and it is a condition of accessing publications that users recognise and abide by the legal requirements associated with these

- Users may download and print one copy of any publication from the public portal for the purpose of private study or research.

- You may not further distribute the material or use it for any profit-making activity or commercial gain

If the publication is distributed under the terms of Article $25 \mathrm{fa}$ of the Dutch Copyright Act, indicated by the "Taverne" license above, 


\section{The Diabetic Foot}


(1) MH Nabuurs-Franssen, Roermond 2005

\section{ISBN $90-9019456-8$}

Coverdesign: Björn Nelissen

Layout:" Tiny Wouters

Production: Datawyse / Universitaire Pers Maastricht 


\section{The Diabetic Foot}

\section{Proefschrift}

ter verkrijging van de graad van doctor aan de Universiteit Maastricht,

op gezag van de Rector Magnificus, Prof. mr. G.P.M.F. Mols, wolgens het besluit van het College van Decanen,

in het openbaar te verdedigen

op vrijdag 17 juni 2005 om 12.00 uur

door

Marrigje Hubertine Nabuurs-Franssen geboren op 6 maart 1971 te Nijmegen 
Promotor

Prof. dr. A.C. Nieuwenhuijzen Kruseman

\title{
Co-promotores
}

\author{
Dr. N.C. Schaper \\ Dr. M.S.P. Huijberts
}

\section{Beoordelingscommissie}

Prof. dr. P.J.E.H.M. Kitslaar (voorzitter)

Prof. dr. J.M. Apelquist, University of Lund, Sweden

Prof. dr. C. Spreeuwenberg

Prof. dr. C.D.A. Stehouwer 
Voor pap en mam

en 'mijn mannen' 



\section{Contents}

Chapter 1 Introduction and outline of the thesis 9

Chapter 2 The diabetic foot: pathogenesis and clinical evaluation 19 Vascular Medicine 2002;2(2):221-228

Chapter 3 The effect of polyneuropathy on foot microcirculation 35 in Type 2 diabetes Diabetologia 2002;45:1164-1171

Chapter 4 Total contact casting of the diabetic foot in daily practice: a prospective follow-up study Diabetes Care 2005;28(2) 243-247

Chapter 5 Recurrent casting diabetic foot ulcers: effective and save? 65 Diabetes Care 2005, in press

Chapter 6 Quality of Life in diabetic patients: the impact of neuropathy and a foot ulcer

Submitted

Chapter 7 Health-Related-Quality of Life of diabetic foot ulcer patients and their caregivers

Diabetologia 2005, in press

Chapter 8 Summary and conclusions

Nederlandse samenvatting

Dankwoord

Curriculum vitae 

Chapter

1

Introduction and outline of the thesis
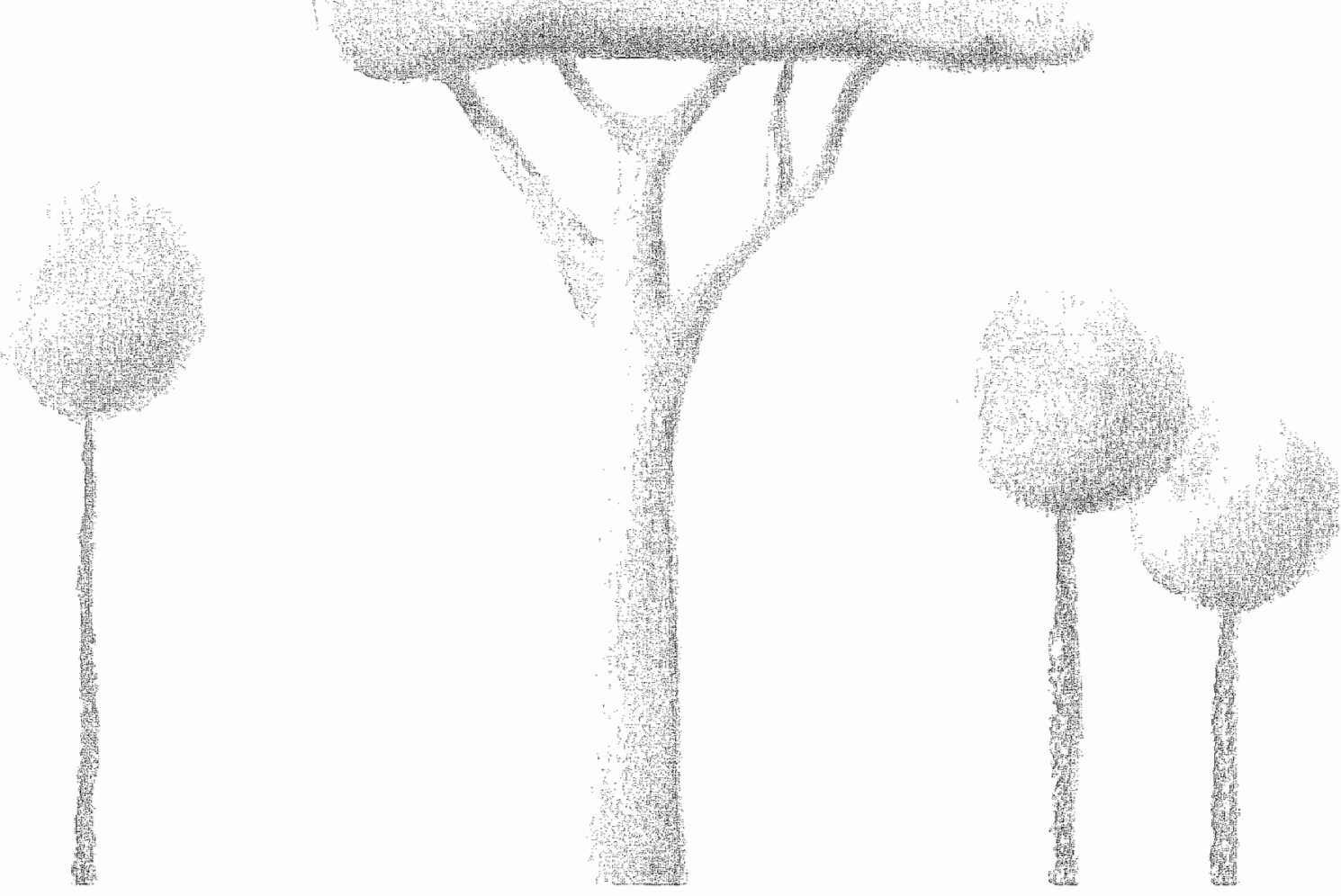
Chather 


\section{Diabetes and diabetic complications}

Diabetes mellitus is one of the most frequent chronic diseases. The World Health Organization estimates that 150 million people worldwide have diabetes and predicts a rise to approximately 330 million by the year $2025^{\prime}$. This increase will occur in particular in developing countries and will partly be due to population growth, ageing, unhealthy diets, obesity and sedentary lifestyles. There is, however, evidence that the increase of the number of diabetic patients is not only dependent on changes in demography, which may implicate that the future prevalence of diabetes mellitus is higher than expected and thus the impact on public health even greater 2.3 . The prevalence of diabetic patients in The Netherlanids was 244.000 in 1990 and expected to rise to approximately 300.000 in 2005 according to a model based on demographic changes. With a more dynamic model in which life expectancy data were included a $2.5 \%$ annual rise to 355.000 in 2005 was forecasted by Ruwaard et $a^{2}$. Even that calculation appeared to be an underestimation, partly due to changes in the diagnostic criteria for diabetes mellitus. At present the prevalence of diabetes mellitus in The Netherlands is $480.000^{4-7}$.

Diabetes mellitus ${ }^{8}$ is defined as chronic hyperglycemia due to insulin deficiency (Type 1 diabetes), or a combination of a relative insulin deficiency and impaired insulin sensitivity (Type 2 diabetes). The insulin deficiency in Type 1 diabetes is caused by an auto-immune destruction of the B-cells of the pancreas. Both genetic and environmental factors such as viral infections probably play a role in the development of this "insulitis". Insulin resistance plays a central role in the development of Type 2 diabetes mellitus and once the pancreas fails to produce sufficient amounts of insulin, blood glucose levels will rise. The insulin resistance is not only associated with impaired glucose homeostasis, but also with disturbances in various other systems. The causes of both the insulin resistance and the gradual decrease of insulin production by the pancreatic B-cells are still unclear, but in many patients hereditary factors and obesity seem to play a central role.

An important part of the burden of diabetes mellitus is caused by long-term or chronic complications. People can have undetected Type 2 diabetes for many years, with $\pm 50 \%$ of individuals with the condition being unaware of it ${ }^{9}$. At the time of diagnosis, over half of the patients have one or more diabetic complications ${ }^{10}$, although at this time the disease is often without many symptoms. Long-term or chronic complications of diabetes involve the eyes (retinopathy, glaucoma, cataract), the kidney (nephropathy), the nervous system (autonomic, sensory and motor neuropathy) and the heart and blood vessels (cardiovascular disease). Patients with diabetes are 2-4 times more likely to develop cardiovascular events than non-diabetic individuals, and cardiovascular disease is 
the major cause of premature death in diabetes. There is a relationship between the severity of hyperglycemia and the development of chronic complications ${ }^{11-14}$, although this is certainly not the only contributing factor. Good metabolic control is therefore important to delay the development of chronic complications ${ }^{15}$ and to improve quality of life. From the UKPDS ${ }^{16}$ we know that besides good metabolic control also tight blood pressure control, adequate lipid lowering and life style modification are very important measures to prevent or retard the development of diabetic complications. In diabetic patients with foot problems, macro- and microvascular complications tend to cluster and high mortality rates are observed in these patients' 1 .

\section{The diabetic foot}

\section{Prevalence and cost}

The development of a diabetic foot uicer is a serious complication of diabetes mellitus. The annual incidence of foot uicers is 2 to $6 \%{ }^{18}$, the prevalence 3 to $8 \%{ }^{19}$ and the recurrence rate is $70 \%$ after 5 years ${ }^{20}$. The treatment of diabetic patients with a foot ulcer is complex and usually protracted, with an average healing rate of 70 days $^{21}$ and after one year amputation has to be performed in approximately $15 \%$ of these patients ${ }^{22}$. Forty to $60 \%$ of all amputations of the lower extremity are performed in patients with diabetes and in some reports proportions of 70 to $90 \%$ are mentioned. More than $85 \%$ of these amputations are preceded by a foot ulcer progressing to deep infection and gangrene ${ }^{23.24}$. A recent study reported still 36 lower extremity amputations per 10.000 diabetic patients per year in the Netherlands ${ }^{25}$. The social impact of such amputations for the patient as well as the financial implications for the health care system are serious $^{26-30}$. US investigators have callculated that the cost for primary healing of a foot ulcer amounts to 7.000-10.000 dollars. The direct cost of an amputation associated with a diabetic foot ulcer are in the order of 30.000-60.000 dollars with corresponding long-term cost ( 3 years) of 43.100-63.100 dollars, mainly due to the increased need for home care and social services ${ }^{22,31,32}$. In addition to these costs, indirect costs due to loss of productivity, the individual patient's costs and loss of quality of life have to be considered as well ${ }^{18}$. Extrapolating these data the total annual cost for diabetic foot problems in Europe is estimated to be up to 4.930.000.000 Euro $^{33}$. This is about $20 \%$ of the total annual cost for the management of diabetic patients.

\section{Definition and pathogenesis}

Based upon the intermational consensus of the diabetic foot ${ }^{18}$ and the World Health Organization a "diabetic foot" is defined as: "infection, ulceration and/or 
destruction of deep tissues associated with neurological abnormalities and various degrees of peripheral vascular disease in the lower limb'. Diabetic neuropathy plays a central role in the development of diabetic foot problems. Diabetic neuropathy affects all different fibers: autonomic, sensory and motoric fibers. Autonomic neuropathy may result in reduced sweat secretion leading to dry skin with cracks and fissures. In sensory neuropathy, chronic or acute trauma are perceived less well, which may result in damage of the skin. Due to motor neuropathy, foot deformities develop and this results in areas of increased pressure with local callus formation, ischemia and eventually ulceration. Although peripheral arterial disease (PAD) in itself may result in an ischemic foot ulcer, the combination of neuropathy and PAD renders the vasculature more susceptible to occlusion during periods of elevated biomechanical pressure on the skin. Moreover, PAD delays ulcer healing. Infection is rarely the direct cause of an ulcer. However, once an ulcer is complicated by an infection, the risk for subsequent amputation is substantial. Several of the above described pathophysiological pathways act in concert in the majority of diabetic foot ulcers. These pathways to ulceration are summarized schematically in figure 1.1. An understanding of these pathways is essential in the treatment of diabetic patients with a foot ulcer: first for the diagnostic work-up and second for the treatment of these ulcers.

\section{Consensus and guidelines for the management of diabetic foot problems}

The complexity of diabetic foot problems and the different disciplines involved in the care for these patients have contributed to a lack of uniformity in diagnostic and treatment strategies. Several studies have shown that a multidisciplinary approach with a well-structured organization and appropriate facilities can reduce the risk of development and progression of diabetic foot disorders ${ }^{23,34-37}$. For this reason an international working group was formed in 1997 to formulate a consensus document on the management of diabetic foot problems and a practical guideline for diabetes clinics and primary care practioners with an interest in diabetes mellitus. This consensus document ${ }^{18}$ was prepared by a group of 4.5 international experts and was finally launched in 1999. Since then it has been translated in 22 languages and has also been endorsed by the World Health Organization. A report on these guidelines can be found in this thesis. 


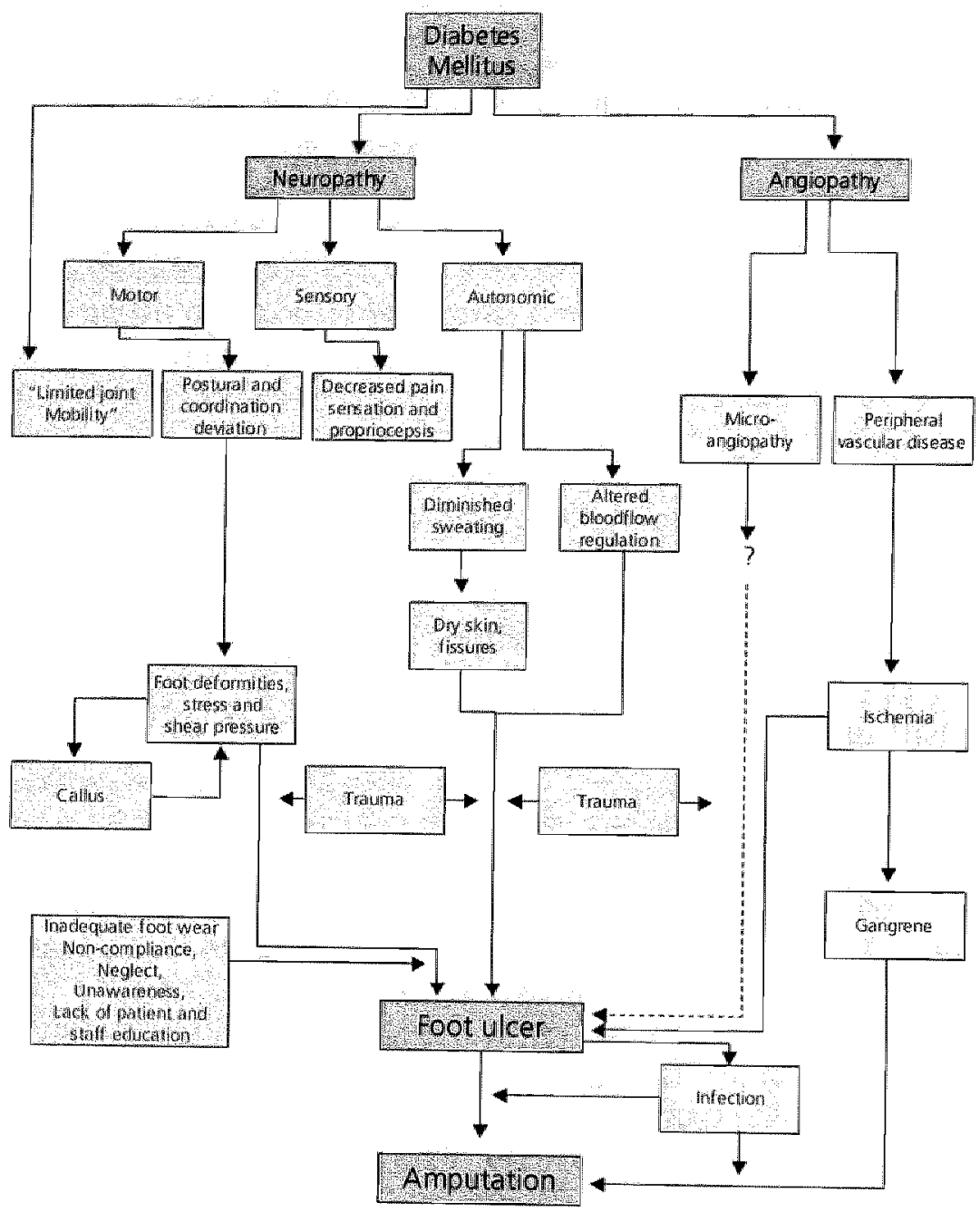

Source: Intermational Working Group on the Diabetic Foot. Apelqvist J, Bakker $K$, Van Houtum, WH Nabuurs-Fransen MH, Schaper NC, (ed). International Consensus on the Diabetic Foot. Schaper NC. Maastiricht, 1999. 


\section{Outline of the thesis}

The research described in this thesis addressed three aspects of diabetic foot ulcer problems:

1. the effect of neuropathy on the microcirculation in Type 2 diabetes mellitus (chapter 3);

2. the effect of biomechanical off-loading with total contact casting in the treatment of foot ulcers (chapters 4 and 5);

3. quality of life of diabetic foot ulcer patients (chapters 6 and 7);

4. these subjects are introduced by a review of the pathogenesis and clinical evaluation of the diabetic foot (chapter 2).

The study described in chapter 3 was performed to get more insight into the effects of polyneuropathy on skin hemodynamics in the pathogenesis and healing of foot ulcers. Several abnormalities have been found in the cutaneous microcirculation of diabetic patients. In Type 1 diabetes increased cutaneous blood flow, elevated skin capillary pressure in combination with an increased transcapillary fluid filtration during dependency have been observed. In Type 2 diabetes the effect of polyneuropathy on skin hemodynamics is still unclear. Little is known about the cutaneous total and capillary blood flow and foot swelling rate of patients with Type 2 diabetes with and without polyneuropathy. Clinical studies suggest that edema is a contributory factor in the pathogenesis and clinical outcome of foot ulcers. In chapter 3 these parameters were measured in the supine position and during dependency in Type 2 diabetic patients with and without neuropathy and in non-diabetic subjects.

Total contact casting (TCC) is seen as the golden standard in the treatment of neuropathic plantar foot ulcers. Up to 2004 , three randomised clinical trials have reported on the beneficial effects of TCC in diabetic patients with plantar foot ulcers $^{38-40}$. These studies have been performed in a relatively small number of patients (in total 60). Moreover, in these series only patients with pure neuropathic ulcers and no infection were included. The data are therefore not applicable to the majority of patients who often have combined neuropathic and angiopathic ulcers, and are complicated by infection as well. The study described in chapter 4 was therefore done to determine the efficacy and safety of TCC in daily practice in patients with neuropathic and neuro-ischemic ulcers, with and without infection. As diabetic foot ulceration is often a recurrent problem and no data are available on treatment of these recurrent ulcers, results of a study on repeated TCC treatment are described in chapter 5.

The studies described in chapter 6 and 7 involve determination of Health-RelatedQuality-of-Life of diabetic patients with a foot ulcer, using two different 
instruments. As mentioned before, diabetic foot ulcers have a large impact on the health care system. Treatment of these ulcers is expensive, due to a high demand on health resources as wound care, hospital admissions, surgical procedures, rehabilitation, and loss of work. Diabetic foot ulcers are, however, not only a burden for the health care system, but also and in particular for the patients and his or her carers. Patients are usually immobilised, are dependent on others for wound care, need to visit the outpatient clinic frequently, and fear of further deteriotation of the ulcer is often present. There are, however, only few data available on objective measurement of the impact of diabetic foot uicers on quality of life.

In Chapter 8 a summary of the main findings of this thesis is given. These data are discussed in the context of the recent literature and the implications for the daily care of diabetic patients with a foot ulcer are defined. Chapter 9 is a translation in dutch of chapter 8 . 


\section{References}

1. King $H$, Rewers $M$. Global estimates for prevalence of diabetes mellitus and impaired glucose tolerance in adults. WHO Ad Hoc Diabetes Reporting Group. Diabetes Care 1993:16:157-77.

2. Ruwaard $D$, Hoogenveen RT, Verkleij $H$, Kromhout D, Casparie Af, van der Veen EA. Forecasting the number of diabetic patients in The Netherlands in 2005. Am J Public Heath 1993:83:989-95.

3. Gijsen RBCA, Feskens EM, Poos MIJC. Neemt het aantal mensen met diabetes mellitus toe of at? In: Volksgezondheid Toekomst Verkenning, Nationaal Kompas Volksgezondheid. Bithowen: RIVM.

4. Mooy $\mathrm{JM}_{\text {n }}$ Grootenthuis PA, de Vries H, Valkenburg HA, Bouter LM. Kostense PI. Heine RU. Prevalence and determinants of glucose intolerance in a Dutch caucasian population. The Hoorn Study. Diabetes Care 1995:18:1270-3.

5. Vegt FD. Verhoogde glucoseconcentraties in nuchtere toestand en na glucosebelasting: risicofactoren vam het ontstaan van diabetes mellitus type 2: resultaten van de Hoom-sifulie. Ned Tijdschr Geneeskd2003;147:1414-8.

6. Stolk RP, Pols HA, Lamberts SW, de Jong PT, Hofman A, Grobbee DE. Diabetes mellitus, impaired glucose tolerance, and hyperinsulinemia in an elderly population. The Rotterdam Study. Am I Epidemial 1997:145:24-32.

7. Feskens EM, Bowles $\mathrm{CH}$, Kromhout D. Glucose tolerance in the elderly. Proceedings of the $32 \mathrm{nd}$ Dutch Federation meeting. Federation of Medical Scientific Societies 1991;95.

8. van Ballegooie E, Heine RV. Diabetes mellitus, Utrechit, 2003.

9. Harris Ml. Undiagnosed NIDDM: clinical and public health issues. Diabetes Care 1993;16:642-52.

10. Colagiuri S, Cull CA, Holman RR. Are lower fasting plasmia glucose levels at diagnosis of type Z diabetes associated with improved outcones? U.K. prospective diabetes study 61. Diaberes Care $2002 ; 25: 1410-7$.

11. DCCT rg. The effect of intensive treatment of diabetes on the development and progression of long-term complications in IDDM. New England louna/ of Medicine 1993;329:977-83.

12. MlcCarter RJ, Hempe JM, Gomez R, Chalew SA. Biological Variation in HbAlc Predicts Risk of retinopathy and nephropathy in Type 1 Diabetes. Diabetes Care 2004:27:1259-64.

13. Stratton IM, Adler Al, Neil HA, Matthews DR, Manley SE, Cull CA, Hadden D. Turner RC, Holman RR. Association of glycaemia with macrovascular and microvascular complications of type 2 diabetes (UIKPDS 35): prospective observational study. BM/2000;321:405-12.

14. UK Prospective Diabetes Study (UKPDS) Group. Effect of intensive bload-glucose control with metformin on complications in overweight patients with type 2 diabetes (UKPDS 34). Lancet 1998:352:85:-65.

15. Intensive diabetes management. implications of the DCCT and UKPDS. Diabetes Edur $2002: 28: 735-40$

16. U.K. Prospective Diabetes Study Group. Quality of life in type 2 diabetic patients is affected by complications but not by intensive policies to improve blood glucose or blood pressure control (UKPDS 37). Diabetes Care 1999;22:1125-36.

17. Boyko EJ, Ahroni JH, Smith DG, Davignon D. Increased mortality associated with diabetic foöt ulcer. Diabet Med $1996 ; 13: 967-72$.

18. International Working Group on the Diabetic Foot. Apelquist J, Bakker $K$, Van Houtum WH, Nabuurs-Franssen MH. Schaper NC (ed). International Consensus on the Diabetic Foot. Schaper NC. Maastricht, 1999

19. Ragnarson Tenrvall $G$, Apelqwist J. Cost-effectiwe management of diabetic foot ulcers. A. review Pharmacoeconomics 1997;12:42-53.

20. Apelquist J, Larsson J. Agardh CD. Long-term prognosis for diabetic patients with foot ullcers Jintern Med 1993:233:485-91.

21. Chantelau $E$, Breuer $U$, Leisch AC, Tanudjaja T. Reuter M. Outpatient treatment of unilateral diabetic foot ulcers with 'half shoes'. Diabet Med 1993:10:267*70.

22. Ramsey SD, Newton K, Blough D, McCulloch DK, Sandhu N, Reiber GE, Wagner Ely. Incidence, outcomes, and cost of foot ulcers in patients with diabetes. Diabetes Care 1999;22:382-7.

23. Larsson I, Apelquist J, Agardh CD, Stenstrom A. Decreasing incidence of major amputation in diabetic patients: a consequence of a multidisciplinary foot care team approach? Diabet Med $1995 ; 12: 770-6$. 
24. Reiber GE Vileikyte L, Boyko El, del Agulla M, Smith DG, Lavery LA, Boulton AJ. Causal pathways for incident lower-extremity ulcers in patients with diabetes from two settings. Diabetes Care $1999: 22: 157-62$

25. Wan Houtum WH, Rauwerda JA, Ruwaard D, Schaper NC, Bakker K. Reduction in diabetes-related lower-extremity amputations in The Netherland's: 1991-2000. Diabetes Care 2004:27:1042 w6.

26. Ragnarson Tennvall $G$, Apelquist I. Health related quality of life in patients with diabetes mellitus and foot ulcers. J Diabetes Complications 2000; 14:235-41.

27. van Houtum WH, Lavery LA, Harkless LE. The costs of diabetes-related lower extremity amputations in the Netherlands. Diabet Med 1995;12:777-81.

28. Peters EJ, Childs MR, Wunderlich RP, Harkess LB, Armstrong DG, Lavery LA. Functional Status, of persons with diabetes-related lower-extremity amputations. Diabetes Care 2001;24:1799-804.

29. Apelquist 1. Wound healing in diabetes. Outcome and costs. Clin Podiatr Med Surg 1998;15: $21-39$

30. Currie Cl, Morgan $\mathrm{CL}$. Peters IR. The epidemiology and cost of inpatient care for peripheral vascular disease, infection, neuropathy, and ukeration in diabetes. Diabetes Care 1998:21:42-8.

31. Apelqvist $J$, Ragnarson Tennvall $G$. Persson U, Larsson J. Diabetic foot ulcers in a multidisciplinary setting. An economic analysis of primary healing and healing with amputation. I intern Med $1994: 235: 463-71$

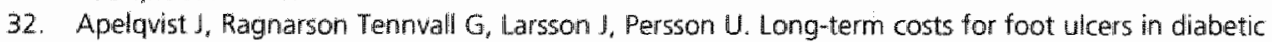
patients in a multidisciplinary setting. Foot Ankle int 1995; 166:388-94.

33. Eurodiale $\mathrm{sg}$. Optimal organisation of health care in diabetic foot disease. Maastricht, 2003 .

34. Edmonds ME, Blundell MP, Morris ME, Thomas EM, Cotton LT. Watkins PI. Improved survival of the diabetic foot: the role of a specialized foot clinic. Q $/$ Med $1986: 60: 763-71$.

35. Bakker $K$, Dooren J. A specialized outpatient foot clinic for diabetic patients decreases the number of amputations and is cost saving. Ned Tjdschr Geneeskd 1994;138:565-9.

36. Assail JP, Muhlhauser I. Pernet $A_{*}$, Gfeller $R_{*}$ Jorgens $V$, Berger $M$. Patient education as the basis for diabetes care in clinical practice and research. Diabetologia 1985:28:602-13.

37. Holstein PE, Sorensen S. Limb salvage experience in a multidisciplinary diabetic foot unit. Diabetes Care 1999:22 52:B97-103.

38. Armstrong $D G$, Nguyen $H C$, Lavery LA, van Schie $C H$, Boulton $A$, Harkless $L B$. Off-loading the diabetic foot wound: a randomized clinical trial. Diabetes Care 2001;24:1019-22

39. Caravaggi C, Faglia E, De Giglio R, Mantero M, Quarantiello A, Sommariva E, Gino M, Pritelli C. Morabito $A$. Effectiveness and safety of a nonremovable fiberglass off-bearing cast wersus a therapeutic shoe in the treatment of neuropathic foot ulcers: a randomized study. Diabetes Care 2000;23:1746-51.

40. Mueller MJ. Diamand IE, Sinarore DR, Delitto A, Blair VP, 3ra, Drury DA, Rose SI. Total contact casting in treatment of diabetic plantar ulcers. Controlled clinical trial. Diabetes Care 1989:12 $384-8$. 
The diabetic foot: pathogenesis and clinical evaluation

NC Schaper, MH Nabuurs-Franssen

Vascular Medicine 2002,2(2):22 7-228 


\section{Abstract}

Foot ulcers are one of the major complications of diabetes. They have a poor tendency to heal, which may result in long-term in-hospital treatment and/or amputation. The foot in diabetic patients is the crossroad of several pathological processes, in which almost all components of the lower extremity are involved: skin, subcutaneous tissue, muscles, bones, joints, blood vessels and nerves. An understanding of these processes is necessary for the development and application of preventative and management strategies. In this article the pathogenesis of the major abnormalities in the diabetic foot are described, the pathways to ulceration are summarised, and a systematic evaluation of a diabetic patient with a foot ulcer is given. 


\section{Introduction}

Diabetic foot ulcers pose a great burden to both the patient and the health care system. These ulcers have a poor tendency to heal and can result in infection and gangrene, leading to long-term in-hospital treatment and/or amputation'. The prevalence of diabetic foot ulcers has been estimated to be 3 to $8 \%$, and of all lower-extremity amputations, 40 to $60 \%$ are related to diabetes mellitus ${ }^{1.2}$. Foot ulcers have major negative effects on the quality of life due to morbidity, loss of work, loss of mobility, and reduction of social activities ${ }^{3,4}$. Moreover, these ulcers and their consequences are associated with major health care consumption and high costs ${ }^{1}$. In a prospective study, the direct costs to treat 274 individuals with a foot ulcer were approximately 4 million Euros annually ${ }^{5}$.

Traditionally, the feet of diabetic patients have received relatively little attention from health care workers and scientists. However, in recent decades our knowledge has grown, resulting in the development of new diagnostic and management strategies. Presently, a diabetic foot ulcer is seen as the result of a complex interplay of several factors, necessitating a multidisciplinary approach in both research and clinical practice. In this article the pathogenesis of the major abnormalities in the diabetic foot are described. The pathways to ulceration are summarized and a systematic evaluation of a diabetic patient with a foot ulcer is given.

\section{Pathogenesis}

\section{Polyneuropathy}

Distal symmetrical polyneuropathy is a major factor in the pathogenesis of foot ulceration. The gradual loss of nerve function affects almost all elements in the foot, including skin, connective tissue, bone and blood vessels. Distal polyneuropathy is characterized by a chronic and progressive sensory-motor loss. Clinical neuropathy can be defined as "the presence of symptoms and/or signs of peripheral nerve dysfunction in people with diabetes after exclusion of other

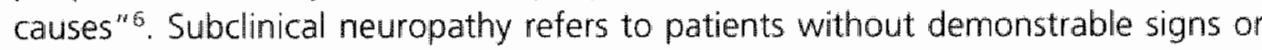
symptoms and can be detected with diagnostic procedures such as electrodiagnostic or (semi-) quantitative sensory tests ${ }^{7}$. Data on the prevalence of neuropathy in unselected groups of diabetic patients are relatively scarce. Crosssectional studies suggest that at least $50 \%$ of elderly patients with diabetes have clinical signs of sensory loss $s^{8}$, and in one prospective study ${ }^{9}$ clinical neuropathy was present in $42 \%$ of the patients with Type 2 diabetes 10 years after the initial diagnosis was made. 


\section{Chronic distal sensory and autonomic neuropathy}

In daily life our feet are continuously threatened by multiple minor and major insults, and loss of protective sensation is a cardinal event in the pathway to foot ulceration in many patients ${ }^{10}$. The sensory deficits include diminished perception of pain, temperature, light touch, and pressure ${ }^{7}$. Although some patients have symptoms such as paresthesia or pain, many patients do not have major symptoms and are not aware of the diminished protective sensation. Polyneuropathy is frequently accompanied by distal autonomic neuropathy, which leads to diminished sweat secretion and increased thermoregulatory shunt blood flow, resulting in a dry and warm foot ${ }^{5}$.

\section{Chronic motor neuropathy}

Although clinically less apparent, recent studies using quantitative measurements of muscle strength and MRI indicate that distal neuropathy is associated with diminished muscle strength and atrophy in the foot and the lower leg ${ }^{11-14}$. It is likely that this motor loss contributes to the development of foot deformities, but the mechanism remains to be clarified. However, it seems logical to assume that an imbalance of the extensors and flexors results in the typical clawing or hammering of the toes ${ }^{15}$. Such a deformity would increase the biomechanical loading of the metatarsal heads or the tip of the toes during standing and waiking. Moreover, if the height of the shoe at the forefoot region is insufficient, this may lead to ulcers on the dorsum of the toes.

\section{Increased Biomechanical Stress}

At present it is believed that the majority of neuropathic or neuro-ischemic foot ulcers are caused by chronic repetitive biomechanical stress due to elevated foot pressures and/or ill-fitting shoes". With the advent of optical electronic devices which measure plantar pressures while walking barefoot or in shoes, much has been learned about the pathogenesis of plantar foot ulcerations ${ }^{15}$. Cross-sectional and prospective studies have shown that elevated peak plantar pressures can predict future ulceration in patients with diabetic neuropathy ${ }^{46,17}$. This abnormal loading of the foot during standing and walking can be caused by foot deformities (such as claw toes or hallux valgus) and limited joint mobility ${ }^{18,19}$. In addition, changes in plantar tissue thickness ${ }^{20}$, and perhaps loss of skin elasticity in areas overlying bony prominences, could contribute to elevated foot pressures. The repetitive biomechanical stress induces the formation of callus. This callus further elevates foot pressures and is associated with a high risk of future ulceration in neuropathic patients ${ }^{21}$. Finally the skin breaks down, sometimes preceded by a subcutaneous haemorrhage, with the formation of a painless ulcer. 
It should be pointed out that a neuropathic foot does not ulcerate spontaneously. It is the combination of sensory loss and trauma (either acute or chronic repetitive stress) that leads to breakdown of the skin ${ }^{10}$. Abnormal plantar pressures can also be observed in patients with rheumatoid arthritis, but these patients have intact sensation and are not prone to develop foot ulceration? ${ }^{22}$. Although several abnormalities are associated with elevated plantar pressures during walking, identification of the specific cause(s) in an individual patient is frequently a clinical challenge ${ }^{23}$. Moreover, at present little is known about the role of shear stress, which theoretically might be an important pathogenic factor. Finally, some patients develop neuropathic or neuro-ischemic ulcers on sites such as the toes, the dorsum of the foot, or the lateral side of the foot. In many of these patients, ill-fitting shoes, not sensed by the patient, probably play an important role, frequently in combination with ischemia ${ }^{24}$. The measurement of these shoe related forces is a challenge for research and daily clinical practice.

\section{Peripheral Vascular Disease}

Atherosclerotic obstructive, peripheral vascular disease (PVD) is the most important factor related to the outcome of a diabetic foot ulcer'. PVD is a common finding in patients with Type 2 diabetes mellitus, with a prevalence of approximately 20 to $40 \%{ }^{25}$. In the Framingham study, diabetic patients were four times more likely to develop PVD than the general population ${ }^{26}$. In many patients the disease has no or few symptoms and runs a relatively benign course, but in others it leads to gangrene or impaired healing of a (neuro-) ischemic foot ulcer. Only a small number of these patients have a "pure" ischemic ulcer; the majority have a neuro-ischemic ulcer, with signs of both neuropathy and ischemia'. Although histologically there seem to be no major differences in the atherosclerotic lesions of the legs of diabetic and non-diabetic patients, PVD in diabetes does have certain typical characteristics. ${ }^{127}$.

PVD in diabetes frequently has a specific anatomical pattern, which can be interpreted as a sign of premature ageing of the vascular tree. The proximal vessels are relatively spared, with less involvement of the aortic iliac arteries and more extensive disease in the arteries of the lower leg ${ }^{28-30}$. Such distal disease is also observed in elderly patients without diabetes, in contrast to nondiabetic patients younger than 50 years who more frequently have aorta-iliac disease ${ }^{\text {. }}$. In diabetic patients, the atherosclerotic changes seem to be more extensive and also more aggressive, with a faster progression of disease ${ }^{32}$. McDaniel ${ }^{33}$ showed that patients with claudication and diabetes had a $35 \%$ risk of sudden ischemia and a $21 \%$ risk of major amputation, compared to 19 and $3 \%$, respectively, in non-diabetic patients. 


\section{Pathophysiology}

The major risk factors for the development of symptomatic PVD in the general population are older age, smoking, diabetes, and possibly hypertension ${ }^{32}$. Although clinically PVD and coronary heart disease (CHD) are clearly associated ${ }^{32}$. some studies suggest that the risk factors for atherosclerosis (such as hyperglycaemia, smoking, and hypercholesterolemia) in these two different vascular beds might not be identical and/or might have a different impact. in several prospective studies ${ }^{34}$, high blood-glucose levels and/or glycated haemoglobin predicted CHD in subjects with Type 2 diabetes. However, as suggested by one prospective study ${ }^{35}$ in Type 1 diabetic patients, hyperglycaemia seems to be a stronger risk factor for PVD than CHD. Also smoking was, in a general population, a stronger risk factor for PVD than $\mathrm{CHD}^{36}$. Both hyperglycaemia and smoking can result in the formation of advanced glycation end-products (AGEs), suggesting that these products might play a central role in the development or progression of PVD ${ }^{37}$. Although hypercholesterolemia was a risk factor for PVD in several epidemiological studies, not all have consistently shown a relationship between total cholesterol or $L D L$-cholesterol and PVD ${ }^{38.39}$. The same pattern is seen in intervention studies in which (LDL-) cholesterol was pharmacologically lowered, with both negative and positive studies $32.38,40$. However, several studies ${ }^{32,38,39,41}$ suggest that in both diabetic and non-diabetic patients, PVD is associated with an atherogenic dyslipidemia, which is characterized by elevated triglycerides, low levels of HDL-cholesterol and increased number of small dense LDL particles.

Apart from the more classical risk factors, several novel risk factors have been identified in the general population for the development of PVD (and atherosclerosis in other vascular beds), such as hyperhornocysteinemia, elevated markers of inflammation, and insulin resistance. Interestingly, it was shown in a recent cross-sectional population study". "that elevation of plasma homocysteine levels was associated with aorto-iliac disease, but not with isolated crural disease. In an earlier study the same research group showed that in diabetic patients plasma homocysteine levels are closely linked to kidney function ${ }^{42 a}$. Hyperhomocysteinemia could, therefore, be one of the links between diabetic nephropathy and (proximal) PVD ${ }^{43}$. Several studies ${ }^{44}$ have shown that circullating inflammatory mediators can predict the future development of coronary artery disease. The same pattern was observed in patients with PVD: elevated acute phase proteins (e.g. C-reactive protein), white blood cell count, and cytokines

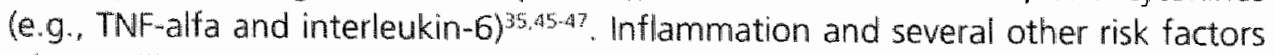
of PVD, like older age, Type 2 diabetes, and hypertension, are all associated with insulin resistance ${ }^{25}$. Interestingly, in both diabetic and non-diabetic patients with PVD, a relationship between insulin resistance and PVD has been observed, suggesting that insulin resistance could be one of the fundamental abnormalities 
in PVD ${ }^{48,49}$. Although an attractive hypothesis, further studies are needed to clarify the relationship of insulin resistance, dyslipidemia, and PVD. In addition, the mechanisms by which diabetes could promote a more distal localization of PVD remain to be further explored.

\section{Diabetic microangiopathy}

At present, diabetic microangiopathy is not seen as an important pathogenic factor in the development of a diabetic foot ulcer'. However, several abnormalities can be observed in the skin microcirculation of diabetic patients, which might increase the vulnerability of the skin or which might contribute to impaired wound healing. In this context it is important that a distinction be made between Type 1 and Type 2 diabetic patients. In addition, the effect of diabetic complications, such as nephropathy and neuropathy, should be taken into account.

Skin blood flow and skin capillary pressure are enhanced in uncomplicated patients with Type 1 diabetes ${ }^{50-51}$. Moreover, in these patients capillary permeability of water is increased and the arteriolar vasoconstriction in the skin of the foot is impaired during standing ${ }^{52,53}$. These abnormalities could contribute to the increased swelling rate of the foot during dependency, which in its turn could lead to tissue edema, hampering diffusion of oxygen and nutrients ${ }^{54}$. In Type 2 diabetic patients a different picture emerges. Basal skin blood flow and capillary pressure are not increased ${ }^{55}$ in these patients. In addition, permeability to water and foot swelling rate are unaltered ${ }^{56,57}$. However, the maximal vasodilator capacity of the skin microcirculation is greatly reduced in these patients ${ }^{58}$.

Polyneuropathy in both Type 1 and Type 2 diabetic patients results in increased shunt blood flow and an impaired vasodilatory response to various noxious stimuli $1^{53}$. In Type 1 diabetic patients, this increase in shunt blood flow is accompanied by a parallel increase in capillary blood flow" . In contrast, capillary blood flow is reduced in patients with Type 2 diabetes and polyneuropathy, as was recently shown by our group ${ }^{57}$. Further studies are necessary to determine if this "capillary steal phenomenon" contributes to the impaired wound healing of diabetic foot ulcers.

\section{Impaired wound healing}

Several lines of evidence suggest that, apart from repetitive biomechanical stress and impaired tissue perfusion, diabetic foot ulcers have an intrinsic defect in wound healing. Glycation of skin collagen and possibly of other matrix components probably impairs matrix degradation ${ }^{60}$. Leukocyte function is impaired 
in diabetic patients with poor metabolic control, resulting in defective chemotaxis, phagocytosis, and intracellular killing ${ }^{61-63}$. Increased shunting of glucose through the polyol pathway might be responsible for the defect in intracellular killing ${ }^{64}$. Moreover, recruitment of leukocytes is an important early event in wound healing and is impaired in experimental models of diabetes ${ }^{65}$. Recently Goova and coworkers ${ }^{65}$ showed that blockade of the AGE receptor in genetically diabetic mice accelerated the development of an inflammatory infiltrate, with restoration of the impaired wound healing. These data suggest that activation of the AGE receptor could play an important role in the disturbed wound healing in diabetes. Abnormalities have also been observed in the proliferative capacity of fibroblasts of diabetic patients, derived from normal skin and from foot ulcers ${ }^{67.68}$. The mechanism of this decreased fibroblast proliferation is unclear, but could be caused by impaired cellular responsiveness to one or more growth factors, as recently suggested by Loots et $a^{69}$. Although the topic of wound healing in diabetes has traditionally received little attention, the advent of new therapeutic strategies such as therapeutical matrix products, granulocyte colony stimulating factor, growth factors, and bio-engineered skin will, it is hoped, stimulate further research in this field ${ }^{70}$

\section{Clinical evaluation of a diabetic foot ulcer}

Diabetic foot ulcers are usually caused by a combination of factors. The triad neuropathy, deformity, and minor foot trauma was present in more than $60 \%$ of patients, treated in two specialised diabetic foot clinics ${ }^{71}$. Edema and ischemia, in combination with other factors, were thought to contribute to ulceration in $37 \%$ and $35 \%$ of the patients in this study, respectively. A multidisciplinary approach in the evaluation of a diabetic foot ulcer is therefore mandatory and a standardised strategy of evaluating diabetic foot ulcers is essential to guide further diagnostic work-up and therapy. The clinical evaluation of a diabetic foot ulcer, as discussed in this article, is largely based upon the International Consensus on the Diabetic Foot 1.72 . One of the pitfalls in this evaluation is the very limited value of historytaking in assessing the presence and the severity of a foot ulcer. In one population study ${ }^{8}$, almost $50 \%$ of the patients with an ulcer were not aware that they had a foot ulcer. Moreover, due to limited joint mobility or poor vision, patients may not be able to visualise a defect in the skin of the foot. Also, unfortunately, a substantial number of ulcers seem to be missed by diabetologists if they are specifically requested to examine the feet of patients with polyneuropathy ${ }^{73}$. Finally, underestimation of the severity of a lesion can falsely reassure the clinician. resulting in additional delay or inappropriate management ${ }^{2}$. 


\section{Site, size, and depth}

The location (site) of an ulcer can give clues to its cause and will help to determine if some form of pressure relief should be applied. Neuropathic ulcers are mostly located on the plantar sidle of the foot and especially on areas with elevated pressure. Ischemic or neuro-ischemic ulcers are more common on the tips of the toes or the lateral border of the foot'. Evaluation of the depth of an ulcer is essential to determine the extent of tissue involvement, which is a predictor of outcome (healing or amputation) ${ }^{24}$. However, the ulcer is frequently covered by callus or necrotic tissue, impairing adequate evaluation. An ulcer should, therefore, be debrided immediately during the first consultation, with the exception of noninfected ulcers with signs of severe ischemia. Due to neuropathy, anaesthesia is usually not necessary. If bone is probed in an infected ulcer before debridement, the risk of osteomyelitis is increased ${ }^{75}$.

\section{Ischemia}

Evaluation of the adequacy of tissue perfusion in the feet of diabetic patients can be a difficult clinical challenge, as almost all tests have a moderate accuracy in predicting outcome. Many patients do not have claudication or severe ischemic rest pain, probably due to sensory neuropathy'. However, if claudication or rest pain are present, the probability of amputation is greatly enhanced ${ }^{2}$. The pulses of the femoral, popliteal, dorsalis pedis, and posterior tibial artery should be palpated The proximal vessels should be auscultated for bruits, particularly the iliofemoral segment. If both foot arteries are palpated, severe ischemia is unlikely. However, the inter-and intraobserver variability of palpation of foot pulses is rather poor and severe PVD can be present in a minority of patients in the presence of palpable pulses $^{76,77}$. Therefore, further (non-) invasive vascular evaluation is indicated if the wound has no healing tendency in three weeks despite optimal therapy.

Additional signs of severe ischemia are skin necrosis, gangrene, and blanching of the feet on elevation with a red-purple discoloration on dependency (in the absence of infection)'. Other signs are probably of little value in diabetic patients ${ }^{76}$. The colour and temperature of the skin is usually not helpful as the feet of diabetic patients can be red and warm, despite (severe) ischemia. An explanation could be the relative high (thermoregulatory) shunt blood in diabetic patients with peripheral ischemia, as observed in one study ${ }^{78}$.

Non-invasive vascular evaluation is indicated in case of nonhealing ulcers, nonpalpable pulses, or other signs of ischemia. In nondiabetic patients measurement of the systolic arterial pressure at the ankle with a hand held 
Doppler is a reliable screening test for severe ischemia ${ }^{32}$. Also, in diabetic patients an absolute ankle pressure less than $50 \mathrm{mmHg}$ indicates critical limb ischemia. However, due to media calification, these arteries can become less compressible in diabetic patients, resulting in falsely elevated ankle pressures ${ }^{1,32}$. Ankle pressures above $50 \mathrm{mmHg}$, therefore, are of very limited predictive value. In contrast, measurement of systolic toe pressures is probably more reliable and can predict wound healing in diabetic patients, ${ }^{1,32}$. In particular, values below $30 \mathrm{mmHg}$ are associated with a poor outcome, and values between 30 and $50 \mathrm{mmHg}$ should alert the clinician of the possibility of severe PVD'. Unfortunately, toe pressure measurements can also be affected by media calcification in a minority of patients. Measurement of the transcutaneous pressure of oxygen $\left(\operatorname{tc} \mathrm{pO}_{2}\right)$ can give additional information on the probability of wound healing ${ }^{79,80}$. Wound healing is very unlikely if $\mathrm{tcpO}_{2}$ values are below $20 \mathrm{mmHg}$ and healing is likely with a $\mathrm{tcpO}_{2}$ value above $40 \mathrm{mmHg}^{32}$. Also, segmental limb systolic pressure measurements and plethysmographic pulse volume recordings can be informative in patients with suspected severe ischemia ${ }^{32}$.

If clinical and noninvasive assessments suggest significant PVD with a low probability of wound healing, or if the patient has persistent rest pain, revascularisation should be considered in all patients'. In these patients further investigations are necessary to localize the responsible arterial lesions, to grade their severity, and to assess the possibility of a revascularisation procedure ${ }^{32}$. As stated in the International Consensus, in all cases the arterial tree of the lower extremity should be visualised". It is crucial to visualise the entire tibial and foot circulation, as the former is a common location of the most significant occlusive lesion and the latter is an important potential site for the anastomosis of a distal bypass. In most centers angiography will be performed, but this technique might be replaced in the future by magnetic resonance angiography (MRA) 32.8 ? In addition, colour duplex ultrasound scanning can detect haemodynamic significant stenoses; the extent and the degree of occlusive lesions can also be accurately visualised ${ }^{32}$. This technique can help select patients with severe ischemia for a percutaneous balloon angioplasty, especially if clinical evaluation or noninvasive vascular assessment suggest a lesion proximal of the popliteal arteries ${ }^{32}$.

\section{Neuropathy and biomechanical evaluation}

The Semmes-Weinstein monofilaments are a simple tool to asses loss of protective sensation, particularly the 10 gram monofilament ${ }^{1.82}$. This cheap instrument is usually a hollow fibre, which buckles at a force of $10 \mathrm{~g}$. resulting in a standardised pressure at that weight ${ }^{83}$. The monofilament should be placed perpendicular to the surface of the skin; three plantar sites per foot are probably sufficient (inallux, 
MTP I, and MTP V)'. Additional simple sensory tests are light touch (cotton wisp) and vibration perception ( $128 \mathrm{~Hz}$ tuning fork). Vibration perception thresholds can be determined with semiquantitative devices such as the Biothesiometer or Neurometer $^{76}$.

Callus and foot deformities, such as hallux valgus, prominent metatarsal heads, or clawing of the toes, are easily recognised during inspection of the feet (performed both supine and in standing position) $)^{15}$. Mobility in the first toe (hallux rigidus) and in the ankle joint should be estimated in plantar ulcerations; these measurements are, however, difficult to standardise in clinical practise ${ }^{76}$. Finally, both shoes and socks should be examined; in particular, the fitting of the footwear should be evaluated.

\section{Infection}

Infection of the foot is one of the major reasons for lower-extremity amputation in diabetic patients ${ }^{7484}$. Unfortunately, there is as yet no golden standard for the diagnosis of infection in the diabetic foot and signs or symptoms can be very subtle, despite extensive tissue destruction'. The diagnosis of a superficial infection (not extending through the fascia) is made on clinical signs such as pus, erythema, foul smell, edema or pain. A swab taken of the surface of the ulcer is of little value for microbiological diagnosis, as the ulcer is usually colonised by various microorganisms ${ }^{85}$. These superficial infections are usually caused by a grampositive micro-organism, in particular 5 . aureus or a beta-haemolytic streptococcus $^{85}$. Deep foot infections frequently have a mixed flora, with gram-positive and - negative (an)aerobic microorganisms ${ }^{85}$. Samples for microbiological diagnosis are, preferably, pus or a curretement of the ulcer base, obtained after debridement, 185 . Systemic signs, such as elevated white blood cell count, erythrocyte sedimentation rate, or body temperature, are frequently absent in these deep infections (in almost $50 \%$ of the patients in one prospective study ${ }^{46}$ ). Foot infections in diabetic patients tend to have an aggressive course, which could be due to the specific anatomy of the foot, defective leukocyte function, neuropathy, vascular disease, and/or edema". These infections tend to spread rapidly into the different compartments of the foot. Swelling of the muscles in these compartments could result in a rise of the hydrostatic pressure above the capillary pressure, leading to an impaired microcirculation with subsequent muscle necrosis, starting a vicious cycle of edema, microvasculatory thrombosis, necrosis, and progressive infection ${ }^{87}$. Measurement of a high compartimental pressure above $25 \mathrm{mmHg}$ might be an indication for surgical decompression, but clinical studies on this important topic are scarce ${ }^{87}$.

Not only soft tissue infections but also osteomyelitis can pose diagnostic problems. As mentioned earlier, probing to bone before debridement in an ulcer with signs 
of infection, is suggestive of osteomyelitis ${ }^{75}$. A bone $X$-ray should be considered in any infected foot ulcer, but it may take several weeks before radiological changes appear and a normal $X$-ray does not exclude osteomyelitis $5^{1,85}$. In these cases, a repeat $X$-ray after 2 to 4 weeks can be helpful. The specificity of an X-ray is also relatively low, as bony abnormalities (e.g. acute Charcot neuro-osteoarthropathy) can also be caused by neuropathy. Bone scans are more sensitive, but again specificity is (relatively) low. At present, a MRI is seen as the most accurate imaging technique ${ }^{1,85,85}$. A more definitive diagnosis can be obtained with a bone biopsy, with subsequent microbiological and histological evaluation. However, information in the literature on the risks and pitfalls of a bone biopsy in diabetic foot infections is scarce.

\section{Conclusion}

The foot in diabetic patients is the crossroad of several pathological processes, which as a consequence of the diabetic state evolve slowly over time and which seem to interact closely. In these processes almost all components of the lower extremity are involved: skin, subcutaneous tissue, muscles, bones, joints, blood vessels, and nerves. A foot ulcer, however small it may seem, is the consequence of the interplay of these frequently irreversible changes. An understanding of these processes is necessary for the development and application of preventative and management strategies. 


\section{References}

1. International Working Group on the Diabetic Foot. Apelqwist I. Bakker K. Van Howtum WH, Nabuurs-Franssen MH. Schaper MC (ed). International Consensus on the Diabetic Foot. Schaper NC, Maastricht, 1999.

2. Apelquist $\mathrm{I}$, Larsson $\mathbb{J}$. What is the most effective way to reduce incidence of amputation in the diabetic foot? Diabetes Metab Res Rev2000;16 51:575-83.

3. Brod M. Quality of life issues in patients with diabetes and lower extremity ulcers: patients and Caregivers. Qual Life Res 1998;7:365-72.

4. Nabuurs-Franssen $M H$, van de Berg $R$, Redekop W, et al. Medical consumption and quality of life of diabetic foot patients in comparison to a background population. Diabetologia 2000;43:A224.

5. Apelquist $\downarrow$, Ragnarson Tennval $G$, Larsson J, et al. Longuterm costs for foot ulcers in diabetic patients in a multidisciplinary setting. Foot Ankte int 1995:16:388-94.

6. Boulton $A$, Gries FA, Jervell JA. Guidelines for the diagnosis and outpatient managenent of diabetic peripheral neuropathy. Diabet Med 1998;15:508-14.

7. Ziegler D. Diagnosis and management of diabetic peripheral neuropathy. Diabet Med 1996;13:534-8

8. Young MJ. Boulton A. MacLeod AF, et al. A multicentre study of the prevalence of diabetic peripheral neuropathy in the United Kingdom hospital dinic population. Diabetologia 1993;36:150-4.

9. Partanen J, Niskanen L, Lehtinen J, et al. Natural history of peripheral neurapathy in patients with non-insulin- dependent diabetes mellitus. N Eng/ / Med 1995;333:89-94.

10. Boulton AJ. The pathogenesis of diabetic foot problems: an overview. Diabet Med 1996:13: $512-6$

11. Simoneau GG, Ulbrecht JS, Derr JA, et al. Postural instability in patients with diabetic sensory neuropathy. Diabetes Care 1994;17:1411-21.

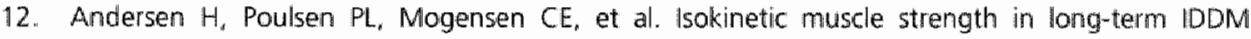
patients in relation to diabetic complications. Diabetes 1996;45:440-5.

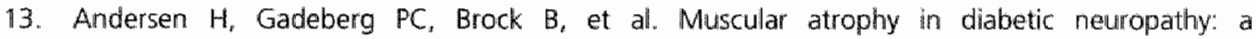
stereological magnetic resonance imaging study. Diabetologia 1997;40:1062-9.

14. Brash PD. Foster J, Vennart W, et al. Magnetic resonance imaging techniques demonstrate saft tissue damage in the diabetic foot. Diabet Med 1999;16:55-61.

15. Cawanagh PR, Ulbrecht JS, Caputo GM. New developments in the biomechanics of the diabetic foot. Diabetes Metab Res Rev 2000;16 51:56-510.

16. Frykberg $R G$, Lavery $L A$, Pham $H_{\text {, et }}$ al. Role of meuropathy and high foot pressures in diabetic foot ulceration. Diabetes Care 1998;21:1714-9.

17. Veves $A$, Murray HI, Young MJ, et al. The risk of foot ulceration in diabetic patients with hight: foot pressure: a prospective study. Diabetologia 1992;35:660-3.

18. Ahroni $1 \mathrm{H}$, Boyko El, Forsberg $\mathrm{BC}$. Clinical correlates of plantar pressure among diabetic veterans. Diabetes Care 1999:22:965-72.

19. Fernando DJ, Masson EA, Veves $A_{v}$ et al. Relationship of limited joint mobility to abnormal foot pressures and diabetic foot ulceration. Diabetes Care 1991:14:8-11.

20. Abowaesha $F$, van Schie $C H$. Griffths $G D$, et all. Plantar tissue thickness is related to peak plantar pressure in the high-risk diabetic foot. Diabetes Care 2001;24:1270-4

21. Murray HJ, Young MJ, Hollis $S_{n}$ et al. The association between callus formation wigh pressures and neuropathy in diabetic foot ulceration. Diabet Med 1996;13:979-82.

22. Masson EA, Hay EM, Stockley I et al. Abnormal foot pressures alone may not cause ulceration. Diaber Med 1989;6:426.8.

23. Cavanagh $P R$, Ulbrecht $I S_{*}$ Caputo GM. What the practising physician should know about diabetic foot biomechanics. In:Boulton Al, et al., ed. The foot in diabetes. 3rd edn. Chichester: Wiley; 2000:33-59

24. Apelquist J, Larsson 1, Agardh CD. The influence of external precipitating factors and peripheral meuropathy on the development and outcome of diabetic foot ulcers. J Diabet Complications $1990,4: 21-5$. 
Antrate 2

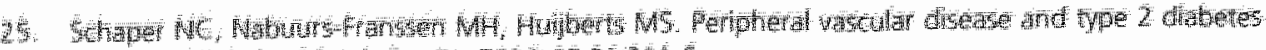

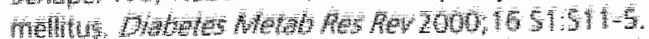

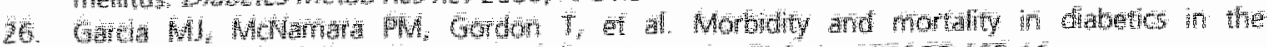

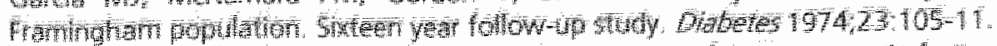

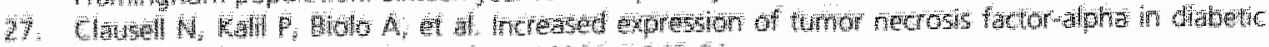

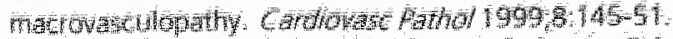

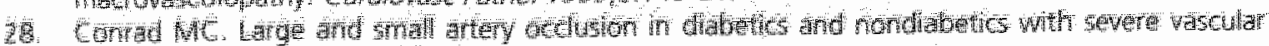

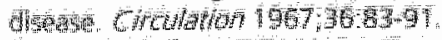

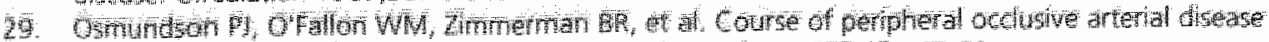

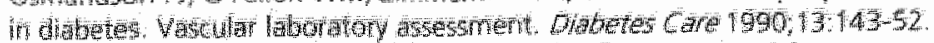

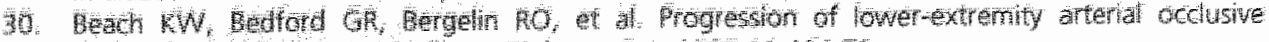

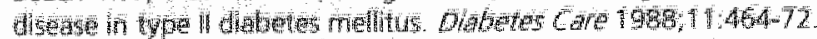

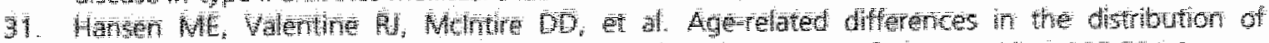

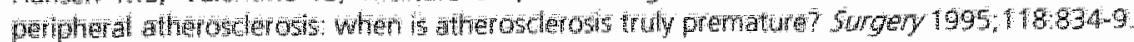

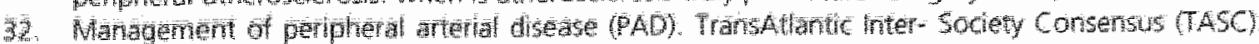

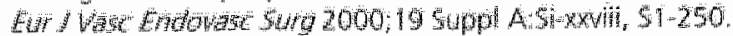

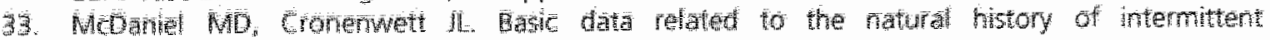

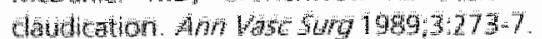

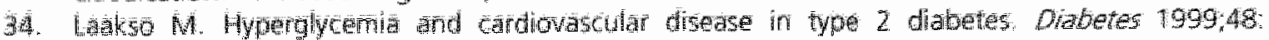
93742

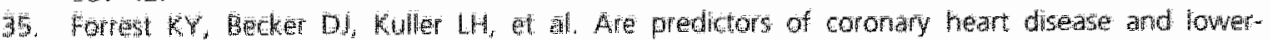

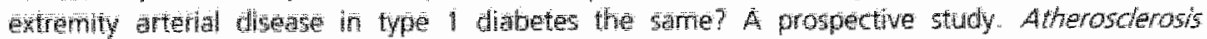
$2000+48 \cdot 159-69$

36. Fice if, Mowbiay $\mathrm{P}$, Le Al, en al. Retationship between smoking and cardiowascular risk lactors in the development of penpheral artarlal disease and cononery antery clisease: Edinburgh Artery

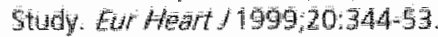

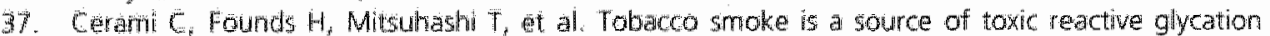

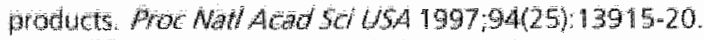

30. Vigna GB. Fellin R. Dyslipidemia in peripheral vascular disease. Curr opon Lipidor 1996;7:254-9

39. O'Neal CN, Lwicki 1. Ariarin Mz, et al. Lipid levels and penpheral vascular disease in diabetic and non-dibietic subjects. Atheroscterosis 1998; $136: 1-8$.

40. Pedersen TR. Kekshus $3_{\text {. Pyorala }} R_{n}$ et al. Effect of simwastatin on ischemic signs and symptoms in the Scandinavan simwastatin sumval study (45). Am /Cardio/ 1998;81:333-5

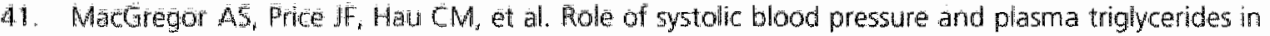
diabetic peripheral arterial disease. The Edinburgh Artery Study. Diabetes Care 1999:22:453-8.

42. Hoogeveen Ek, Kostense $\mathrm{PJ}$, Jakobs $\mathrm{C}$, et al. Hyperhomocysteinaemia is not associated with isolated crural arterial occlusive disease: The Hoom Study. J intern Med 2000;247:442-8.

42a. Hownd P. Tanow I, Teerlinz T. Stehouwer CD, Emeis II, Parving HH. Progession of plasma homcysteine and plasminogen activator inhibitor-1. Am / Kidney Dis 2001;38:1376-80.

43. Smuders YM, Rakic M. Slaats $\mathrm{EH}$, et al. Fasting and post-methionine homocysteine levels in MIDOM. Determinants and correlations with retinopathy, albuminuria, and cardiovascular disease. Diaderes Care 1999;22:125-32.

44. Ross $\mathcal{R}$. Atherosderosis--an inflammatory disease. N Engl / Med 1999:340:115-26.

45. Ridker PM, Cushman M, Stampfer MJ, et al. Plasma concentration of C-reactive protein and risk of developing peripheral vascular disease. Circulation 1998;97:425-8.

46. Fiotti N, Giansante C. Ponte $E$, et al. Atherosclerosis and inflammation. Patterns of cytokine regulation in patients with peripheral anterial disease. Atherosc/erosis 1999:145:5*-60.

47. Blann AD, McCollum CN. increased levels of soluble tumor necrosis factor receptors in atherasclerosis: no clear relationship with levels of tumor necrosis factor. Inflammation $1998 ; 22: 483-91$.

48. Matsumoto $K$, Miyake $S$, Yano $M$, et al. Insulin resistance and arteriosclerosis obliterans in patients with NDOM. Diabetes Care 1997;20:173:83

49. Price JF, Lee A.J, Fowkes FG. Hyperinsulinaemia: a risk factor for peripheral arterial disease in the non-diabetic general population. J Cardiovasc Risk 1996;3:501-5. 
50. Houben AJ, Nieuwenhuizen Kruseman AC, Bouhouch $E$, et at. Peripheral macro and microcirculation in short-term insulin-dependent diabetes mellitus: the role of prostaglandins in early haemodynamic changes. Eur J C/m Invest 1993;23:662-7.

51. Sandeman DD, Shore AC. Tooke JE. Relation of skin capillary pressure in patients with insulindependent diabetes mellitus to complications and metabolic control. N Engl / Med 1992;327: $760-4$.

52. Jaap $A$, Shore $A C$, Gartside $\mathbb{B}$, et al. Increased microvascular fluid permeability in young type 1 (insulin-dependent) diabetic patients. Diabetologia 1993;36:648-52.

53. Flym MD, Tooke JE. Diabetic neuropathy and the microcirculation. Dlabet Med 1995;12:298-301.

54. Rayman $G$, Williams 5A, Gamble 3 , et al. A study of factors governing fluid filtation in the diabetic foot. Eur J Clim /owest 1994:24:830-6.

55. Shore AC, Jaap A. Tooke JE. Capillary pressure in patients with NDDM. Diabetes 1994;43: 1 198-202.

56. Jaap $A$, Shore $A C_{x}$ Gamble J, el al. Capillary filtration coefficient in type II (non-insulimdependent') diabetes. I Diabetes Complications 1994;8:111-6.

57. Nabuurs-Franssen MH. Houben AI, Dennert J, et al. The effect of polyneuropathy of the foot microcirculation in type 2 diabetes. Diabetologia 2001;44:A1065.

58. Jaap AJ, Hammersley MS, Shore $A C_{s}$ et al. Reduced microvascular hyperaemia in subjects at risk of developing type 2 (non-insulin-dependent) diabetes mellitus. Diabetologia 1994;37:214-6.

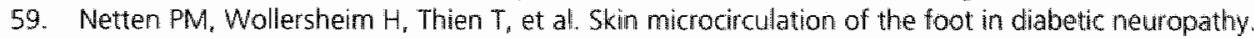
Clin So (tond) 1996;91:559-65.

60. Dyer DG, Dunn JA, Thorpe SR, et al. Accumulation of Maillard reaction products in skin collagen in diabetes and aging. I Clin Irvest 1993,91:2463-9.

61. Mowat A. Baum J. Chemotaxis of polymorphonuclear leukocytes from patients with diabetes mellitus. N Engl / Med 1971:284:621-7.

62. Davidson NJ, Sowden JM, Fletcher J. Defective phagocytosis in insulin controlled diabetics: evidence for a reaction between glucose and opsonising proteins. J Clin Patho/ 1984:37:783-6.

63. Repine JE, Clawson CC. Goetz FC. Bactericidal function of neutrophils from patients with acute bacterial infections and from diabetics. I/nfect Dis 1980;142:869.75.

64. Boland $\mathrm{OM}$. Blackwell $\mathrm{CC}$. Clarke $\mathrm{BF}$, et al. Effects of ponalrestat "an aldose reductase inhibitor, on neutrophil killing of Escherichia coli and autonomic function in patients with diabetes mellitus. Diabetes 1993:42:336-40.

65. Fahey TJ, 3rd, Sadaty $A$, Jones WG, 2nd, et al. Diabetes impairs the late inflammatory response to wound healing. I Surg Res 1991:50:308-13.

66. Goova MT, Li J, Kislinger $\mathrm{T}$, et al. Blockade of receptor for advanced glycation endeproducts restores effective wound healing in diabetic mice. Am J Patho/2001;159:513-25.

67. Rowe DW, Starman BI. Fujimoto WY, et al. Abnormalities in praliferation and protein synthesis in skin fibroblast cultures from patients with diabetes mellitus. Diabetes 1977;26:284-90.

68. Loots MAs Lamme EN, Mekkes JR, et al. Cultured fibrablasts from chronic diabetic wounds on the lower extremity (non-insulin-dependent diabetes mellitus) show disturbed proliferation. Arch Dermatol Res 1999;291:93-9.

69. Loots MAM, Kenter $5 \mathrm{~B}$. Au AL, et al. Fibroblast derived from chronic diabetic ulcers differ in their response to stimulation with $A G, F, I G F-1, b F G F$ and PDGF-AB compared to controls. Europ $j$ Cell Biol in press.

70. Edmonds $M$, Bates $M$, Doxford $M$, et al. New treatments in wher healing and wound infection. Diaberes Metab Res Rev 2000;16 51:551\%4.

71. Reiber GE, Wileikyte L. Boyko EJ, et al. Causal pathways for incident lower-extremity ulcers in patients with diabetes from two settings. Diabetes Care 1999:22:157-62.

72. Apelquist J. Bakker $\mathrm{K}$, wan Houtum WH, et al. International consensus and practical guidelines on the management and the prevention of the diabetic foot. International Working Group on the Diabetic Foot. Diabetes Metab Res Rev 2000;16 $51: 584-92$.

73. Schaper NC, Van Putten MA. Do diabetologist adequately detect patients at risk for amputation? Diabetologra 2001;44:A1076. 
25. Schaper MC, Naburs Franssen MH. Huiberts MS. Peripheral vascular disease and type 2 diabetes mellitus. Diabetes Metab Res Rev 2000;1651:511-5.

26. Garcia M, MCNamara PM, Gordon T, at al. Morbidity and mortality in diabetics in the Framingham population. Sixteen year follow-up study. Diaberes 1974;23:105-11

27. Claucell $N$, Kalli $P$. Biolo $A$, ef al. Increased expression of tumor necrosits factor-alpha in diabetic macrovasculopathy. Cardovasc Pathol 1999:8:145-51.

28. Conrad MC. Large and small artery occlusion in diabetics and nandiabetics with severe vascular disease Circulation 1967;36:83-91.

29. Osmundson PI, O'fallon WM, Zimmemen BR, et al. Course of peripheral ocdusive arterial disease in diabetes. Vascular laboratory assessment. Diabetes Care 1990; 13:143-5.2.

30. Beach KW, Bedford GR, Bergelin RO, et al. Progression of lower-extremity arterial acclusive disease in type ll diabetes mellitus. Diabetes Care 1988;11:464-72.

31. Hansen ME, Valentine $\mathrm{RJ}$, Mantire $\mathrm{DD}$, et al. Age-related differences in the distribution of peripheral atherosclerosis: when is atherosclerosis truly premature? Surgery 1995; 118:834-9.

32. Management of peripheral arterial disease (PAD). TransAtlantic Intep Society Consensus (TASC). Eur I Vasc Endavasc Surg 2000; 19 Suppl A.Si-xwiii, Sil-250.

33. MoDaniel MD, Cronenwett JL. Basic data related to the natural history of intermittent claudication. Ann Vasc Surg 1989;3:273-7.

34. Laakso M. Hyperglycemia and cardiovascular disease in type 2 diabetes. Diabetes 1999;48: $937-42$

35. Forrest $\mathrm{Kr}$, Becker $\mathrm{DJ}, \mathrm{Kuller} \mathrm{LH}$, et al. Are predictors of coronary heart disease and lowerextremity arterial disease in type 1 diabetes the same? A prospective study. Atherosclerosis $2000 ; 148: 159-69$.

36. Price IF, Mowbray PI, Lee Al, et al. Relationship between smoking and cardiovascular risk factors in the development of peripheral arterial disease and coronary artery disease: Edinburgh Artery Study. Eur Heart / 1 999;20:344-53.

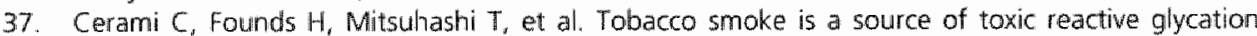
products. Proc Nat Acad Sci USA 1997:94(25):"3915-20.

38. Vigna GB. Fellin R. Dyslipidemia in peripheral vascular disease. Curr Opin Lipidol 1996;7:254-9.

39. O'Neal DN, Lewicki J, Ansari MZ, et al. Lipid levels and peripheral vascular disease in diabetic and non-diabetic subjects. Atherosiderosis 1998;136:1-8.

40. Pedersen TR, Kjekshus J, Pyorala $K$, et al. Effect of simwastatin on ischemic signs and symptoms in the Scandinavian simvastatin survival study (4S). Am / Cardiol 1998;81:333-5.

41. MacGregor AS. Price JF. Hau CM, et al. Role of systolic blood pressure and plasma triglycerides in diabetic peripheral arterial disease. The Edinburgh Artery Study. Diabetes Care 1999;22:453-8.

42. Hoogeveen EK, Kostense PI, Jakobs C, et all. Hyperhomocysteinaemia is not associated with isolated cural anterial ocelusive disease: The Hoorn Study. Intern Med 2000;247:442-8.

42a. Hownd P. Tarnow I. Teerlinz T. Stehouwer CD, Emeis JI, Parving HH. Progession of plasma homcystene and plasminogen activator inhibitor-1. Am I Kidney Dis 2001;38:1376-30.

43. Smulders $Y M$. Rakic $M$. Slaats $E H$, et al. Fasting and post-methionine homocysteine levels in NDDM. Determinants and correlations with retinopathy, albuminuria, and cardiovascular disease. Drabetes Care 1999:22:1:25-32.

44. Ross R. Atherasclerosis-an inflammatory disease. N Eng/ Med 1999;340:115-26.

45. Ridker PM. Cushman M, stampfer MJ, et al. Plasma concentration of C-reactive protein and risk of developing peripheral wascular disease. Circulation 1998:97:425-8.

46. Fiotti $N_{i}$ Giansante $C$. Ponte $E$, et al. Atherosclerosis and inflammation. Patterns of cytokine regulation in patients with peripheral arterial disease. Atherosclerosis 1999:145:51-60.

47. Btann AD. McCollum CN. Increased levels of soluble tumor necrosis factor receptors in atherosclerosis: no chear relationship with leveis of tumor necrosis factor. Inflammation $1998 ; 22: 483-91$.

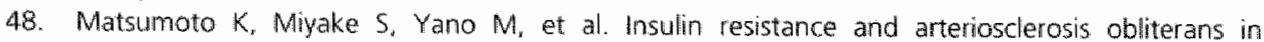
patients with NIDDM. Diabetes Care 1997:20:1738-43:

49. Price JF, Lee AJ, Fowkes FG. Hyperinsulinaemia: a risk factor for peripheral arterial disease in the non -diabetic general population. 1 Cardiovasc Risk 1996;3:501-5. 
50. Houben $A$, Nieuwenhuijzen Kruseman AC, Bouhouch $E$, et al Peripheral macro- and microcircutation in short-term insulin-dependent diabetes mellitus: the role of prostaglandins in early haemodynamic changes. Eu $/$ Clin hivest 1993:23:662-7.

51. Sandeman DD, Shore AC. Tooke JE. Relation of skin capillary pressure in patients with insulindependent diabetes mellitus to complications and metabolic control. N Engl $1 \mathrm{MeO} 1992 ; 327$ $760-4$.

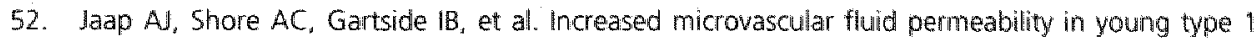
(insulin-dependent) diabetic patients. Diabetologia 1993;36:648-52.

53. Flynn MD, Tooke JE. Diabetic neuropathy and the microcirculation. Diabet Med 1995; 12:298-301.

54. Rayman $G$, Williams $S A$, Gamble $\rfloor$, et al. A study of factors governing fluid filtration in the diabetic foot. Eur / Clin Invest 1994:24:830-6.

55. Shore AC. laap Al, Tooke JE. Capillary pressure in patients with NIDDM. Diabetes 1994,43: $1198-202$.

56. Jaap Al, Shore AC, Gamble J, et al. Capillary filltration coefficient in type Il (non-insulindependent) diabetes. J Diabetes Complications 1994:8:111-6.

57. Nabuurs-Franssem $M H_{*}$ Houben $A J_{*}$ Dennert $J_{0}$ et al. The effect of polyneuropathy of the foot microcinculation in type 2 diabetes. Diabetologia 2001:44:A1065.

58. Jaap AJ, Hammersley MS, Shore AC, et al. Reduced microvascular hyperaemia in subjects at risk of developing type 2 (non-insulin-dependent) diabetes mellitus. Diabetologia 1994;37:214-6.

59. Netten PM. Wollersheim $H_{*}$ Thien $T$, et al. Skin microcirculation of the foot in diabetic neuropathy. Clin Sal (Lond) 1996:91:559-65.

60. Dyer DG, Dunn JA, Thorpe SR, et al. Accumulation of Maillard reaction products in skin collagen in diabetes and aging. I Clin Invest 1993:91:2463-9.

61. Mowat A, Baum 1. Chemotaxis of polymorphonuclear leukocytes from patients with diabetes mellitus. NEngl/ Med 1971;284:621-7.

62. Davidson NJ, Sowden JM, Fletcher 1. Defective phagocytosis in insulin controlled diabetics: evidence for a reaction between glucose and opsonising proteins. I Clin Pathol 1984:37:783-6.

63. Repine JE, Clawson CC. Goetz FC. Bactericidal function of neutrophils from patients with acute bacterial infections and from diabetics. I infect Dis 1980;142:869-75

64. Boland $\mathrm{OM}, \mathrm{Blackwell} \mathrm{CC}, \mathrm{Clarke} \mathrm{BF}$, et al. Effects of ponalrestat, an aldose reduictase inhibitor, on neutrophil killing of Escherichia coli and autonomic function in patients with diabetes mellitus. Diabetes 1993;42:336-40.

65. Fahey TJ, 3rd, Sadaty A, Jones WG, 2nd, et al. Diabetes impairs the late inflammatory response to wound thealing. I Surg Res 1991;50:308-13.

66. Goova MT, Li J, Kislinger T, et al. Blackade of receptor for advanced glycation end-products restores effective wound healing in diabetic mice. Am J Patho/2001;159:513-25.

67. Rowe DW, Staman BJ. Fujimoto WY, et al. Abnormafities, in proliferation and protein synthesis in skin fibroblast cultures from patients with diabetes mellitus. Diabefes 1977:26:284-90.

68. Loots MA, Lamme EN, Mekkes JR, et al. Cultured fibroblasts from chronic diabetic wounds on the lower extremity (non-insulin-dependent diabetes mellitus) show disturbed proliferation. Arch Demator Res 1999:291:93-9

69. Loots MAM, Kenter $5 \mathrm{~B}$, Au AL, ef all. Fibroblast derived from chronic diabetic ulcers differ in their response to stimulation with $\mathrm{AGF}$, IGF-1, bFGF and PDGF-AB compared to controls. Europ I Cell Biol, in press.

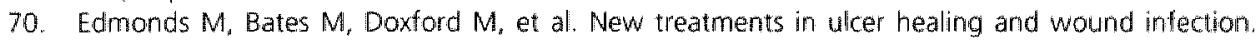
Diabetes Metab Res Rev 2000;1651:551-4.

71. Reiber GE, Vileikyte $L_{,}$Boyko $\mathrm{E}$, et al. Causal pathways for incident lower-extremity ulcers in patients with diabetes from two settings. Diabetes Care 1999;22:157-62.

72. Apelquist 1 , Bakker $K$, van Houtum WH, et al. International consensus and practical guidelines on the management and the prevention of the diabetic foot. International Working Group on the Diabetic Foot. Diabetes Metab Res Rev 2000; 16 51:584-92.

73. Schaper NC. Van Putten MA. Do diabetologist adequately detect patients at risk for amputation? Diabetologia 2001:44:A1076. 
74. Armstrong DG, Lavery LA, Harkless LB. Validation of a diabetic wound classification system. The contribution of depth, infection, and ischemia to risll of amputation. Drabetes Care 1998,21: $855-9$.

75. Grayson ML, Gibbons GW; Balogh $K$, et al. Probing to bone in infected pedal ulcers. A clinical sign of underlying osteornyelitis in diabetic patients. Jama 1995;273:721-3.

76. de Heus-van Putten MA, Schaper NC, Bakker K. The dinical examination of the diabetic foot in daily practise. Diabet Med 1996: $13: 555-7$.

77. MCGee SR. Boyko El. Physical examination and chronic lower-extremity ischemia: a critical review. Arch Intern Med 1998; 158:1357-64.

78. Jorneskog $G$. Brismar $K$, Fagrell B. Skin capillary circulation is more impaired in the toes of diabetic than non-diabetic patients with peripheral vascular disease. Diabet Med 1995:12:36-41.

79. Pecoraro RE, Ahroni JH. Boyko El, et al. Chronology and determinants of tissue repair in diabetic lower extremity ulcers. Diabetes 1991;40:1305-13.

80. Kalani $M$, Brismar $K$, Fagrell $B$, et al. Transcutaneous oxygen tension and toe blood pressure as predictors for outcome of diabetic foot ulcers. Diaberes Care 1999:22:147-51.

81. Ho KY, Leiner T, de Haan MW, et al. Peripheral vascular tree stenoses: evaluation with moving. bed infusion- tracking MR angiography. Radiology 1998;206:683-92.

82. Rith-Najarian SJ, Stolusky T, Gohdes DM. Identifying diabetic patients at high risk for lowerextremity amputation in a primary health care setting. A prospective evaluation of simple screening citeria. Diabetes Care 1992:15:1386-9

83. McGill M, Molyneaux L. Yue DK. Use of the Semmes-Weinstein 5.07/10 gram monofilament: the long and the short of it. Diabet Med 1998;15:615-7.

84. Eneroth $M$, Apelquist J. Stenstrom A. Clinical characteristics and outcome in 223 diabetic patients with deep foot infections. Foot Ankle int 1997;18:716-22.

85. Lipsky BA, Berendt AR. Principles and practice of antibiotic therapy of diabetic foot infections. Diabetes Metab Pes Rev 2000; 16 51:542-6.

86. Eneroth M, Larsson J, Apelquist J. Deep foot irfections in patients with diabetes and foot ulcer: an entity with different characteristics, treatments, and prognosis. I Diabetes Complications 1999:13:254-63

87. Rauwerda IA. Foot debridement: anatomic knowledge is mandatory. Diabetes Metab Res Rev 2000;16 \$1:\$23-6.

88. Craig JG. Amin MB, Wu $K$, et al. Osteornyelitis of the diabetic foot: MR imaging-pathologic correlation. Radiology 1997;203:849-55. 


\section{Chapter}

The effect of polyneuropathy on foot microcirculation in Type 2 diabetes

MH Nabuurs-Franssen, AJHM Houben, JE Tooke, NC Schaper

Diabetologia 2002;45:1164-1171 


\section{Abstract}

\section{Aims/hypothesis}

The aim of this study was to investigate the influence of peripheral polyneuropathy (PNP) on skin microcirculation and foot swelling rate in the feet of patients with Type 2 (non-insulin-dependent) diabetes mellitus.

\section{Methods}

38 Type 2 diabetic patients, 24 with PNP (PNP+), 14 without PNP (PNP-), and 16 healthy control subjects were studied, first supine and subsequently sitting with the foot dependent for $50 \mathrm{mn}$.

\section{Results}

In patients with PNP, foot skin temperature was higher, $(\mathrm{p}<0.04)$ and capillary blood cell velocity (CBV, nailfold capillary microscopy), was lower compared to patients without PNP (222 v5 $313 \mu \mathrm{m} / \mathrm{s}$ respectively, $p<0.03$ ). Compared to the control subjects, the percentage reduction in skin blood flux, (LDF, laser-Doppler fluxmetry), after $10 \mathrm{~min}$ was higher in the PNP- and PNP+ patients ( $3 \%$ vs 18\% and $26 \%$ respectively, $p<0.02$ ). These disturbances were most pronounced in PNP+ patients with a history of a foot ulcer. Foot swelling rate (mercury strain gauge plethysmography) in the first $10 \mathrm{~min}$ of dependency, was lower in patients with PNP+ compared to the control subjects $\left(0.00165 \mathrm{vs} 0.00286 \mathrm{ml}^{*} 100 \mathrm{ml}^{-1} \mathrm{~s}\right.$ respectively, $p<0.01)$. In addition, we found a negative correlation $(r=-0.41$; $p<0.01$ ) between Valk-score (severity of PNP) and FSR.

\section{Conclusion/interpretation}

Type 2 diabetes PNP is associated with multiple abnormalities in the (skin) microcirculation of the foot, characterised by reduced capillary blood flow, an enhanced reduction in skin blood flux and impaired fluid filtration after sitting up. The most severe abnormalities were observed in patients with a history of foot ulceration. 


\section{Introduction}

Neuropathic foot ulcers are a serious complication of diabetes mellitus, resulting in high morbidity and significant mortality'. These poorly healing ulcers are frequently the consequence of a complex interplay of several factors, such as impaired protective sensation, biomechanical abnormalities and external trauma'. In contrast to (neuro)ischaemic ulcers, macroangiopathy does not play a role in these neuropathic ulcers and perfusion in the large arteries of the foot is not impaired? However, the precise role of diabetic microangiopathy in these poorly healing ulcers has not been determined.

Several abnormalities have been observed in cutaneous microcirculation of diabetic patients, with different abnormalities being reported in Type 1 (insulin-dependent) and Type 2 (non-insulin-dependent) diabetic patients. Thermoregulatory blood flow is increased in the skin of Type 1 diabetic patients early in the course of the disease ${ }^{2}$. As shown by another study ${ }^{3}$ skin capillary pressure is also increased, in particular in patients with poor metabolic control or (incipient) nephropathy. In Type 1 diabetic patients with polyneuropathy total limb blood flow and thermoregulatory skin blood flow is further increased, due to loss of sympathetic constrictor tone ${ }^{4}$. Capillary skin blood flow also seems to be increased in these patients ${ }^{4,5}$, although conflicting results have been reported ${ }^{6}$. Ulnar blockade results in a rise of both shunt and capillary blood flow, suggesting that sympathetic denervation results in a parallel increase in both shunt (i.e. thermoregulatory) and nutritive (i.e. capillary) blood flow 7 . In contrast to Type 1 diabetes, Type 2 diabetes is probably not associated with increased cutaneous blood flow or elevated capillary pressure ${ }^{2}$, unless hypertension co-exists, as hypertension is associated with increased capillary pressure ${ }^{9}$. In patients with Type 2 diabetes the most marked abnormality is a profound reduction in the maximal hyperaemic blood flow due to an impaired vasodilatory capacity of the skin microvasculature ${ }^{10}$. The majority of neuropathic foot ulcers develop in patients with Type 2 diabetes'. However, the effect of polyneuropathy on the cutaneous microcirculation of the foot in Type 2 diabetic patients is still not clear. In most studies of neuropathic patients the subjects had either Type 1 diabetes $^{4}$ or a mixed cohort of Type 1 and Type 2 diabetes was investigated ${ }^{5,11,12}$. Finally, most studies were carried out on skin microcirculation of the hand. However, these observations cannot be extrapolated to the skin microcirculation of the foot ${ }^{13}$.

During daily life many changes occur in arterial perfusion and venous pressure, due to changes in posture. In healthy subjects pre-capillary arteriales consitrict, on changing from the supine to standing position ${ }^{1 / 4}$. This veno-arteriolar reflex limits the rise in capillary hydrostatic pressure and helps to prevent the development of interstitial edema, which otherwise would increase diffusion distance and could lead to local hypoxia ${ }^{14}$. Clinical studies suggested that edema is a contributory 
Clapter 3

factor in the pathogenesis ${ }^{15}$ and clinical outcome ${ }^{16}$ of diabetic foot ulcers. Postural vasoconstriction was impaired in several but not all studies of patients with Type 1 diabeteg ${ }^{2,4.14}$, and another study ${ }^{17}$ observed an increased foot swelling rate in Type 1 diabetic patients without peripheral polyneuropathy. However, little is known of the extent to which these parameters are abnormal in Type 2 diabetic patients with and without polyneuropathy. Therefore, we assessed the effect of periphera! neuropathy on cutaneous total and capillary blood flow in patients with Type 2 diabetes, both supine and during dependency of the legs. Furthermore, we measured foot swelling rate during dependency. The Type 2 diabetic patients with polyneuropathy were compared with patients without neuropathy and with nondiabetic subject matched for age and sex.

\section{Subjects and methods}

\section{Subjects}

In the study there were 54 participants, of whom 38 were Type 2 diabetic patients, 24 with clinical polyneuropathy (PNP+) and 14 without clinical signs of polyneuropathy (PNP-). In addition a contral group of 16 non-diabetic subjects were recruited and matched for age and sex. Type 2 diabetes was defined as onset of diabetes at age 40 years or older, the use of glucose lowering medication for at least 6 months and lack of ketosis at diagnosis. Peripheral polyneuropathy (PNP) was defined as a Valk score ${ }^{18}$ greater than 4.0 . The Valk score is a scoring system for the presence of polyneuropathy, based on clinical examination. The clinical examination consists of examination of sensory functions (pinprick sense, light touch sense, vibration sense, position sense), tendon reflexes and muscle strength in the lower extremities ${ }^{18}$. This clinical scoring system corresponds well with the results of neurophysialogical examination and has acceptable sensitivity and specificity for the diagnosis of polyneuropathy when a cut-off point of more than 4 is used ${ }^{19}$. In the PNP+ patients, nine patients had a history of a foot ulcer, which had healed after conservative treatment. These past ulcers were not located on the areas were measurements were carried out. None of the subjects had clinical signs of peripheral vascular disease (claudication or absent pulses). Furthermore, all patients had a toe-pressure greater than $70 \mathrm{mmHg}$ and a transcutaneous oxygen pressure $\left(\mathrm{tcpO}_{2}\right)$ above $30 \mathrm{mmHg}$. No subject had signs of lymph edema or varicose veins, which was confirmed by normal findings of venous Doppler analysis or Light Reflex Rheography (LRR).

The clinical characteristics of all subjects are shown in table 3.1 and 3.2. At the time of the investigation 11 patients used anti-hypertensive or anti-angina pectoris medication. In the PNP-group two patients used a beta-blocker and one a diuretic (hydrochloortiazide). In the PNP+ group eight patients used vaso-active medication: beta-blocker $(n=3)$, ACE-inhibitor $(n=3)$, nitrates $(n=2)$, diuretic $(n=2$, hydrochloor- 
tiazide, bumetanide) and an $\alpha$-blocker $(n=1)$. The results obtained in these patients did not differ from those obtained in patients without vasoactive medication. None of the control subjects used any medication. All participants gave their written informed consent and the study was approved by the hospital's medical ethics committee.

\section{Protocol}

All experiments started at 8:00 am and were carried out in a quiet, temperaturecontrolled room (mean temperature (SD) $23.5 \pm 0.2^{\circ} \mathrm{C}$ ). Precautions were taken to minimize external disturbances. Subjects were not allowed to smoke, eat, or drink (except for water) from 10:00 pm the night before the study untill the end of the study. They omitted their morning insulin dose or any other medication on the morning of the study. At the beginning and at the end of the study blood glucose was assessed and mean blood glucose was calculated. If a patient suffered from symptomatic hypoglycaemia, had a blood glucose concentration below 3.5 or above $10 \mathrm{mmol} / \mathrm{l}$, the study was postponed. First the subjects were studied in the supine position. After fixing the different probes on the foot of the patient and an acclimatisation period of $20 \mathrm{~min}$ in supine position, we started with capillary microscopy measuring capillary density (CD) and capillary blood cell velocity (CBV). Subsequently, laser Doppler fluxmetry (LDF), transcutaneous oxygen tension $\left(\mathrm{tcpO}_{2}\right)$ and skin temperature were measured. The patients then changed from the supine to the sitting posture with minimum disturbances, which resulted in the hanging down of both legs, without support under the feet. On dependency, care was taken to prevent venous obstruction in the knee bend and the patient's back was supported enabling the patient to sit comfortably for 50 min. Subsequently, $\mathrm{LDF}$, tcpO $\mathrm{C}_{2}$, skin temperature and foot swelling rate (FSR) were measured continuously and all data were stored on a computer for off-line analysis. After 50 min we repeated the capillary microscopy with the subject in the sitting position. measuring both CD and CBV.

In six patients it was technically possible to measure foot intravenous pressure on the dorsum of the foot supine and during dependency. Mean venous pressure increased from $10 \mathrm{mmHg}$ supine to $60 \mathrm{mmHg}$ sitting.

\section{Methods}

The skin microcirculation in the foot was studied using capillary microscopy of the nailfold and LDF on the dorsum of the foot ${ }^{20}$. In short, capillary blood cell velocity ( $C B V_{\text {; }}$ representing skin nutritive blood flow) was monitored during $2 \mathrm{~min}$ in two distal capillaries of the first toe nailfold using epi-POL intravitalmicroscopy, with a $10 x$ objective (numeric aperture: 0.32 ). These capillary loops are located paralell to the surface of the skin. The patient's foot was placed on the platform of the microscope and the first toe was gently immobilized in a mass of clay. For 
measurements in the supine position the microscope was rotated $90^{\circ}$. Images were videotaped for off-line analysis. Mean CBV (mm/s) of two (erythrocyteperfused) capillaries was used for calculation, which was evaluated off-line using a computerised, videophotometric, cross-correlation technique ${ }^{21}$ (Capiflow, Stockholm, Sweden). The coefficient of variation of two consecutive CBV measurements was $31 \%{ }^{2}$. Skin capillary density (CD) was measured approximately $6 \mathrm{~mm}$ proximal to the distal row of capillaries of the first toe. In contrast to the distal capillaries, these capillary loops are lacated perpendicular to the skin. Capillary density was assessed in three adjacent microscopic images $\left(1.6 \mathrm{~mm}^{2}\right)$ which were video-taped for off-line analysis. During $2 \mathrm{~min}$ all continuously and intermittently erythrocyte-perfused capillaries were counted and the mean of these images was used for the number of erythrocyte-perfused capiliaries (expressed as number $1.6 \mathrm{~mm}^{2}$ ). Thermoregulatory (shunt) skin perfusion was assessed using Laser-Doppler fluxmetry (LDF; Periflux PF3, Perimed, Järfälla, Sweden), with probe PF 308, wide band $(12 \mathrm{~Hz}$ ) mode, and time constant $0.2 \mathrm{~s}$. Results are expressed as arbitrary perfusion units (PU), calibrated against an external standard. The probe was placed on the dorsum of the forefoot proximal to toe 2 and 3 and remained in the same position during the experiment. Transcutaneous oxygen pressure ( $\mathrm{tcpO} \mathrm{O}_{2}$; Radiometer, TCM3, Copenhagen, Denmark) was measured at $44^{\circ} \mathrm{C}$ at the dorsum of the foot proximal to the first and second toe and the probe remained in the same position during the study. Skin temperature was measured at the dorsum of the same foot using a Hewlett. Packard 78214C monitor ( $H P$, Böblingen, Germany). Foot swelling rate (FSR) was assessed using mercury strain gauge plethysmography (EC4, Hokanson, USA $)^{1 \%}$. The strain gauge was placed around the midfoot and fixed with 5 small tapes to prevent the gauge from rolling when the foot position was changed. Preliminary studies had shown that these tapes did not affect the measurements. After changing from the supine to the sitting position, the volume of the foot, as assessed by the strain gauge, increased in all subjects. After dependency the swelling of the foot can be divided into a rapid venous filling phase, a venous distension phase and the fluid filtration phase. As it was technically impossible to distinguish the first two phases, in the analyses these phases were combined into a "rapid filling phase". Foot swelling rate (expressed as $\mathrm{ml}^{*} 100 \mathrm{ml}^{-1} \mathrm{~s}$ ) was calculated from the swelling curve in periods of $10 \mathrm{~min}$ each, except in the first $10 \mathrm{~min}$ period in which the swelling rate was assessed after termination of the "rapid filling phase".

Blood glucose concentration was measured by the hexokinase method on the Coball Bio analyser (Hoffman Laroche, Basel, Switserland), HbA1c by HPLC (Diamat Bio-Rad Laboratories, Richmond, Calif. USA), Creatinin and blood albumin concentration by a commercial spectofotometric final point-method. Microalbuminuria was assessed in fasting morning urine by an immunoturbidimetric method. 


\section{Statistical analysis}

All data are shown as medians and ranges. Statistical significance was considered as $p$ value of less than 0.05 . As the distribution of some microcirculatory variables was not normal, non-parametric tests were used: the Kruskal-Wallis test was used for multiple group comparison, the Mann-Whitney $U$ test for two group comparison and correlations were calculated using Spearman's test. The independent contribution of different variables to CBV supine, and percentage LDF reduction and fluid filtration after 10 min of dependency was assessed by multiple linear regression analysis. Variables with a $p$ value of less than 0.1 in Spearman correlations and Variance Inflation Factor (VIF) below 10 were entered into the multivariate analyses. Statistical analyses were performed with the SPSS statistical package (SPSS, Chicago, III., USA).

\section{Results}

\section{Clinical characteristics}

There were no differences in sex, age, BMl and blood pressure between the groups (table 3.1 and 3.2). In line with the group definition, patients with polyneuropathy had a higher Valk score than patients without polyneuropathy, $(p<0.001)$. As expected $\mathrm{HbA} 1 \mathrm{c}$ was higher in diabetic patients than in the control subjects $(p<0.001)$ but no differences were observed between the two diabetic groups (PNP- and PNP+). At baseline, half of the patients had mild ankle edema, defined as the appearance of an impression or "pitting" of the skin above the ankle after local firm compression with one finger but there were no differences between the groups. Foot skin temperature was higher in patients with polyneuropathy in both the supine and dependent position compared to healthy control subjects (table $3.3, p<0.04$ ).

\section{Supine skin microcirculation}

There was no difference in LDF in the supine position between the groups, although the highest supine LDF values were observed in the PNP+ patients $(p=0.165)$. Analysis of the CBV showed that patients with polyneuropathy had a lower supine CBV compared to the patients without polyneuropathy (table 3.3; $\mathrm{p}<0.03$ ). Capillary density and $\mathrm{tcpO}_{2}$ values did not differ between the three groups. 
Table 3.3 Foot skin microcirculatory variables supine (T 0 ) and after 50 minutes of sitting (T 50 ) in Type 2 diabetic patients with and without polyneuropathy and non-diabetic control subjects

\begin{tabular}{|c|c|c|c|c|c|c|}
\hline & \multicolumn{3}{|c|}{$\mathrm{TO}$} & \multicolumn{3}{|c|}{150} \\
\hline & Control & PNP - & PNP * & Control & PNP - & PNP + \\
\hline Skin Temp $\left({ }^{\circ} \mathrm{C}\right)$ & $\begin{array}{c}29.0 \\
(26.7-31.2)\end{array}$ & $\begin{array}{c}29.1 \\
(27.8-30.9)\end{array}$ & $\begin{array}{c}29.9^{\prime} \\
(27.2-33.1)\end{array}$ & $\begin{array}{c}28.3 \\
(26.3-30.3)\end{array}$ & $\begin{array}{c}28.6 \\
(27.0 .34 .9)\end{array}$ & $\begin{array}{c}30.1^{1} \\
(26.5-32.4)\end{array}$ \\
\hline LDF (PU) & $\begin{array}{c}5.9 \\
(2.8-9.0)\end{array}$ & $\begin{array}{c}7.2 \\
(3.4-10.0)\end{array}$ & $\begin{array}{c}7.4 \\
(3.4-23.28)\end{array}$ & $\begin{array}{c}6.9 \\
(1.9-11.3)\end{array}$ & $\begin{array}{c}6.1 \\
(4.6-10.4)\end{array}$ & $\begin{array}{c}6.9 \\
(3.2-37.93)\end{array}$ \\
\hline$C B V(\mu \mathrm{m} / \mathrm{s})$ & $\begin{array}{c}237 \\
(76-408)\end{array}$ & $\begin{array}{c}313 \\
(113-527)\end{array}$ & $\begin{array}{c}222^{c} \\
(31-474)\end{array}$ & $\begin{array}{c}67 \\
(38-367)\end{array}$ & $\begin{array}{c}89 \\
(35-394)\end{array}$ & $\begin{array}{c}76 \\
(16-224)\end{array}$ \\
\hline $\mathrm{CD}$ (number/mm $\left.\mathrm{m}^{2}\right)$ & $\begin{array}{c}55 \\
(43-82)\end{array}$ & $\begin{array}{c}53 \\
(26-73)\end{array}$ & $\begin{array}{c}54 \\
(33-87)\end{array}$ & $\begin{array}{c}68 \\
(45-106)\end{array}$ & $\begin{array}{c}74 \\
(43-100)\end{array}$ & $\begin{array}{c}65 \\
(36-90)\end{array}$ \\
\hline
\end{tabular}

Data shown as median (ranges). Control = age- and sex matched non-diabetic subjects, PNP= peripheral polyneuropathy, $P N P=$ Type 2 diabetic patients without polyneuropathy, $P N P+=T y p e 2$ diabetic patients with polyneuropathy. LDF=laser doppler flux, PU=perfusion units, CBV=capillary blood cell velocity, $C D=$ capillary density.

a $p<0.04$ : pnp+ ws control. " $p<0.01$ : pnpt vs control. " $p<0.03 p n p+$ vs pnp-

\section{Skin microcirculation during sitting}

In all groups LDF showed a marked but transient rise within seconds after dependency of the leg. In comparison to the control subjects and PNP. patients, this peak LDF was higher in the PNP+ patients: $21(17-41)$ and $25(21-87)$ vs 57 (28-92) PU, respectively $(p<0.05)$. Relative to the control subjects, the time-to-LDF peak was shorter in PNP- and PNP+ patients: 13.4 (8.9-19.1) vs $7.0 \mathrm{~s}$ (3.6-11.8) and $7.4(5.4-10.2)$, respectively $(p<0.01)$. Following the initial peak, LDF dropped in all groups. After 10 min dependency LDF had returned to baseline in the healthy control subjects but was reduced relative to baseline in both PNP- and PNP+ patients. Compared to the control subjects, this percentage LDF reduction after 10 min was higher in the PNP. and PNP+ patients: $3 \%(-15-17)$ vs $18 \%(9-29)$ and $26 \%(9-38)$, respectively $(p<0.02)$. Between PNP- and PNP+ this percentage LDF reduction did not differ. After 50 min dependency no differences in absolute or percentage reduction in LDF were found between the three groups. In comparison with the supine position. CBV was markedly lower in all groups after 50 minutes dependency (table $3.3, p<0.002$ ), but no differences were observed between the three groups. No differences were observed in capillary density (table 3.3) or tcpO values between the groups after 50 min of dependency.

\section{Swelling parameters}

No differences were observed between the three groups in the amount of swelling during the "rapid filling phase". The duration of this rapid filling phase in healthy control subjects, PNP-, and PNP+ patients was: 54 (42-86) s, 40 (25-53) s, and 
$31(23-39)$ s, respectively. In comparison to healthy control subjects, rapid filling was faster in the PNP+ group $(p<0.01)$. In the PNP-group this difference was almost significant $(p=0.058)$. After the rapid filling phase, the volume of the foot increased progressively during dependency in all subjects. Median foot swelling rate during the first $10 \mathrm{~min}$, was in the healthy control subjects, PNP- and PNP+ patients: $0.00268,0.00194$, and $0.00165 \mathrm{ml}^{*} 100 \mathrm{ml}^{-1} \mathrm{~s}$, respectively. Compared to the control subjects the foot swelling rate was lower in the patients with polyneuropathy $(p<0.01$; figure 3.1 ). Moreover, the total amount of foot swelling on dependency (cumulative foot swelling = rapid venous filling + fluid filtration) in the first $10 \mathrm{~min}$, was lower in the PNP+ patients in comparison to control subjects and PNP- patients: $1.35(1.09-1.97) \mathrm{ml}^{*} 100 \mathrm{ml}^{-1}$ vs $2.09(1.73-2.70) \mathrm{ml}^{*} 100 \mathrm{ml}^{-1}$ and $2.12(1.64-2.53) \mathrm{ml}^{*} 100 \mathrm{ml}^{-1}$, respectively $(p<0.03)$. After $50 \mathrm{~min}$ of leg dependency, both foot swelling rate (figure 3.1) and cumulative foot swelling did not differ between the groups.

Figure 3.1 foot swelling rate during dependency.

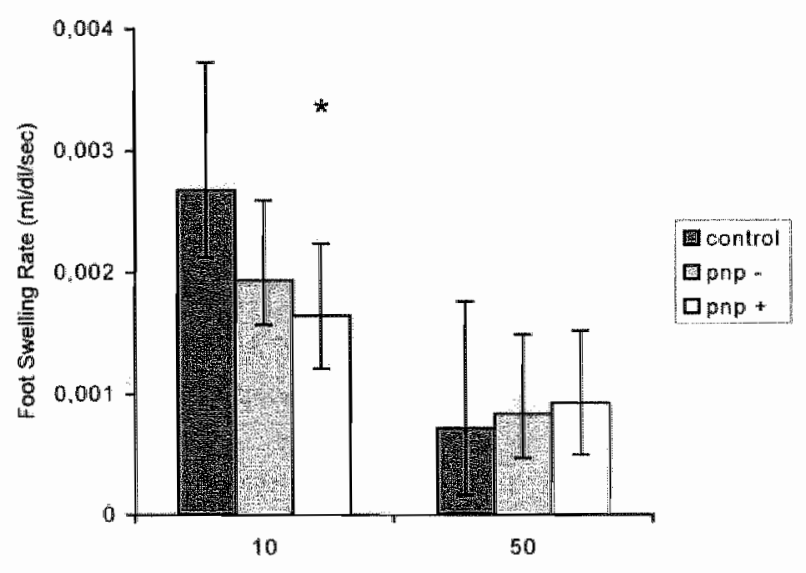

Foot swelling rate $0-10$ minutes and $40-50$ minutes during dependency in Type 2 diabetic patients with (PNP + ) and without (PNP-) polyneuropathy and non-diabetic controls. Data shown as medians (interquartile ranges), $p<0.01$ : pnp+ ws controls.

\section{Post-hoc analyses ulcer patients}

To evaluate if more profound abnormalities could be observed in patients with a history of a foot ulcer, these patients were analysed separately. In comparison to PNP+ patients without a history of a foot ulcer, these patients had a higher valk score, indicating a more severe polyneuropathy: $19(17-26)$ ws $11(8-17),(p<0.01)$. In these patients with a healed ulcer we observed the most profound abnormalities 
in microcirculatory blood flow and fluid filtration. Although skin temperature was higher in the ulcer patients: $30.9(29.5-32.5)^{\circ} \mathrm{C}\left(\mathrm{p}<0.01\right.$ vs $\mathrm{PNP}_{-}$and control subjects), CBV supine was markedly lower, $171(98-230) \mu \mathrm{m} / \mathrm{s}_{\text {, compared to PNP. }}$ $(p<0.01)$. Furthermore, in comparison to the control subjects, peak LDF immediately after dependency was higher in the ulcer group: $20.8(17.4-40.8)$ vs 87.6 (28.1-137.3) s, respectively $(p<0.02)$. In comparison to the PNP-group, the difference was almost significant $(p=0.057)$. The percentage reduction in LDF after 10 min dependency was largest in the ulcer group as compared to healthy control subjects and PNP- 38\% (26-43), $(p<0.02)$. Also, in these patients with a history of an ulcer the lowest values of fluid filtration during the first $10 \mathrm{~min}$ of dependency were observed: $0.00121(0.001-0.002) \mathrm{ml}^{*} 100 \mathrm{ml}^{-1} \mathrm{~s}(\mathrm{p}<0.03$ vs PNP- and control subjects).

\section{Correlations}

Univariate correlation analyses were carried out in the diabetic patients to assess the effect of neuropathy (the Valk score) on microvascular blood flow and fluid filtration. Furthermore, the effect of potential confounding parameters was measured. The Valk score correlated inversely with CBV supine $(r=-0.55, p<0.01$, figure 3.2). Furthermore, both the rapid filling phase, and fluid filtration in the first 10 min correlated inversely with the Valk score: $r=-0.41(p<0.01)$ and $r=-0.37$ $(p<0.03)$, respectively. The percentage LDF reduction correlated positively with the Valk score: $r=0.43 \quad(p<0.01)$. As expected the Valk score was also correlated to microalbuminuria $(r=0.46, p<0.01)$. Microalbuminuria was inversely correlated with supine CBV $(r=-0.50, p<0.01)$. During the first 10 min of dependency we found a correlation between microalbuminuria and the percentage LDF reduction $(r=0.50$, $p<0.01$ ). No correlations were observed between blood pressure, glucose concentration, $\mathrm{HbA} 1 \mathrm{C}, \mathrm{BMI}$ with CBV or the swelling parameters. In the patients without polyneuropathy we found a strong correlation between skin temperature and CBV $(r=0.71, p<0.01)$.

\section{Multivariate analyses}

Stepwise backward multivariate analysis showed that the severity of PNP (Valk score) contributed to CBV supine and fluid filtration in the first $10 \mathrm{~min}$ of dependency: $r^{2}=0.40(p<0.05)$ and $r^{2}=0.14(p<0.05)$, respectively. With respect to the percentage LDF reduction after $10 \mathrm{~min}$ of dependency, the analysis showed that log microalbuminuria was the only significant contributing factor $\left\langle r^{2}=0.16\right.$, $p<0.05$ ). In this analysis the variable Valk score was excluded at the last step of the regression analysis. Sex was not a contributing factor in these (multivariate) analyses. 


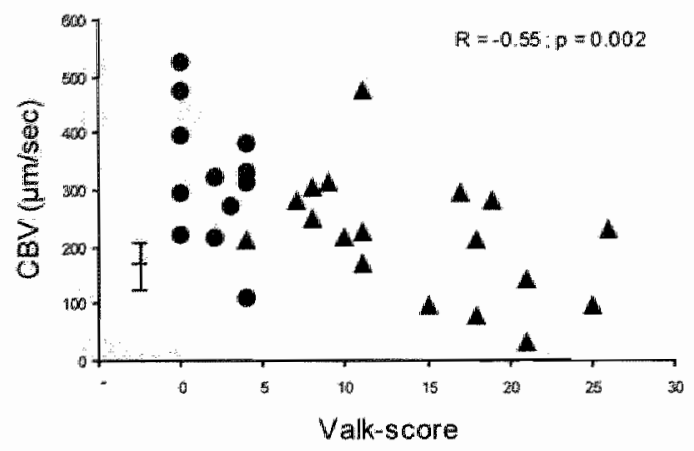

Correlation between capillary blood flow (CBV) supine and Polyneuropathy (Valk score) in Type 2 diabetic patients with (solid triangles) and without (solid circles) polyneuropathy. Straight line indicates median values and interquartile ranges of non-diabetic controls.

\section{Discussion}

We have found that polyneuropathy in Type 2 diabetic patients is associated with multiple microvascular abnormalities. In particular, polymeuropathy was associated with impaired skin capillary blood flow in the foot, with an enhanced reduction is skin blood flux (LDF) and impaired food swelling rate after dependency. Furthermore, the most severe abnormalities were observed in patients with a history of a diabetic foot ulcer.

The increased skin temperature in our patients with polyneuropathy is in line with an increase in thermoregulatory shunt blood flow, due to loss of sympathetic vasoconstrictor tone, as shown previously", ${ }^{\prime 4}$. Thermoregulatory blood flow (laser doppler flux), which was measured on the dorsum of the foot, was not increased in our neuropathic patients, also in accordance to earlier observations $\mathrm{s}^{22}$. With this technique an increase in blood flow on the volar pulp of the toe can be observed 17, an area with the most abundant arterio-venous shunts ${ }^{23}$. The effect of polyneuropathy on supine capillary skin blood flow is less well studied. Others ${ }^{4.7}$ observed an increased number of visible capillaries and an increased CBV after ulnar blockade in both healthy subjects and in neuropathic patients with Type 1 diabetes. In another study ${ }^{5}$ of a mixed cohort of Type 1 and Type 2 diabetic patients with polyneuropathy, CBV was not altered; however, when the width of the erythrocyte column was taken into account, erythrocyte flux was increased. In contrast, another study ${ }^{6}$ found a reduced CBV in Type 1 diabetic patients with and without polyneuropathy and other microvascular complications compared to healthy control subjects. Although these studies are somewhat conflicting, these 
data suggest that withdrawal of sympathetic constrictor tone in healthy subjects and patients with Type 1 diabetes results in a parallel increase in both shunt and capillary blood flow, with additional recruitment of capillaries. In our patients with Type 2 diabetes and polyneuropathy we observed a different response of the skin microcirculation to chronic denervation. Although thermoregulatory flow was probably increased, there was no recruitment of erythrocyte-perfused capillaries and supine nutritive flow was decreased. Several studies have suggested that both endothelium-dependent and endothelium-independent vasodilation of the peripheral microcirculation is impaired in subjects at risk for ${ }^{24}$, or very early in the course of Type 2 diabetes ${ }^{25}$, and when Type 2 diabetes is complicated by neuropathy ${ }^{26}$. Hence, we hypothesise that polyneuropathy in Type 2 diabetic patients results in an increase in shunt blood flow, but due to the loss of vasodilator capacity of precapillary resistance vessels there is no parallell rise in capillary blood flow. The increased venous inflow (due to the increased shunt flow), possibly in combination with a reduced venous compliance ${ }^{27}$, would result in a marked rise in post-capillary pressure, which would further limit capillary inflow. The final result is a capillary steal with a relative capillary hypoperfusion of the skin. Furthermore, in neuropathic patients an increased skin temperature was found, which increases metabolic demand which amplifies the significance of the observed reduction in nutritive capillary flow. Probably due to this capillary steal, the strong relationship between skin temperature and capillary blood flow, as observed in the patients without polyneuropathy, was lost in the patients with neuropathy.

On changing from the supine to the sitting position pre-capillary vessels constrict to limit the rise in capillary pressure (and subsequent increase in fluid filtration), which would otherwise be the consequence of the marked rise in arterial and venous pressure. Both local (neurogenic and/or myogenic) and systemic mechanisms seem to play a role in this postural vasoconstriction ${ }^{14}$. Indeed, CBV after $50 \mathrm{~min}$ of sitting showed a marked reduction in all three groups and polyneuropathy did not seem to affect the vasoconstrictor response at this timepoint in our patients. These data are in line with earlier studies in Type 1 diabetic patients and polyneuropathy ${ }^{4}$. Nevertheless, the percentage reduction in skin perfusion assessed as LDF was higher in our diabetic patients after $10 \mathrm{~min}$ of sitting, suggesting that Type 2 diabetes is associated with an enhanced acute postural vasoconstrictor responses of the skin. Univariate analysis suggested that this acute vasoconstrictor response could be further enhanced in the presence of polyneuropathy.

After changing from supine to the sitting position the patients with polyneuropathy had the lowest foot swelling rate. This attenuated swelling rate could be due to the enhanced acute postural vasoconstriction, as suggested by the 
LDF values at the same time-point, resulting in a higher reduction in capillary perfusion. Unfortunately, we do not have data on capillary blood flow after $10 \mathrm{~min}$ of dependency and therefore we cannot exclude alternative explanations. In contrast to our data, another study ${ }^{17}$ with an identical study protocol, found an increased foot swelling rate and elevated toe blood flow in patients with Type 1 diabetes after 20 min of sitting. Other investigators observed in these patients an increased capillary pressure ${ }^{3}$ and an increased capillary filtration rate of water ${ }^{23}$. Each of these abnormalities could contribute to the increased foot swelling rate in Type 1 diabetes. In patients with Type 2 diabetes both capillary pressure ${ }^{8}$ and filtration ${ }^{29}$ do not seem to be altered, although in one study a reduced capillary filtration was observed ${ }^{30}$. Data on the effect of polyneuropathy, however, are lacking. An alternative explanation for the attenuated foot swelling rate could be that the interstitial hydraulic pressure was increased in our patients with neuropathy already at the start of the study. indeed in one earlier study increased interstitial pressures ${ }^{30}$ were observed in patients with neuropathy, which could have limited capillary filtration during dependency. Finally, both MRI and autopsie studies have shown that polyneuropathy is associated with marked qualitative and quantative changes in soft tissues within the diabetic foot ${ }^{32}$. These structural changes could clearly have affected the rate of foot swelling.

Apart from denervation, metabolic control probably affects capillary blood flow in subjects with diabetes, as well. In a cross-sectional study a higher $\mathrm{HbA}$ Ic value was associated in Type 1 diabetic patients with a lower capillary blood flow and, in another study, improvement of metabolic control resulted in a rise in CBV ${ }^{33.34}$. Short-term intravenous insulin infusion resulted in an increase in CBV in hyperglycaemic Type 2 diabetic patients with polyneuropathy ${ }^{35}$. Although our patient groups were well matched for $\mathrm{HbAlc}$ and glucose concentrations at the time of the study, it remains to be evaluated if strict metabolic control would have abolished the effects of polyneuropathy on nutritive blood flow.

The patients with a history of a foot ulcer had the most severe microvascular abnormalities and the lowest fluid filtration after sitting up, as indicated by the post hoc analyses. It should be stressed that these patients had no active foot uicer and the microvascular measurements were not carried out in a region of a previous ulcer. As expected these patients had the most severe polyneuropathy and had more frequently (incipient) nephropathy, which was also associated with a decrease in capillary blood flow. Thus, in patients with a history of foot ulceration several diabetic complications cluster which exert negative effects on skin microcirculation. To what extent these abnormalities contribute to the development of foot ulcers or impaired wound healing, is not clear. 
A limitation of our study was that some patients had (mild) hypertension or angina pectoris and were using vaso-active medication. which could have affected the measurements. However, when patients using vaso-active medication were excluded in the analyses, the same results were obtained. The effect of hypertension on skin microcirculation is still a matter of debate, but some authors observed a reduction in capillary density and CBV in non-diabetic patients compared with healthy control subjects ${ }^{36} .38$. However, our groups (in particular the diabetic patients) were well matched for blood pressure and the severity of polyneuropathy was in these patients independently associated with a reduction of CBV. We tried to exclude important obstructive peripheral atherosclerotic disease and the groups were well matched for $t \mathrm{CpO}_{2}$ and toe-pressure. It is likely that some of these elderly patients did have some degree of (silent) peripheral vascular disease but is unlikely that this would have affected the measurements. Polyneuropathy is closely associated with other microvascular complications. Although we tried to match the two diabetic patient groups as closely as possible, (incipient) nephropathy was more prevalent in the patients with polyneuropathy. Multivariate analyses, however, indicated that polyneuropathy was independently associated with a reduction in CBV and foot swelling rate.

In conclusion, in contrast to several earlier studies on Type 1 diabetes, polyneuropathy in Type 2 diabetes is associated with multiple abnormalities in the (skin) microcirculation of the foot, characterised by reduced capillary blood flow with the foot at heart level and impaired fluid filtration when the foot is lowered. Furthermore the skin blood flow data suggest an enhanced vasoconstricor response after lowering of the foot. The most severe abnormalities were observed in patients with a history of foot ulceration, suggesting that such disturbances in the skin microcirculation could contribute to the impaired healing capacity of diabetic foot ulcers. These data also provide further evidence for a difference in microvascular behaviour in Type 2 diabetic patients compared to those with Type 1 diabetes. 


\section{References}

1. International Working Group on the Diabetic Foot. Apelqvist J, Bakker K, Van Houtum WH, Nabuurs-Franssen MH, Schaper NC (ed). International Consensus on the Diabetic Foot. Schaper NC. Maastricht 1999

2. Houben AMM W Weuwenhuizen Kruseman AC, Bouhouch E, Slat DW, Schaper NC. Peripheral macro- and microciculation in short-tem insulim-dependent diabetes mellitus: the role of prostaglandins in early haemodynamic changes. Eurj Clin Invest 1993;23:662-7.

3. Sandernain DD. Shore AC, Tooke JE. Relation of skin capillary pressure in patients with insulindependent diabetes mellitus to complications and metabolic control. N Engl I Med 1992;327 $760-4$

4. Netten PM, Wollersheim H, Thien T. Lutterman JA. Skin microcirculation of the foot in diabetic neuropathy. Clin Sci(Lond) 1996,91:559-65.

5. Flynn MD, Edmonds ME, Tooke JiE, Watkins PJ. Direct measurement of capillary blood flow in the diabetic neuropathic foot. Diabetologia 1988;31:652-6.

6. Jorneskog 6 , Brismar $K$, Fagrell B. Skin capillary circulation severely impaired in toes of patients with IDDM, with and without late diabetic complications. Diabetologia 1995;38:474-80.

7. Netten PM, Wollersheim H, Gielen MJM, Den Arend JACJ, Lutterman JA, Thien Th. The influence of ulnar nerve blockade on skin microvascula blood flow. Eur 1 Clin inwest 1995;25:515-22.

8. Shore AC, Jaap AJ, Tooke IE. Capillary pressure in patients with NIDDM. Diabetes 1994:43: $1198-202$.

9. Jap AJ, shore AC, Tooke JE. The influence of hypertension on microvascular blood flow and resistance to flow in the skin of patients with type 2 (non-insulin-dependent) diabetes. Diabet Med 1994;11:883-7.

10. Jaap Al, Hammersley MS, Shore AC. Tooke JE. Reduced microvascular hyperaemia in subjects at risk of developing type 2 (non-insulin-dependent) diabetes mellitus. Diabetologia 1994;37:214-6.

11. Uccioli L, Mancini L, Giordano A, Solini A, Magnani P, Manto A, Cotroneo P, Greco AV, Ghirlanda G. Lower limb arterio-venous shunts, autonomic neuropathy and diabetic foot. Drabetes Res Chin Pract 1992:16:123-30.

12. Benbow S). Pryce DW, Noblett K, MacFarlane IA, Friedmann PS, Williams G. Flow motion in peripheral diabetic neuropathy. Clin SCi(Lond) 1995;88:191-6.

13. Jormeskog $G$, Fagrell $B$. Discrepancy in skin capillary circulation between fingers and toes in patients with type id diabetes. Int I Microcirc Exp 1996;16:313-9.

14. Flynn MD. Tooke IE. Diabetic Neuropathy and the Microcirculation. Diabetic Medicine $1995: 12: 298-301$.

15. Rebei GE, Vileikyte L, Boyko El, del Aguila M, Smith DG, Lavery LA, Boulton AJ. Canusal pathways for incident lower-extremity ulcers in patients with diabetes from two settings. Diabetes Care $1999: 22: 157 \cdot 62$

16. Apelquist J, Larsson J. Agardh CD. Medical risk factors in diabetic patients with foot ulcers and severe peripheral vascular disease and their influence on outcome. Drabetes Complications $1992 ; 6: 167-74$

17. Rayman G. Williams SA, Gamble J, Tooke JE. A study of factors governing fluid filtration in the diabetic foot. Eur J Clin invest" 994:24:830-6.

18. Vallk GD, Nauta JIP, Strijers RLM. Bertelsman FW. Clinical examination wersus neurophysiological examination in the diagnosis of diabetic polyneuropathy. Diabet Med 1992:9:716-21.

19. Valk GD. Sonnaville de JJJ. Houtum van WH, van Eijk JT, Bouter LM, Bertelsmann FW. The assessment of diabetic polyneuropathy in daily clinical practice: reproducibility and validity of sememes weinstein monofilaments examination and clinical neurological examination. Muscle a Nhone 1997:20:116-8.

20. Houben AJ, Schaper NC, de Haan $\mathrm{CH}$, Huvers FC, Slaaf DW, de Leeuw PW, Nieuwenhuijzen Kruseman AC. The effects of 7 -hour local hyperglycaemia on foream macro and microcirculatory blood flow and vascular reactivity in thealthy man. Diabetologia 1994:37:750-6.

21. Jeurens TI. Arts T, Reneman RS. Slaaf DW. Analysis of the bidirectional optical three-stage prism girating system for red blood cell velocity measurements in microvessels. Med Brol Eng Comput $1984: 22: 521-8$ 
22. Houben AJHM, Nieuwenhuijzen Kruseman AC, Bouhouch E, 5 laaf DW, Schaper NC. Peripheral macro- and microcirculation in short-term insulin-dependent diabetes mellitus: the role of prostaglandins in early haemodynamic changes. Eur / din thest $1993,23,662-7$.

23. Rendell $M_{x}$ Bamisedun O. Diabetic cutaneous microangiopathy. Am / Mled 1992,93:61 1-8

24. Tooke JE, Ostergren J, Fagrell B. Synchronous assessment of human skin microcirculation by laser doppler flowmetry and dynamic capillaroscopy. Int / Alicrocirc Clin Exp 1983;2:277-84.

25. Cabalero AE, Arora S, Saouaf R, Lim SC, Smakowski P. Park $Y^{\prime}$. King GL, LoGerfo FW, Horton ES, Veves A. Microvascular and macrovascular reactivity is reduced in subjects at risk for type 2 diabetes. Diabetes 1999;48:1856-62.

26. Schaper $\mathrm{NC}_{x}$ Nabuurs-Franssen $\mathrm{MH}_{n}$ Huijberts MSP. Peripherad vascular disease and Type 2 diabetes mellitus. Diabetes Metab Res Rev 2000;16 \$1:\$11-5.

27. Haimdy O, Abou-Elenin K, LoGerfo FW. Horton ES, Veves A. Contribution of nerve-axon reflexrelated vasodilation to the total skin vasodilation in diabetic patients with and without neuropathy. Diabetes Care 2001:24:344-9.

28. Schaper NC. Houben AIHM, Schoon Y, Kooman JP, Huvers FC, Nieuwenhulizen Kruseman AC. Verous compliance and the venodilatory effect of nitroglycerin in insulin-dependent diabetic patients with and without (imcipient) nephropathy. Eur J C/in Mnest 1994:24:382-7.

29. Jaap AJ, Shore AC, Gartside IB, Gamble J, Tooke JE. Increased microvascular fluid permeability in young type 1 (insulin-dependent) diabetic patients. Diabetologia 1993;36:648-52.

30. Jaap AJ, Shore AC, Gamble J, Gartside IB, Tooke JE. Capillary filtration coefficient in type II (noninsulin-dependent) diabetes. J Diabetes Complications 1994;8:111-6.

31. Katz MA, Janjan N. Forearm hemodynamics and responses to exercise in middle-aged adult-onset diabetic patients. Diabetes 1978;27:726-31.

32. Lower RF, Kenzora JE. The diabetic neuropathic foot: a triple crush syndromemeasurement of compartmental pressures of normal and diabetic feet. Orthopedics 1994:17:241-8.

33. Birash PD, Foster $\rfloor$, Vennart W. Anthony $P$, Tooke JE. Magnetic resonance imaging techuiques demonstrate soft tissue damage in the diabetic foot. Diabet Med 1999;16:55-61.

34. Jorneskog $G, B r i s m a r ~ K$. Fagrell $B$. Pronounced skin capillary ischemia in the feet of diabutic patients with bad metabolic control. Diabetologia 1998:41:410-5.

35. Jaap AJ, Pym CA, Seamark C, Shore AC, Tooke JE. Microvascular function in type 2 (non-insulindependent) diabetes: improved vasodilation after one year of good glycemic control. Diabet Med $1995 ; 12: 1086-91$.

36. Fyyn MD, Boolell M. Tooke JE. Watkins. PJ. The effect of insulin infusion on capillary blood fllow in the diabetic neuropathic foot. Diabet Med 1992;9:630-4.

37. Serne EH, Gans RO, ter Maaten IC, Tangelder GJ, Donkeir AJ, Stehouwer CD. Impaired skin capillary recrutment in essential hypertension is caused by both functional and structural capillary rarefaction. Hypertension $2001 ; 38: 238-42$.

38. Shore AC, Tooke JE. Microwasculiar function in human essential hypertension. I Hypertens $1994 ; 12: 717: 28$

39. Duprez D, De Buyzere M, De Backer $T$, Vercammen I, Brusselmans F. Clement DL. Impaired microcirculation in mild-to-moderate essential arterial hypertension. I Hypertens 1992;10:251-4. 

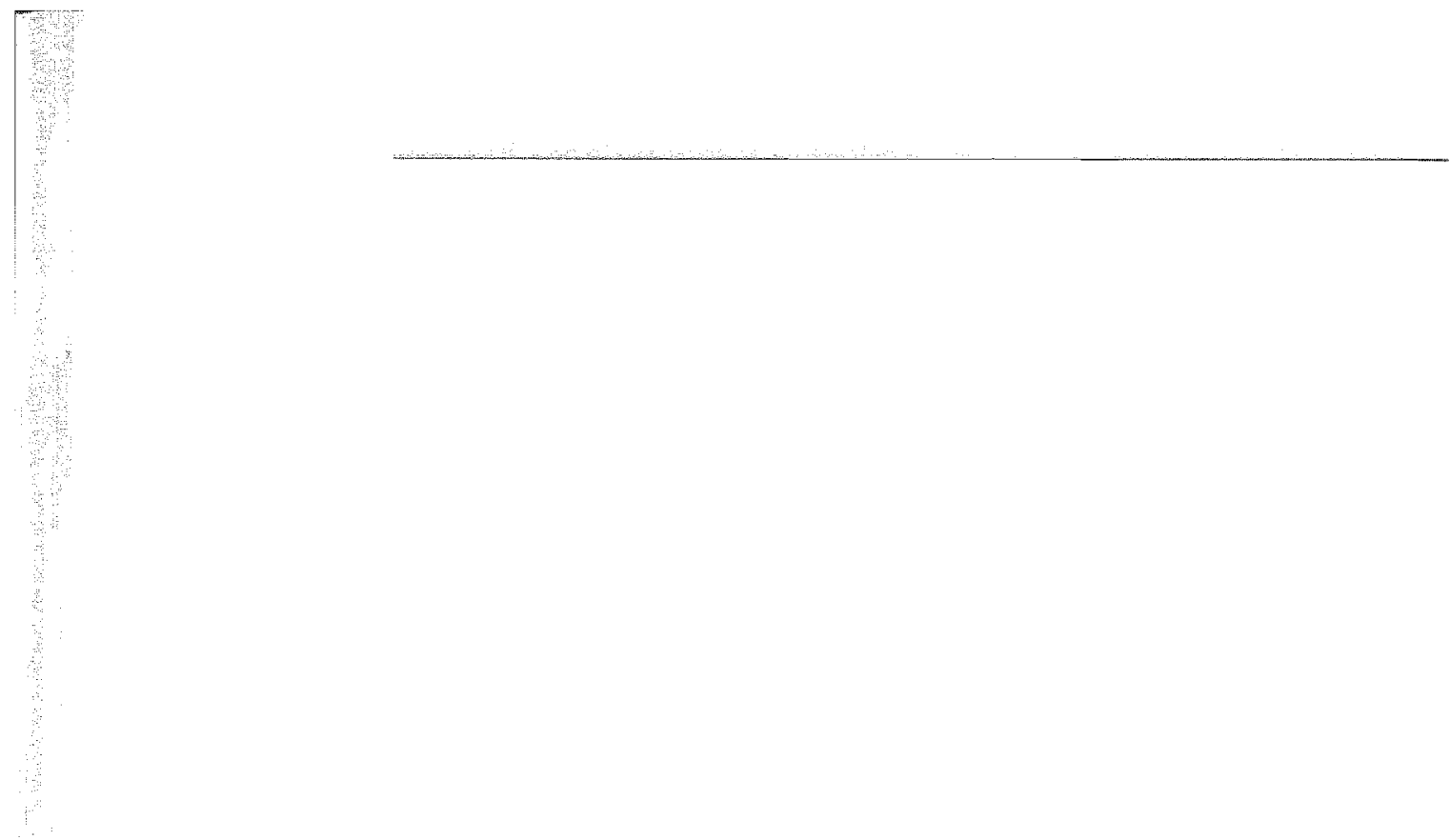

52 


\section{Chapter 4}

\section{Total contact casting of the diabetic foot in daily practice: a prospective follow-up study}

MH Nabuurs-Franssen, R Sleegers, MSP Huijberts, W Wijnen, AP Sanders, G Walenkamp, NC Schaper

Diabetes Care 2005;28(2):243-247 


\section{Abstract}

\section{Objectives}

A limited number of cinical trials have shown that the total contact cast (TCC) is an effective treatment in neuropathic, non-infected and non-ischemic, foot ulcers. In this prospective data collection study, we assessed outcome and complications of TCC treatment in neuropathic patients, with and without peripheral arterial disease (PAD) or (superficial) infection.

\section{Research design and methods}

98 consecutive patients selected for casting were followed until healing; all had polyneuropathy, $44 \%$ had PAD and $29 \%$ had infection. Primary outcomes were: $\%$ healed with a cast, time to heal and number of complications.

\section{Results}

$90 \%$ of all non-ischemic ulcers without infection and $87 \%$ with infection healed in the cast (ns). In patients with PAD, but without critical limb ischemia, 69\% of the ulcers without infection and $36 \%$ with infection healed $(p<0.01)$. In multivariate analyses PAD, infection and heel ulcers were associated with lower percentage thealed (all $p<0.05$ ). Median duration of cast treatment was 34 days. New ulcers, all superficial, developed in $9 \%$ and pre-ulcerative lesions in $28 \%$ of the patients; these skin lesions healed in the cast within a maximal of 13 days.

\section{Conclusions}

In comparison to pure neuropathic ulcers, ulcers with moderate ischemia or infection can be treated effectively with casting. However, when both PAD+ and infection are present, or the patient has a heel ulcer, outcome is poor and alternative strategies should be sought. The high rate of pre-ulcerative lesions stresses the importance of close monitoring during TCC treatment. 


\section{Introduction}

Off-loading of the wound is one of the key elements in treating diabetic (neuropathic) foot ulcers. Several off-loading devices are available, such as walkers, half shoes, orthoses, felted foam and the total contact cast (TCC) ${ }^{2-5}$. which is seen as the definitive standard therapy ${ }^{2.6-8}$. There are three randomised clinical trialls ${ }^{6-8}$ published on the effectiveness of total contact casts in neuropathic plantar foot ulcers, in which a non-removable total contact cast was compared with no offloading ${ }^{6}$, with a removable aircast walker ${ }^{7}$ and/or a shoe modality ${ }^{3}$. These studies concluded that a TCC healed a higher proportion of neuropathic non-infected ulcers in a shorter amount of time, with healing rates of approximately $90 \%$.

Although a total contact cast seems a highly attractive off-loading modality, several disadvantages have been reported: new ulcers may occur, daily wound care is not possible, mobility is impaired, costs may be relatively high and specialized staff seems necessary ${ }^{3}$. In case of prolonged casting, joint rigidity and muscular atrophy have been documented ${ }^{7}$. Finally, the above described trials were performed in centers of excellence, in patients with superficial, noninfected, nonischemic, plantar ulcers and numbers were relatively small. When combined, these published randomised controlled trials have reported on 66 patients treated with TCC. Although from a biomechanical point of view offloading is indicated in most patients, only a minority of all patients fulfill the aforementioned criteria?. Therefore in many patients the presence of peripheral arterial disease (PAD) and/or infection will be seen as a contra-indication for casting. In addition, fear of complications, and lack of educated staff hamper the implementation of total contact casting in daily clinical practice. A recent European survey revealed that total contact casting is indeed used in a minority of specialized diabetic foot centers (Eurodiale study group, unpublished data).

The present study was undertaken to determine the outcome and complication rate of total contact casting in a wide range of diabetic foot ulcers in daily practice. Patients with moderate peripheral arterial disease and/or (superficial) infection were included in order to compare the outcome of TCC-treatment in these patients with the outcome in patients with non-infected pure neuropathic ulcers.

\section{Research design and methods}

\section{Subjects}

All individuals, starting from the first patient treated, were included in the prospective data collection study, which commenced January 1998 and ended 
March 2003. Eligible were all diabetic patients with polyneuropathy and a foot ulcer in whom off-loading was indicated but not possible with simple measures (e.g. felt). Exclusion criteria were: critical limb ischemia (ankle pressure $<50 \mathrm{mmHg}$, toe pressure $<30 \mathrm{mmHg}$, tcpO $2<30 \mathrm{mmHg})^{10.11}$ and major illnesses affecting wound healing. Patients with infection higher than grade 2 of the PEDIS system 10 , were also excluded, with the exception of 4 patients who were treated with oral antibiotics for a chronic osteomyelitis, without other signs of infection. Results of the first cast treatment are reported and patients with a bilateral cast were not analysed. Data was collected on a weekly or bi-weekly basis until healing or when casting was stopped before healing. Cast treatment was terminated when there was no reduction in wound size or/depth during 4 consecutive weeks, when an infection $>$ grade 2 developed ${ }^{10}$ or when the patient had severe discomfort with the cast. These cases are all defined as cast-failure. The patient remained in the cast until healing, which was defined as an intact skin on clinical examination. complications were scored on each visit, which included discomfort, chafed skin, pre-ulcerative lesion (defined as a non-ulcerative lesion related to local pressure in the cast), new ulcers on the affected foot and lower extremity joint problems. Time to heal was defined as the number of days from baseline until healing in the cast.

\section{Clinical protocol}

Patients were treated by a multidisciplinary team. At every visit, patient characteristics, cast details and complications were registered electronically. Peripheral polyneuropathy was defined ${ }^{10}$ as the absence of two of five sensory modalities (vibration sensation using the $128 \mathrm{~Hz}$ tuning fork, light touch, bluntsharp discrimination, Achilles tendon reflex and 10 grams monofilament). Moderate Peripheral Arterial Disease (PAD) was defined ${ }^{10}$ as absence of both pedal pulses on the affected foot and/or presence of intermittent claudication and/or ankle brachial index $<0.9$ and/or toe brachial index $<0.6$ and/or $t c \mathrm{O}_{2} 30-60$ $\mathrm{mmHg}$, without signs of critical limb ischemia (see above). The anatomical location (35 regions of the foot) was defined as described by Apelquist et al. ${ }^{12}$. The wound surface was estimated ${ }^{10}$ by multiplying the largest by the second largest diameter, measured perpendicular to the first diameter. Superficial infection was defined ${ }^{10.11}$ as an infection involving skin and subcutaneous tissue only, without systemic signs. At least 2 of the following items were present: local swelling or induration, erythema $>0.5 \mathrm{~cm}$ around the ulcer, local tenderness or pain "local warmth, purulent discharge (thick, opaque to white or sanguineous secretion) and lymphangitis 10,11 .

\section{Treatment}

Three total contact casting modalities were used: a non-removable total contact cast (TCC), a removable total contact cast (RCC) and a shoe-model cast (SMC). 
that could not be removed by the patient. These casts were applied using a modification of the technique described by Kominsky ${ }^{13}$ and the choice of cast was based upon both patient and cast characteristics, see table 4.1. Eighty six percent of the patients were treated with one type of cast during the complete treatment period. In the other patients one specific type of cast was prescribed $>60 \%$ of the time, and this cast was used in the amalyses. Felt was applied around the ulcer to reduce peak pressure. Patients with a removable cast were instructed to remove the device only during wound care. At every visit necrotic tissue and callus were surgically debrided; TCC's were renewed every one to two weeks, RCC and SMC devices were modified if necessary.

Table 4.1 Cast characteristics

\begin{tabular}{|c|c|c|c|}
\hline Cast & $\operatorname{TCC}(n=50)$ & $\operatorname{RCC}(n=22)$ & $\operatorname{SMC}(n=26)$ \\
\hline \multicolumn{4}{|l|}{ Picture } \\
\hline Weight (gram) & 700 & 700 & 250 \\
\hline \multicolumn{4}{|l|}{ Indication: } \\
\hline compliance & poor & good & good \\
\hline exsudation & - & $4+++$ & $t+t$ \\
\hline $\begin{array}{l}\text { walking pattern } \\
\text { daily wound }\end{array}$ & - & - & small steps * \\
\hline inspection/care & - & + & + \\
\hline \multicolumn{4}{|l|}{ Contra-indication: } \\
\hline compliance & - & poor & hyperpronated toot. \\
\hline foot characteristics & - & - & $\begin{array}{c}\text { need for suppont } \\
\text { ankle fixation }\end{array}$ \\
\hline ulcers at margin foot & + & + & . \\
\hline
\end{tabular}

* Patients were instructed to walk with small steps, because thils cast is associated with higher mobility

\section{Statistical analyses}

Data are expressed as median and 1Q-ranges. Comparisons were performed using Fisher Exact, Mann-Whitney $U$ test and Kruskar-Wallis test. In all analyses correction was made for ulcer duration. Multivariate analyses were performed to further delineate the effect of PAD and infection on the percentage healed and 
cast failure (logistic regression). In this analysis we included: PAD, infection at baseline, type and duration of diabetes, age and sex, size and duration of the ulcer at baseline, and type of cast. The SPSS statistical package version 11.0, Chicago, 111 , USA was used.

\section{Results}

\section{Patients and clinical outcome}

Ninety-eight patients were enrolled in the study. More than $90 \%$ of these patients had multiple diabetic complications. Patient and wound characteristics are described in table 4.2. PAD was present in $44 \%$ and infection at baseline in $29 \%$ of the patients. Overall, healing was achieved in $74(76 \%)$ of the patients, with a median healing time of 33 days (IQ range 14-63). In 22 patients the ulicer did not heal during cast treatment (cast-failure): nine of these patients developed progressive infection: 6 were hospitalised for i.v. antibiotics and 3 underwent amputation ( 2 lower leg, 1 toe). Because of impaired healing a revascularisation procedure was performed in 2 patients and a free-flap transplantation in 3 patients. In 7 patients casting was stopped due to discomfort with the cast and non-compliance in 1 patient. In all the aforementioned patients alternative offloading techniques were used, which resulted in healing of 20 of the 22 ulcers at the end of the study period. Two patients were lost to follow-up before healing had occurred and were included in the analyses as cast-failures ( $n=24$ in total).

\section{Ulcer healing}

In patients without infection and without PAD healing occurred in $90 \%$, and in patients without PAD but with infection healing was observed in $87 \%$, see figure 4.1 (ns). In patients without infection but with moderate PAD healing occurred in $69 \%$ ( $p<0.01$ v5 PAD-finfection- patients). However, in patients with infection and $P A D$, healing was markedly impaired: only $36 \%$ of the ulcers healed during cast treatment ( $p<0.005$ vs PAD-/infection- patients). The time-to-heal was in the patients without infection and without PAD 18 days (10-41) and in patients without PAD but with infection $29(27-68)$ days $(p<0.05)$. In patients without infection but with moderate PAD the time-to-heal was 42 (14-65) days $(p<0.05$ vs PAD-/infection- patients and PAD-/infection+ patients). As only a minority of patients with infection and $P A D$ healed during cast treatment, the numbers were too small to calculate the time-to-heal. 
Table 42. Patient characteristics of all patients and patients with cast-fallure and healing ulcers

\begin{tabular}{|c|c|c|c|}
\hline Patient characteristics & All $(n=98)$ & Cast-failure $(n=24)$ & Healed $(n=74)$ \\
\hline Agle (yrs) & $67(55-76)$ & $71 \quad(56-78)$ & $64(55-73)$ \\
\hline Gender ( $\%$ malle) & 65 & 71 & 63 \\
\hline Duration diabetes (yrs) & $18(7-24)$ & $15 \quad(10-25)$ & $19(7-24)$ \\
\hline PAD $(\%)$ & 44 & $75^{\circ}$ & 34 \\
\hline Type Diabetes (\% Type 2) & 70 & 68 & 73 \\
\hline \multicolumn{4}{|l|}{ Ulcer characteristics } \\
\hline Size $\left(\mathrm{cm}^{2}\right)$ & $1.3(0.6 \times 7.1)$ & $1.3(0.4-19.5)$ & $1.2(0.6-3.1)$ \\
\hline Duration (days) & $31(28-145)$ & $61 *(28-145)$ & $21(7-74)$ \\
\hline infection $(\%)$ & 29 & $46^{*}$ & 24 \\
\hline \multicolumn{4}{|l|}{ Location $(\%)$} \\
\hline Dig $\mathbb{1}$ plantar & 22 & 8 & 27 \\
\hline MTH 1 plantar & 15 & $0^{-1}$ & 20 \\
\hline Ray 2,3,4 plantar & 30 & 30 & 30 \\
\hline Ray 5 plantar & 14 & 21 & 11 \\
\hline Dorsum / Midfoot & 9 & 12 & 8 \\
\hline Heel & 9 & $29^{*}$ & 3 \\
\hline
\end{tabular}

Data shown as median and interquartiles, ranges. " $\mathrm{p}<0.05 ;$ yrs $=$ years, $P A D=$ peripheral arterial disease, $M T H=$ metatarsal head

Figure 4.1 The effect of PAD and infection on outcome of cast treatment

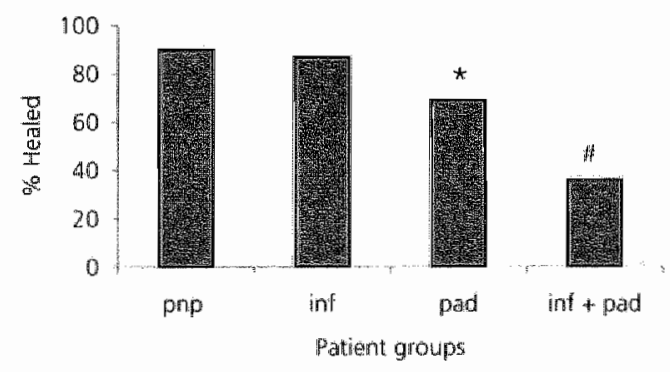

$P N P=$ presence of peripheral polyneuropathy, no signs of infection or $P A D, W F=$ presence of infection, no signs of $\mathrm{PAD}, P A D=$ presence of peripheral arterial disease, no signs of infection. $/ M F$ s $P A D=$ presence of both infection and peripheral arterial disease. "P<0.01 PAD patients VS PNP patientz, "p<0.005 INF + PAD patients vs PNP pattents.

No differences in age, sex, duration of diabetes, type of diabetes, diabetic complications, and ulcer size, were observed between the patients who healed and the patients who did not heal in the cast (table 4.2). Moreover, no differences were observed between the healing rates of the three types of cast (TCC v5 RCC v5 
SMC). Patients with cast-failure had, in comparison to patients in whom the ulcer healed, more frequently moderate PAD $(75 \%$ vs $34 \%, p<0.001)$, longer duration of the ulcer ( 61 vs 21 days, $p<0.05$ ) and more frequently infection at baseline (46\% vs $24 \%, p<0.05$ ). In addition, the anatomical location was clearly related to outcome: all ulcers $(n=15)$ in the MTH 1 region healed, irrespective of the presence of PAD and/or infection. In contrast, the minority of heal ulcers healed $(p<0.02$. table 4.2). Logistic regression analysis also showed that infection at baseline (odd's ratio 3.6), PAD (odd's ratio 7.4) and the location at the heel (odd's ratio 11.4) were associated with a lower percetage of healing in the cast.

\section{Complications}

New ulcers, all superficial, were observed in $9 \%$ of the patients and were not related to ischemia, infection or the anatomical location of the primary ulcer (data not shown). These ulcers healed within a maximum of 13 days in a revised cast. Pre-ulcerative lesions developed in $28 \%$ of the patients but resolved within a few days after minor adaptations of the cast. Chafed skin was found in $8 \%$ of the patients and temporary joint problems were reported in $7 \%$ of the patients.

\section{Conclusions}

Increased biomechanical stress is one of the most important pathways leading to ulceration in patients with neuropathic and neuro-ischemic foot ulcers. Randomised clinical trial $5^{6-8}$ have shown that casting can be an effective offloading modality in the treatment of neuropathic, non-infected, ulcers, but several questions remain about the applicability of these data to daily practice. The current study shows that with casting, in a wide range of ulcers, the majority of patients $(76 \%)$ can be healed in a relative short time span (median 33 days). As expected the best results were obtained in patients with non-infected, pure neuropathic ulcers. Ninety percent of the ulcers healed in a median of 18 days; these results are comparable with the aforementioned randomised controlled trials in which TCC was evaluated ${ }^{6-8}$. These healing rates of approximately $90 \%$ compare favourably to the results obtained in the control arms of randomised controlled trials $5^{14.15}$ on wound care, in which approximately $30 \%$ healed in 140 days, as summarised in a meta-analysis ${ }^{16}$. In the current study, superficial infection in patients with pure neuropathic ulcers did not influence the results, but in patients with neuroischemic ulcers without infection the percentage healed was somewhat lower $(69 \%$ healed). The poorest results were obtained in patients with both neuroischemia and infection ( $36 \%$ healed). 
Infection is a frequent complication of diabetic foot ulcers ${ }^{\text {"I }}$ and the presence of infection greatly enhances the risk of amputation ${ }^{17}$. At present, infection is seen as a contra-indication for total contact casting ${ }^{\bar{a}_{1}}{ }^{18}$, given the risks of spreading of the infection, the inability of daily wound inspection and the need for daily dressing changes. Indeed, infection did have negative effects on healing rates and healing times, although, this effect was small in pure neuropathic ulcers. Therefore, it appears that casting can be applied in infected neuropathic ulcers with results comparable to pure neuropathic ulcers without infection, in the absence of PAD or deep tissue infection. Prerequisites are close monitoring of the patient, weekly wound care and antibiotic treatment. In case of increased exsudation, a removable cast can be safely used as this technique allows daily dressing changes.

Appoximately $40 \%$ of the foot ulcers in Westernized countries are neuro-ischemic. PAD is usually seen as a contra-indication for total contact casting ${ }^{18}$, because of fear of further deterioration of the blood supply and development of new ulcers. However, some authors reported that this treatment was efficacious in small numbers of patients ${ }^{19,20}$. Elevated biomechanical stress is probably as important in neuro-ischemic as in neuropathic foot ulcers ${ }^{21}$, therefore off-loading is indicated in both types of ulcers. Our data show that, in comparison with pure neuropathic ulcers, TCC treatment can be used with limited loss of effectiveness in neuroischemic ulcers, without critical limb ischemia and infection.

The combination of infection and moderate PAD renders a poor prognosis. In the current study only $36 \%$ of the patients with this combination healed with casting. These poor healing rates are in line with an amputation rate of $50 \%$ in patients with infection and peripheral ischemia, as reported earlier ${ }^{22}$. It is likely that the peripheral perfusion deficit resulted in impaired penetration of the antibiotic ${ }^{23}$ and, possibly, contributed to a decreased local immune response. Therefore, other treatment modalities should be used in these types of ulcers.

The anatomical location of the ulcer affected healing rates in our study $y^{24-27}$. All ulcers, at the MTH 1 region healed and very poor results were obtained in patients with heel ulcers. As suggested by previous biomechanical studies ${ }^{28}$, the total contact cast technique is not very effective in reducing elevated plantar pressures at the heel region and, therefore, alternative off-loading strategies should be sought for ${ }^{29}$. The duration of the ulcer, had a negative effect on the time to heal, as also shown in other studies on wound healing ${ }^{15}$. Therefore, we suggest that in patients in whom casting is considered, this treatment should be started as soon as possible.

In addition to the classic rigid TCC, we used two semi-rigid adaptations that were less heavy and that permitted daily wound care: a removable cast up to the knee 
and a shoe-model up to the ankle, that was fixated. The non-removable TCC and the removable TCC were similar in many aspects and earlier studies did not show a difference in pressure relief between these two modalities ${ }^{30,3 i}$. As suggested earlier ${ }^{32}$, part of the efficacy of the non-removable TCC is possibly related to the "forced compliance" for off-loading. We did not observe major differences in the results abtained with these devices, however, our study was not designed to evaluate the efficacy of these different off-loading techniques. Additional studies are needed to determine the (cost-) effectiveness of these more recently developed casting models versus the classic TCC.

In the published randomised controlled trials TCC was associated with a low complication rate ${ }^{6 \cdot 3}$ but this does not mean that similar results will be obtained in daily practice. Our study shows that casting in the elderly and frequently frail patient with a diabetic foot ulcer is indeed applicable in daily practice and can contribute to a favourable outcome of treatment. All consecutive patients were included from the first day we started casting, therefore, our data include the learning curve of the staff. Moreover, casts were applied during the years of the study by seven different casting technicians. Casting therapy is not without risks, as illustrated by the $9 \%$ new ulcers and the $29 \%$ pre-ulcerative lesions in the current study. However, these adverse events did not result in delayed healing of the foot, as all ulcers and pre-ulcerative lesions resolved in the cast before the primary ulcer had heaied. These complications were not related to the presence of infection, PAD or the anatomical location of the ulcer, but were probably the result of sub-optimal casting technique and/or inappropriate use of the cast by the patient. The high number of pre-ulcerative lesions caused by the cast stresses the importance of close monitoring until the last day of treatment.

In conclusion, casting therapy is applicable in daily practice in a wide range of patients, with good healing rates and relative few major complications. In comparison to patients with pure neuropathic ulcers, patients with (superficial) infection or moderate PAD can be treated with limited loss of effectiveness with casting. However, given the poor outcome, alternative strategies should be used in patients with the combination of PAD and (superficial) infection, and in patients with heel ulcers. 


\section{References}

1. Jeffcoate WJ, Harding $K G$. Diabetic foot ulcers. Lancet $2003 ; 361: 1545-51$

2. Spencer 5. Pressure relieving interventions for preventing and treating diabetic foot ulcers (Cochrane review). Cochrane Database Syst Rev 3, 2000.

3. Armstrong DG, Lavery LA. Evidence-based options for off-loading diabetic wounds. Clin podtatr Med Surg 1998;15:95-104.

4. Armstrong DG, Stacpoole-Shea S. Total contact casts and remowable cast walkers. Mitigation of plantar heel pressure. / Am Podiatr Med A.ssoc 1999;89:50-3.

5. Cavanagh PR, Uibrecht $J 5$, Caputo GM. New developments in the biomechanics of the diabetic foot. Diabetes Metab Res Rev 2000; $1651: 56-10$.

6. Mueller Mi, Diamond AE, Sinacore DR, Delitto A, Blair VP 3rd, Drury DA, Rose SI. Total contact casting in treatment of diabetic plantar ulcers. Controlied clinical trial. Diabetes Cate $1989 ; 12: 384-8$

7. Caravaggi C, Faglia E, De Giglio R, Mantero M, Quarantiello A, Sommarive E, Gino M, Pritelli C. Morabito A. Effectiveness and safety of a nonremovable fiberglass off-bearing cast versus a therapeutic shoe in the treatment of neuropathic foot ulcers: a randomized study. Diabetes Care $2000 ; 23: 1746-5: 1$

8. Armstrong DG, Nguyen $H C$, Lavery LA, van Schie CH, Boulton AJ, Harkless LB. Off-loading the diabetic toot wound: a randomized clinical trial. Diabetes Care 2001:24:1019-22.

9. International Working Group on the Diabetic Foot. Apelquist $\perp$. Bakker $K$, Van Houtum WH, Nabuurs-Franssen MH, Schaper MC (ed). International Consensus on the Diabetic Foot. Schaper NC. Maastricht, 1999.

10. Schaper NC. Diabetic foot ulcer classification system for research purposes: a progress report on criteria for including patients in research studies. Diabetes/Metabolism Research and Reviews 2004:20 (\$.1):590-5

11. Lipsky BA. A report from the international consensus on diagrnosing and treating the infected diabetic foot. Diabetes/Metabolism Research and Reviews 2004;20 (51):568-77.

12. Larsson J. Agardh CD. Apelquist J, Stenstrom A. Clinical characteristics in relation to final amputation level in diabetic patients with foot ulcers; a prospective study of healing below or above ankle in 187 patients. Foot Ankle int 1995:16: 69-74.

13. Kominsky 5 . The ambulatory total contact cast. In: The High Risk Foot in Diabetes Mellitus, 1st ed. RG Frykberg. Ed. New York، Churchill Liwingstone, 1991:449-55.

14. Embil JM, Papp K, Sibbald G, Tousignant J, Smiell JM, Wong B, Lau CY. Recombinant human platelet-derived growth factor $\mathrm{BB}$ (becaplermin) for healing chronic lower extremity diabetic ukers: an open-label cinical evaluation of efficacy. Wound Repair Regen 2000; 8:162-8.

15. Gentzkow GD, lwasaki SD, Hershon KS, Mengel M, Prenderglast JI, Ricotta Jj, Steed DP, Lipkin S. Use of dermagraft, a cultured human dermis, to treat diabetic foot ulcers. Diabetes Care $1996: 19: 350-4$.

16. Margolis DJ, Kantor J, Berlin JA. Healing of diabetic neuropathic root ulcers receiving standard treatment. A meta-anallysis. Diabetes Care 1999:22:692-5.

17. Eneroth M. Apelquist 1 , Stenstrom A. Clinical characteristics and outcome in 223 diabetic patients with deep foot infections. Foot Ankle int 1997;18:716-22

18. Laing PW, Cogley DI, Klenerman L. Neuropathic foot ulceration treated by total contact casts. J Bone Joint Surg br 9992;74:133-6.

19. Sinacore DR, Mueller MJ, Diamond JE, Blair VP, 3rd, Drury D, Rose 5J. Diabetic plantar ulcers treated by total contact casting. A clinical report. Phys Ther 1987;67:1543-9.

20. Borssen $B$, Lithner $F$. Plaster casts in the management of advanced ischaemic and neuropathic diabetic foot lesions. Diabet Med 1989:6:720-3

21. Pitei DL, Lord M. Foster A, Wilson S, Watkins P., Edmonds ME. Plantar pressures are elewated in the neuroischemic and the neuropathic diabetic foot. Diabetes Care 1999:22:1966-70.

22. Armstrong DG, Lavery LA, Harkless LB. Validation of a diabetic wound classification system. The contribution of depth, infection, and ischemia to risk of amputation. Diabetes Care 1998; 21 : $855-9$. 
23. Raymakers JTF, Houben Al, Van der Heyden J, Tordoir IHM, Kitslar PJEHM, Schaper NC. The effect of diabetes and severe ischemia on the penetration of ceftazidime into tissues of the limb. Diabet Med $2001 \cdot 18229-34$

24. Sinacore DR. Healing times of diabetic ulcers in the presence of fixed deformities of the foot using total contact casting. Foot Ankle /nt 1998;19:613-8.

25. Lavery LA, Vela SA, Lavery DC, Quebedeaux TL. Total contact casts pressure reduction at uicer sites and the effect on the contralateral foot. Arch Phys Med Rehabil 1997;78:1268-71.

26. Wertsch $\mathrm{l}$, Frank LW, Zhu $\mathrm{H}$, Price MB, Harris GF, Alba HM. Plantar pressures with total contact casting. I Rehabil Res Dev 1995;32:205-9.

27. Walker SG, Helm PA, Pullum G. Total contact casting and chronic diabetic neuropathic foot Ulcerations: healing rates by wound location. Arch Phys Med Rehabi/ 1987;68:217:21

28. Shaw JE, Hisi WL, Ulbrecht JS, Norkitis A, Becker MB, Cavanagh PR. The mechanism of plantar unloading in total contact casts: implications for design and clinical use. Foot Ankle Int 1997:18:809-17.

29. Cevera J. Bolton LL, Kerstein MD. Options for diabetic patients with chronic heel ulcers J Diabetes Complications 1997;11:358-66.

30. Lavery $L A$, Vela $S A$, Lavery DC, Quebedeaux TL. Reducing dynamic foot pressures in high-risk diabetic subjects with foot ulcerations. A comparison of treatments. Diaberes Care 1996;19: $818 \times 21$.

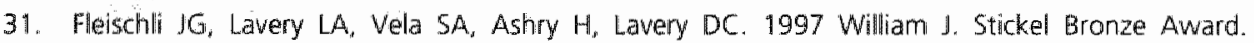
Comparison of strategies for reducing pressure at the site of neuropathic ulcers. I Am Podiatr Med Assoc 1997;87:466-72.

32. Armstrong DG, Lavery LA, Kimbriel HR, Nixon BP, Boulton A. Activity patterns of patients with diabetic foot ulceration: patients with active ulceration may not adhere to a standard pressure off-loading regimen. Diabetes Care 2003;26:2595-7. 
Chapter

\section{Recurrent casting diabetic foot ulcers:} effective and save?

MH Nabuurs-Franssen, MSP Huijberts, R Sleegers, NC Schaper

Diabetes Care 2005, in press 
Choter 5

s.

66

1 


\section{Introduction}

With appropriate wound care and biomechanical off-loading, 80 to $90 \%$ of the neuropathic foot ulcers can heal'. Unfortunately, many ulcers recur ${ }^{2}$ and recurrence rates up to $70 \%$ have been reported ${ }^{3-5}$. Little information is available on the management and outcome of these ulcers. In addition, it is unclear how to approach a patient, in whom customised shoes fail to prevent ulceration and in whom repetitive ulceration could result in progressive scar formation and impaired wound healing. The total contact cast (TCC) is currently seen as the gold standard treatment of neuropathic ulcers ${ }^{1,6,7}$ but the efficacy and safety of repeated treatment is unknown. For this reason, the present study was undertaken to determine whether repeated casting in patients with recurrent foot ulceration remains effective and is not associated with unwanted complications.

\section{Research design and methods}

A prospective data collection study (from 1999 to 2003) was performed in which diabetic patients with polyneuropathy and a first or recurrent foot ulcer in whom off-loading was indicated but not possible with simple measures (e.g. felt) were included. All patients were evaluated and graded according the PEDIS system and were treated with TCC, as previously described by Nabuurs-Franssen and Schaper. Exclusion criteria were: critical limb ischemia and infection > grade 2 of the PEDIS system $^{9}$. Cast treatment was terminated in case of lack of improvement of the wound during 4 consecutive weeks, or infection > grade 2 or severe discomfort with the cast. These cases are defined as cast-failure. Patients remained in the cast until healing, defined as an intact skin on examination. The time to heal was defined as the number of days from baseline until healing in the cast. Complications and "non-compliance", defined as a patient reporting adhering to the off-loading regime less than $75 \%$ per day or if the clinician had the impression the patient was doing so, were scored on each visit.

\section{Statistics}

Data are expressed as means $+\%$ SD or median and interquantile where appropriate. Comparisons between two groups were performed using Fisher Exact test and the Mann-Whitney $U$ test, using the SPSS statistical package version 11.0. Multivariate analyses were performed to determine whether repeated ulceration on identical regions and repeated cast treatment on the same leg affects the \% healed (logistic regression) and/or the time-to-heal (Cox hazard model with time dependent variables) of an ulcer. In these aralyses Peripheral Arterial Disease (PAD), infection, size and duration of the ulcer at baseline were included. 


\section{Results}

A total of 104 patients were treated with a TCC. Their age was $65 \pm 13$ years, $62 \%$ was male and all had peripheral neuropathy. Forty-one patients, with in total 202 ulcers, were treated more than once with casting on the same foot during the five year period (figure 5.1). In comparison with patients who were treated only once with casting, patients with recurrent ulcers had more often foot deformities ( $90 \%$ ws $74 \%$ ) and PAD (69\% vs 44\%), and were more non-compliant ( $20 \%$ vs $2 \%$ ), all $p<0.05$. Seventy five percent of the patients had recurrences on different locations of the foot (median of 2), $25 \%$ had only 1 region with recurrences, $90 \%$ of these recurrences were located on Dig 1 and MTP 1 . The median number of cast treatments per patient was $3(1 \mathrm{Q} 2-6$, maximum 12) and in total $88 \%$ of all ulcers healed with casting.

Figure 5. 11 Patient flow

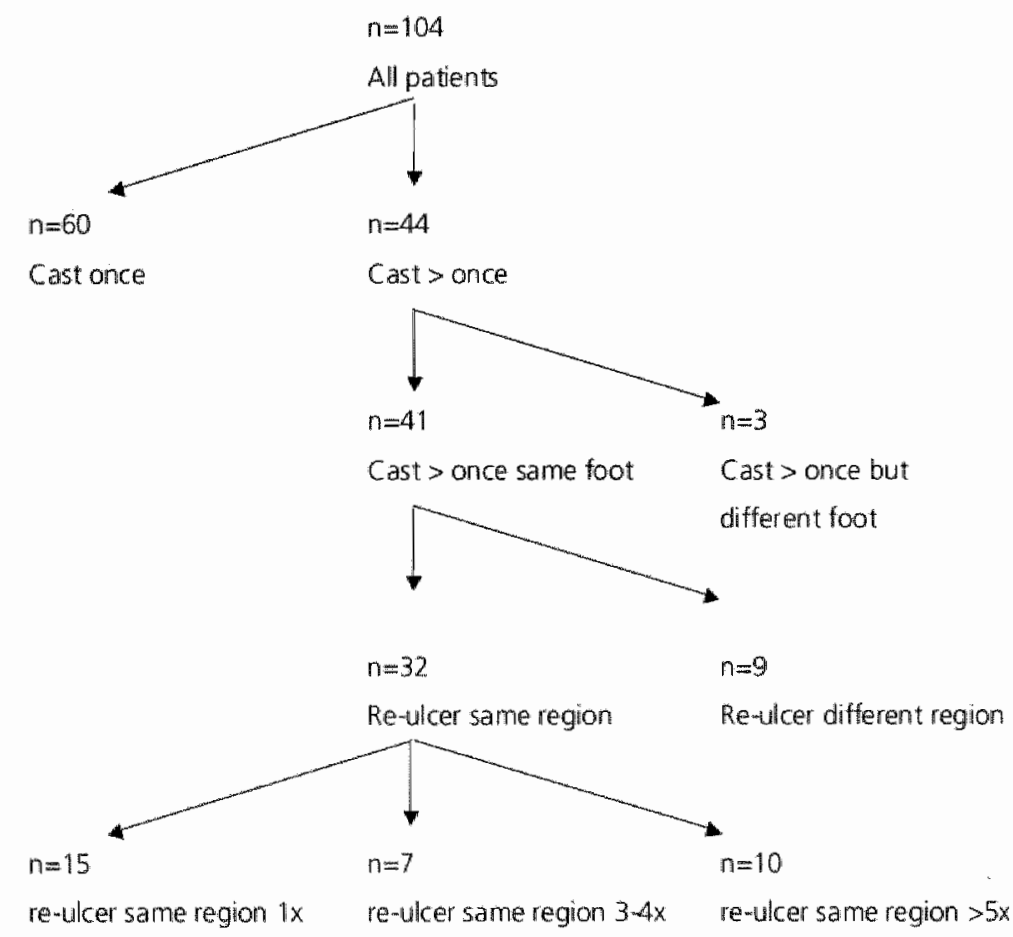

Recurrent foot ulceration was not associated with impaired healing. In comparison with the first ulcer episode, the percentage of patients who healed during the last episode was 94 vs $91 \%$ (ns) and, the difference in healing velocity of ulcers with 
more than 4 recurrences on the same area and treated repeatedly with TCC was -3 days (ns). In addition, fewer complications were found after repeated casting (episode 1-3: $15 \%$ vs episode $4-12: 6 \%, p<0.05$ )

\section{Conclusions}

Recurrent foot ulceration is a major health problem in diabetic patients ${ }^{2 \cdot 4}$. During 2-years follow-up. 39\% of our patients had recurrent ulcers for which treatment with TCC was indicated. We did not observe any difference in healing between the different ulcer periods suggesting that the regenerative capacity of the skin remains intact after repeated episodes of biomechanical damage and ulceration. Surprisingly the number of complications appeared to decrease with repetitive casting, suggesting that this treatment can be repeated without loss of safety. However, because each ulcer episode is a burden to the patient, with a risk for infection and amputation ${ }^{10}$, our findings do not reduce the relevance of effective preventive measures. Our results are limited to patients with recurrent neuropathic or mild-moderate neuro-ischemic plantar foot ulcers, without severe infection. In our clinic all patients with such recurrences are candidates for TCC. However, we cannot exclude that severe complications in an earlier TCC treatment influenced the choice of TCC or other off-loading modalities. This could have resulted in a selective loss of patients.

The majority of our patients with recurrent ulceration had PAD without signs of critical limb ischemia. Although PAD was a clear risk factor for recurrent ulceration, the ulcers healed with casting in almost $90 \%$ of the patients. Customised shoes with orthoses were prescribed to all patients, but they failed to prevent ulceration in a relative large number of patients ${ }^{11}$. Part of this lack of efficacy is probably related to poor compliance and partly to ineffective reduction of increased biomechical stress in patients with foot deformities. Several surgical procedures such as corrective foot surgery ${ }^{12,13}$ and Achilles tendon lengthening ${ }^{14}$ have been proposed to improve the altered biomechanics and to prevent re-ulceration. However, in our experience, the ulcer did not recur on the same area in most patients, suggesting that the whole foot, and not a specific area, is at risk. Exceptions could be the hallux and the MTP 1 region, since we found that these areas were prone to re-ulceration, but the number of randomised controlled clinical trials on these procedures is scarce.

In conclusion, repetitive $T C C$ treatment can be an effective and safe approach in diabetic patients with recurrent neuro-ischemic ulceration. 
Table 3.9 Characteristics of Type 2 diabetic patients with and without polyneuropathy and nondiabetic control subjects.

\begin{tabular}{|c|c|c|c|}
\hline & Control $(n=16)$ & PNP - $(n=14)$ & $P N P+(n=24)$ \\
\hline Matrifemale & $8 / 8$ & $9 / 5$ & $15 / 9$ \\
\hline Age (years) & $58(50-71)$ & $59(43-74)$ & 64. $(47.77)$ \\
\hline$B M\left(\mathrm{~kg} / \mathrm{m}^{2}\right)$ & $25(22-31)$ & $27(21-38)$ & $29(21-37)$ \\
\hline Diabetes duration (years) & - & $11(2-28)$ & $13(1-31)$ \\
\hline PNP (Valkscone) & $0(0-4)$ & $2(0-4)$ & $15^{3}(15-27)$ \\
\hline \multicolumn{4}{|l|}{ Retinopathy (ni pat) } \\
\hline background & $=$ & 1 & 1 \\
\hline proliferative & - & 1 & 10 \\
\hline \multicolumn{4}{|l|}{ Albuminuria (ne pat) } \\
\hline Micro & 0 & 0 & 3 \\
\hline Macro & 0 & $a$ & 3 \\
\hline
\end{tabular}

Data shown as medians (ranges). Control = age- and sex matched non diabetic subjects, PNP= peripheral polyneuropathy, PNP- $=$ Type 2 diabetic patients without polyneuropathy, PNP+ $=$ Type 2 diabetic patients with polyneuropathy, BMMl=Body Mass Index, nr pat=number of patients.

pe 0.001 us control and PNP.

Table 3.2 Peripheral blood pressures, tcpO $\mathrm{O}_{2}$ and blood laboratory data of Type 2 diabetic patients with and without polyneuropathy and non-diabetic control subjects.

\begin{tabular}{|c|c|c|c|}
\hline & Contral $(n=16)$ & PNP- $(n=14)$ & $P N P+(n=24)$ \\
\hline Systole (mm Hg) & $130(1175-154)$ & $140(116-160)$ & $142(110-169)$ \\
\hline Diastole $(\mathrm{mm} H \mathrm{Hg})$ & $81(71-92)$ & $78(63-87)$ & $80(64-89)$ \\
\hline Toe-pressure (mm Hg) & $120(95-180)$ & $118 \quad(90-180)$ & $120(65-184)$ \\
\hline tcpor $\left(\mathrm{mm} \mathrm{Hg}^{2}\right)$ & $48(31-81)$ & $45(30-68)$ & $46(31-68)$ \\
\hline Glucose (mmal/li) & $5.3(4.2-6.0)$ & $7.8^{a}(6.4 m 15.6)$ & $7.5^{a}(4.8-13.9)$ \\
\hline HbAlc $(\%)$ & $5.6(5.1-6.4)$ & $8.1^{\text {1 }}(6-4-11.4)$ & $7.8^{21}(6.2-9.7)$ \\
\hline Creatinin (umo $/$ ) & $81(67-107)$ & $83 \quad(67-138)$ & $82(57-260)$ \\
\hline Albumin $(g / d)$ & $41(38-45)$ & $40(35-46)$ & $41(36-49)$ \\
\hline
\end{tabular}

Data shown as median (ranges). Control = age and sex matched nondiabetic subjects, PNP= peripheral polyneuropathy. $P N P=$ Type 2 diabetic patients without polyneuropathy, $P N P_{+}=$Type 2 diabetic patients with polyneuropathy, BMl=Body Mass Index Toepressure= measured at dig 1. $1 \mathrm{pO}=t r a n s c u t a n e o u s$ oxygen pressure.

it pe 0.001 ws control. 


\section{References}

1. Armstrong DG, Nguyen HC, Lavery $L A$, van Schie CH, Boulton AJ, Harkless LB, Off-loading the diabetic foot wound: a randomized dinical trial. Diabetes Care 2001;24:1019-22.

2. Walsh CH: A healed ulcer: what now? Diabet Med 1996;13 51:558-60.

3. Apelquist I, Larsson J. Agardh CD. Long-term prognosis for diabetic patients with foot ulcers. Intern Med 1993:233:485-91.

4. Mantey 1. Foster AV, Spencer S, Edmonds ME. Why do foot ulcers recur in diabetic patients? Diabet Med 1999:16:245-9.

5. Connor $H$, Mahdi $\mathrm{OZ}$ Repetitive ulceration in neuropathic patients. Diabetes Metab Res Rev 2004:20 $51: 523-8$.

6. Caravaggi $C$, Faglia E, De Giglia R, Mantero M, Quarantiello A, Sommariva $E_{x}$ Gino M, Pritell $C$. Morabito A. Effectiveness and safety of a nonremovable fiberglass off-bearing cast wersus a therapeutic shoe in the treatment of neuropathic foot ulcers: a randomized study. Diabetes Care $2000 ; 23: 1746-51$.

7. Mueller M., Diamond JE, Sinacore DR, Delitto A, Blair WP, 3rd, Drury DA, Rose SJ. Total contact casting in treatment of diabetic plantar ulcers. Controlled clinical trial Diabetes Care $1989 ; 12: 384-8$.

8. Nabuurs-franssen MH. Sleegers R, Huijberts MSP, Wijnen W, Sanders AP, Walenkamp G, Schaper NC. Total contact casting of the diabetic foot in daily practice: a prospective follow up study. Diabetes Care 2004:28(2):243-7.

9. Schaper NC. Diabetic foot ulcer classification system for research purpose: a progress report on criteria for including patients in research studies. Diabetes/metabolism Research and Reviews $2004: 20(51): 590.5$.

10. International Working Group on the Diabetic Foot. Apelqvist \&, Bakker $K$, Van Houtum WH, Nabuurs-franssen $\mathrm{MH}$, Schaper NC (ed). International Consensus on the Diabetic Foot. Maastricht, Schaper NC, 1999.

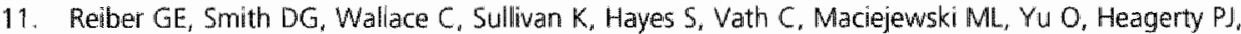
LeMaster J. Effect of therapeutic footwear on foot re-ulceration in patients with diabetes: a randomized controlled trial. Jama 2002,287:2552-8.

12. Fleischili JE, Anderson RB, Davis WH. Dorsiflexion metatarsal osteotomy for treatment of recalcitrant diabetic neuropathic ulcers. Foot Ankle int 1999;20:80-5.

13. Early JS, Hansen ST. Surgical reconstruction of the diabetic foot: a salvage approach for midfoot collapse. Foot Ankle in 1996;17:325-30.

14. Armstrong DG, Stacpoole-Shea $S$, Nguyen $H$, Harkless IB. Leingthening of the Achilles tendon in diabetic patients who are at high risk for ulceration of the foot. I Bone Joint Surg Am $1999,81: 535-8$. 


\section{Chapter $\mathbf{6}$}

Quality of life in diabetic patients: the impact of neuropathy and a foot ulcer

MH Nabuurs-Franssen, K Redekop, G Ragnarson Tennvall, J Apelquist, K Bakker, H Grill-Wikell, NC Schaper.

Submitted 


\section{Abstract}

\section{Objective}

We determined the impact of a diabetic foot ulcer on the Health-Related-Quality of Life (HRQOL), while taking the presence of diabetic complications into account.

\section{Research design and methods}

The cross-sectional part of the study (A): 61 consecutive patients with a foot ulcer (UP) were compared with 2 groups without foot problems: 63 treated by diabetologists (DP) and 1093 treated by general practitioners (GPP). The prospective part of the study (B): HRQOL was measured at baseline in 130 ulcer patients and after 2 years in the 48 with a healed ulcer. HRQOL was evaluated by the EuroQol-5D instrument (EQ-5D), 1.0 represents highest HRQOL.

\section{Results}

Part A: The HRQOL of UP was lower compared to DP and GPP: 0.56 vs 0.73 and 0.75 ( $p<0.05$ ). In all groups, HRQoL decreased as the number of diabetic complications increased. A decrease in HRQoL was associated in particular with older age and neuropathy, and with macrovascular complications, insulin treatment, obesity, and female gender. Ulcer status was not independently associated with HRQOL. Part B: No changes were observed in HRQoL after healing. However, HRQoL at baseline predicted outcome: 0.39 (died), 0.46 (amputation or nom-healing) and 0.65 (healed), $p<0.05$.

\section{Conclusion}

Patients with a diabetic foot ulcer report a marked reduction in HRQOL, determined with the EQ-5D. This reduction is mainly related to the underlying pathology (neuropathy) and other diabetic complications. 


\section{Introduction}

Several studies have shown that patients with diabetes mellitus have a poorer quality of life than individuals without this chronic disorder" However, diabetes mellitus is a heterogeneous disease and different treatment regimens as well as different long-term complications of the disease may affect the quality of life of these patients'. A diabetic foot ulcer, in particular its sequelae, is one of the most serious complications and poses a great burden on the patient and the health care system.

Diabetic foot ulcers need intensive wound care, tend to heal slowly and usually need off-loading of the wound, with subsequent impairment of mobility. Unfortunately, healing can be complicated by infection and gangrene, leading to long-term-in-hospital treatment and/or amputation. Moreover, diabetic foot ulcers and their consequences are associated with major health care consumption and high costs. The prevalence of these ulcers has been estimated at $3-8 \%{ }^{2}$, and these patients use $12-15 \%$ of the total budget ${ }^{3}$ spend on diabetes. Clearly, new therapies are needed to increase the number of healled ulcers and the time-tohealing and in analysing the effectiveness of these therapies, attention should be given both on cost-effectiveness and quality of life.

At present there are only a few cross-sectional studies and no prospective studies published on the impact of a diabetic foot ulcer on the health related quality of life ${ }^{4-8}$. In these cross-sectional studies only a small number of patients ${ }^{5,7,8}$, or a selected group of patients ${ }^{4}$ was included Ragnarson et al. ${ }^{6}$, also using the EQ-5D instrument, found that patients with a current ulcer reported a lower HRQOL than patients with a history of a foot ulcer that had primarily healed. As no control group was included, this lower HRQoL could probably be explained by the poorer health status of the patients with a current ulcer in contrast to the patients who healed (the 'healthy survivor effect'), instead of the effect of the ulcer itself. Furthermore, in all the above mentioned studies, the presence of other diabetic complications and co-morbidity was not taken into account.

The aim of the present studies was to determine the effect of an active foot ulcer per se on the Health-Related-Quality of Life (HRQOL) of a patient with diabetes mellitus. To correct for the presence of other diabetic complications, foot ulcer patients were compared with two control groups without (history of) foot ulcers in a large cross-sectional study. In addition, the impact of healing of the ulcer on the reported quality of life was analysed prospectively in a subset of patients. To exclude regional variation, part of this study was performed in both Sweden and the Netherlands. The EuroQol-5D instrument (EQ-5D), a generic instrument, was used to measure Health-Related-Quality of Life ${ }^{9}$. With this instrument utility 
indexes are generated, which can be the basis for calculating quality adjusted life years (QUALYS) in health-economic analyses, and which make comparison between different disease states possible.

\section{Research design and methods}

\section{Patients and study design}

A. The cross-sectional part was performed in the Netherlands from October 1998 until April 1999. Seventy consecutive Type 2 diabetic patients with an active foot ulcer (ulcer patients, UP), treated by a multidisciplinary foot care team in the outpatient foot clinic of 2 hospitals ( 1 general and 1 university), were asked to participate. Two control groups were defined in order to correct for the influences of other (diabetic) complications on HRQoL. One group consisted of 65 age and sex-matched Type 2 diabetic patients treated by diabetologists in the same outpatient clinics (diabetologist patients, DP). The second group consisted of Type 2 diabetic patients treated by general practitioners (CODE-2 study, General practitioner patients, GPP). Some results involving this second control group have been published separately ${ }^{12-12}$. Only Type 2 diabetic patients were selected to make the groups as homogeneous as possible and minimise the influence of confounding factors such as age and diabetes duration.

B. The prospective part was performed in Sweden and in the Netherlands. All diabetic patients (Type 1 and Type 2) with an active foot ulcer visiting the outpatient clinics from October 1998 until April 1999 were asked to participate. In order to determine the effect of healing of the ulcer on HRQOL, only patients in whom the ulcer had healed were asked to fill out the questionnaires again after two years.

Exclusion criteria were: life threatening disease, cognitive, psychological or psychiatric problems (defined as need for medication), renal dialysis, lower extremity ulcer above the ankle and major lower extremity amputation. Reasons not to participate were: taking part in another clinical trial, no time or not interested. Patient characteristics were not different between participating and non-participating patients. All participants gave written informed consent and both studies were approved by the hospitals' medical ethics committees.

\section{Methods}

Patients were asked to fill out a questionnaire about demographics, medical history, work and quality of life. Additional information about patient characteristics and laboratory tests was obtained from patient charts and the electronic database system of the hospitals. Diabetic complications were 
categorized into macrovascular and/or microvascular complications. Mácrovascular complications consisted of cardiovascular complications (myocardial infarction, angina pectoris, chronic heart failure, Coronary Artery Bypass Graft and Percutaneous Transluminal Coronary Angioplasty), cerebrovascular complications (Cerebrovascular Accident and Transient Ischemic Attack) and peripheral vascular disease (absence of pedal pulses and presence of claudicatio intermittens or $\mathrm{AB}<<0.9$ ). Microvascular complications consisted of neuropathy (peripheral polyneuropathy and autonomic neuropathy), retinopathy and nephropathy (urinair albumin excretion (UAER) $>200 \mathrm{~g} / \mathrm{min}$ or $>300 \mathrm{mg} / 24$ hours and microalbuminuria: (UAER) $20-200 \mathrm{~g} / \mathrm{min}$ or $30-300 \mathrm{~g} / 24$ hours).

The EuroQol-5D instrument was used to determine Health-Related-Quality of Life? it is easy to use and can be completed by the patients themselves in only a few minutes. The EQ-5D is a validated quality of life scale, which identifies 243 (i.e., $3^{5}$ ) possible health states based on five questions concerning mobility (eg walking), self care (e.g. washing or dressing myself), usual activities (e.g. work, housework, family or leisure activities), pain/discomfort and anxiety/depression, with each item having three possible levels (no, moderate, or severe problems). A single index value have been placed on each state through a sample of 3235 persons, using time trade-off technique to determine valuations. Perfect health and death have utility weights of 1 and 0 , and states worse than death $(<0)$ are possible, resulting in a scale ranking from -0.594 to 1.0 . In addition, patients were asked to record their perception of their overall health using a visual analogue scale (VAS), with a scale ranking from $0-100^{9}$.

\section{Statistics}

Data are expressed as mean and SD. Comparisons between two and three groups were performed using Fisher Exact test, Mann-Whitney $U$ test, Wilcoxon rank-sum test, and Kruskal-Wallis test. Multiwariate analyses were performed using stepwise multiple linear regression or logistic regression where appropriate. Inclusion into final models was based on a $p$-value of 0.10 . Analyses were done using the SPSS statistical package version 10.0 (SPSS, Chicago, 111., USA).

\section{Results}

\section{A. Cross-sectional part}

\section{Patients}

Patients characteristics are described in table 6.1. In the ulcer group, patients were older and had a longer duration of diabetes (both $p<0.05$ ). There were no significant differences in gender between the three groups. Both ulcer and 
diabetologist patients used insulin more frequently than GP patients $(p<0.01)$. All ulcer patients had microwascular complications and some also had macrovascular complications. Therefore, data regarding the following subgroups are presented: no complications, microvascular complications and both macro- and microvascular complications. As expected, GP patients had the lowest prevalence of complications and ulcer patients the highest prevalence, see table 6.1. Diabetic foot ulcers were classified as neuropathic (38\%), neuro-ischemic $(60 \%)$ and ischemic (2\%), based on clinical investigations and, if necessary, further (vascular) evaluation. As stated earlier, all patients were treated in the outpatient department. At the time of the study $43 \%$ of the ulcers were infected; in $63 \%$ the infection was superficial and in $37 \%$ deep (osteomyelitis). Neuropathy was present in almost all (98\%) ukcer patients, in $53 \%$ of the diabetologist patients and in $15 \%$ of the GP patients $(p<0.05)$.

Table 6.1 Clinical characteristics and foot ulcer status at time of study-entry of the cross-sectionall part of the study.

\begin{tabular}{|c|c|c|c|}
\hline & $\begin{array}{l}\text { Ulcer patients } \\
\qquad(n=61)\end{array}$ & $\begin{array}{l}\text { Diabeto ogist patients } \\
\qquad(n=63)\end{array}$ & $\begin{array}{c}\text { GP patients } \\
(n=1093)\end{array}$ \\
\hline Age (yrs) & $69^{4} \pm 12$ & $65 \pm 10$ & $65 \pm 12$ \\
\hline Gender (\%female) & 46 & 49 & 50 \\
\hline $\mathrm{BM} \|\left(\mathrm{kg} / \mathrm{m}^{2}\right)$ & $27.3 \pm 4.7$ & $29.1 \pm 6.4$ & $28.1 \pm 5.0$ \\
\hline Duration diabetes (yrs) & $16^{*} \pm 10$ & $11 \# \pm 8$ & $6 \pm 6$ \\
\hline HbAlc $(\%)$ & $8.0 \pm 1.8$ & $8.3^{H} \pm 1.3^{3}$ & $7.5 \pm 1.6$ \\
\hline \multicolumn{4}{|l|}{ Treatment type (\%) } \\
\hline Diet + Orall therapy & 20 & 21 & 855 \\
\hline Insulin (स oral therapy) & 80 & 79 & 155 \\
\hline \multicolumn{4}{|l|}{ Complications $(\%)$} \\
\hline No complications & 0 & 6 & $50^{5}$ \\
\hline Microvascular present & $15^{*}$ & 411 & 21 \\
\hline Micro + macrovasc & $85^{*}$ & 531 & 30 \\
\hline
\end{tabular}

Data shown as mean and 50 . Yrs = years, Microvascular complications = amputation, neuropathy, retinopathy, nefropathy. Macrowascular complications = myocardial infarction, angina, heart failure. Cardiac sufgery (CABG, PTCA), stroke (CVA), transient ischemic attack (TIA), peripheral vascular disease (PVD). "0<0.05 Ulcer vs Diabetologist and GP patients, " $p<0.01$ Diabetologist ws GP patients, 400.05 Ulcer vs GP patients, $5 \mathrm{p}<0.01 \mathrm{GP}$ ws Ulcer and Diabetologist patients, $1 \mathrm{p}<0.05$ Diabetologist vs Ulcer patients.

\section{Health-Related-Quality of Life}

HRQoL values are pictured in table 6.2. HRQoL of ulcer patients was markedly lower compared to diabetologist and GP patients $(p<0.05)$, after correcting for age. In all three groups, patients aged 70 years and older reported a lower HealthRelated-Quality of Life than younger patients $(p=0.05)$. In the ulcer group, patients older than 70 years of age had a lower HRQOL compared to both control groups 
$(p<0.05)$. HRQoL of ulcer patients younger than 70 years of age, was lower in comparison to the GP patients $(p<0.05)$. Moreover, in the ulcer group, male patients reported a lower HRQOL compared to both control groups and female patients reported a lower HRQOL compared to GP patients (both $p<0.05$ ). In all three groups, with an increase in number of diabetic complications, HRQOL decreased. Multivariate linear regression analysis revealed that (r-regression coefficient) gender (male sex, $r=0.079)$, age $(r=-0.002 /$ year), insulin treatment $(r=-0.072)$, micro- and macrovascular complications $(r=-0.074)$ and obesity $(-0.06)$ were independently associated with a poorer Health-Related-Quality of Life. When, in this analysis, the type of microvascular complication was included (neuropathy,

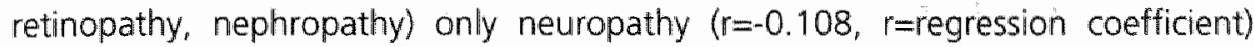
was found to be associated with a poorer quality of life. When group status was also included in the model (ulcer patients, diabetologist patients and GP patients), ulcer status was not an independent predictor of quality of life. The perception of the overall health status, scored as the VAS score, of ulcer patients was also lower compared to both control groups (data not shown, $p<0.05$ )

Table 6.2 Health-Related-Quality of life ( $\mathrm{EQ}-5 \mathrm{D}$ utility score) of Ulcer patients, Diabetologisit patients and GP patients of the cross-sectional part of the study.

\begin{tabular}{lcccc}
\hline EQ-5D & Ulcer $(n=61)$ & Diabetologist $(n=63)$ & GP $(n=1093)$ \\
\hline Overall & & $0.56^{*} \pm 0.33$ & $0.73 \pm 0.25$ & $0.75 \pm 0.27$ \\
Age & $<70$ yrs & $0.69 \pm \pm 0.23$ & $0.79 \pm 0.22$ & $0.77 \pm 0.25$ \\
& $>70$ yrs & $0.44^{*} \pm 0.36$ & $0.64 \pm 0.30$ & $0.71 \pm 0.27$ \\
Gender females & $0.491^{*} \pm 0.37$ & $0.66 \pm 0.24$ & $0.71 \pm 0.27$ \\
& males & $0.62^{*} \pm 0.28$ & $0.80 \pm 0.25$ & $0.79 \pm 0.24$ \\
No compl. & - & $0.92 \pm 0.14$ & $0.81 \pm 0.23$ \\
Microw. present & $0.56^{*} \pm 0.33$ & $0.70 \pm 0.27$ & $0.69 \pm 0.29$ \\
Micro + macro & $0.51^{*} \pm 0.33$ & $0.67 \pm 0.28$ & $0.63 \pm 0.29$ \\
\hline
\end{tabular}

Data shown as mean and $\mathrm{SD}$. Y $\mathrm{rs}=$ years, Compl $=$ complication. "p<0.05: Ulcer ws Diabetologist and GP patients, $p<0.05$ Ulcer vs GP patients.

The Euroqol-5D instrument consists of five dimensions. In comparison to diabetologist and GP patients, ulcer patients reported more problems with mobility ( $54 \%$ and $46 \%$ vs $90 \%)$, with self care $(11 \%$ and $11 \%$ ws $30 \%)$, with performing usual activities ( $35 \%$ and $37 \%$ vs $59 \%$ ) and experienced more feelings of anxiety and depression ( $17 \%$ and $29 \%$ vs $44 \%$ ), all $p<0.01$. No differences were observed in pain/discomfort. Multivariate analyses revealed that neuropathy was associated with an increased risk of problems with mobility and anxiety/depression and to a lesser extent of the other three dimensions. Also in these analyses, ulcer group status was not an independent predictor of problems in any of the five dimensions. 


\section{B. Prospective part}

\section{Baseline cohort}

In 1999 a total of 130 patients with a diabetic fcot ulcer filled out the EuroQol-5D questionnaire, see table 6.3. In general, the group consisted of elderly (mean age 69 years) diabetic patients with multiple microvascular en macrovascular complications. After 2 years, 48 patients were alive with a healed foot ulcer and without a major amputation. Of the remaining 82 patients, $43 \%$ had persistent ulcers, new ulcers or underwent a major amputation and $57 \%$ died during followup. No differences were observed in gender distribution, diabetes duration or diabetes treatment between the two groups, except that the patients who healed during the 2 years follow-up were younger in comparison to the other patients, see table 6.3. Furthermore, the presence of diabetic complications was comparable (data not shown). After correcting for age, the HRQoL and the VAS-score at baseline was higher in patients who healed during follow-up, in comparison to the other patients $(0.64$ vs 0.43 and 64 vs 55 respectively). Patients who died during follow-up had the lowest utility - and VAS score 10.39 and 50, respectively). Patients with a HRQOL utility index $<0.5$ had an odds ratio for primary healing of 0.39 and for dying of $1.7(p<0.01)$.

Table 6.3 Clinical characteristics and HRQoL of the baseline cohort in the prospective part of the study $(n=130)$

\begin{tabular}{|c|c|c|}
\hline Clinical characteristics & $\begin{array}{c}\text { Healed } \\
(n=48,37 \%)\end{array}$ & $\begin{array}{l}\text { Non-healing/Amputation, Deceased } \\
\qquad(\mathrm{n}=82,63 \%)\end{array}$ \\
\hline Age (yrs) & $65^{*} \pm 13$ & $72 \pm 12$ \\
\hline Gender (\%female) & 36 & 41 \\
\hline Duration diabetes (yrs) & $20 \pm 13$ & $19 \pm 11$ \\
\hline \multicolumn{3}{|l|}{ Treattment type $(\%)$} \\
\hline Diet + Oral therapy & 14 & 26 \\
\hline Insulin (t oral thi) & 86 & 74 \\
\hline \multicolumn{3}{|l|}{ HRQQL } \\
\hline EQ-5D, 1999 & $0.64 t \pm 0.28$ & $0.43 \pm 0.35$ \\
\hline EQ-5D, 2001 & $0.65^{*} \pm 0.25$ & \\
\hline VAS, 1999 & $64^{*} \pm 20$ & $55 \pm 20$ \\
\hline VAS, 2001 & $58^{*} \pm 20$ & \\
\hline
\end{tabular}

Data shown as mean and SD. Yrs $=$ years, th $=$ therapy. "p<0.05. Healed ws non healing/amputation and dead patients, $: p<0.01$ Healed ws non-healing/amputation and dead patients. 
In the 48 patients with a healed uicer at follow-up, the ulcers were classified as neuropathic $(54 \%)$, neuro-ischemic $(37 \%)$ and ischemic $(9 \%)$; peripheral polyneuropathy was present in $91 \%$ of the patients: No differences were observed in the reported age-corrected utility index between baseline and after 2 years: 0.64 vs $0.65(p=0.456)$. Also no changes could be observed in any EQ-5D dimension and the VAS score. To exclude negative effects of new complications, the data of the 27 patients $(56 \%)$ who did not develop any new complications during the follow-up period were analysed separately. Also in these patients the utility index, the VAS score and the five dimensions of the EQ-5D did not change.

\section{Conclusions}

Type 2 diabetic patients with an active foot ulcer reported a remarkably low Health-Related-Quality of Life, as expressed by the EQ-5D utility index. In comparison to both control groups, patients with a foot uicer reported more problems with walking, washing/dressing, usual activities (e.g., work, study, family or leisure activitietes) and experienced more feelings of anxiety/depression. To our knowledge only a few studies, with limited numbers of patients ${ }^{7,8}$, have reported on the quality of life in diabetic patients with such an ulcer. Brod et al. ${ }^{7}$ observed in 14 patients a negative impact on all domains of Qol, which was mainly caused by limitations in mobility. Carrington et al..$^{8}$ found in 13 diabetic patients with an active foot ulcer or a lower limb amputation a worse psychological status (poorer psychosocial adjustments to illness, depression), in comparisson with diabetic controls. Finally, a lower Qol was reported in fourteen patients with a former or a present foot ulcer, but the effect of an active ulcer per se was not determined ${ }^{4}$.

The EuroQol-5D instrument was used to measure Health-Related-Quality of Life (HRQOL). The reproducibility of the instrument is rather good ${ }^{13}$ and the utility score of the GP patients without complications in the present study $(0.81)$ corresponded very well with the utility score of patients without complications in the UKPDSstudy $(0.80)^{14}$. The utility index in our ulcer patients (0.56) was lower than the index $(0.72)$ reported by patients with moderate severe asthma ${ }^{15}$ and comparable to the index $(0.58)$ reported by patients with lung cancer ${ }^{16}$. Patients with a major amputation or patients admitted to the hospital were not included in the current studies, as this would clearly affect quality of life. As also shown in earlier studies, we found a negative association between age and quality of life ${ }^{17.18}$. Furthermore, men reported a better health status than women, which is also observed in both the general population and in subjects with diabetes ${ }^{17.19}$. Indeed, the elderly female patient with a diabetic foot ulcer reported in this study the lowest HRQOL (index 0.44). 
In patients with a foot ulcer a low HRQOL was associated with a poor outcome. The highest utility index was reported in patients who subsequently healed, an intermediate index in patients who did not heal or were amputated and the lowest index was observed in patients who died during follow-up. Analysing both patients without and with a foot ulcer, we found that an increase in the number of diabetic complications was associated with a progressive decline in quality of life. Patients on kidney dialysis or blind patients were not included and also patients admitted to the hospital were excluded. With these limitations, the patients included in the current study are representative for the majority of patients treated by the GP or a diabetologist in the Netherlands. Unexepectedly, neuropathy was found to be one of the most powerful predictors of a loss of HRQOL in the three cohorts of our study. Diabetic neuropathy is frequently seen as a relative benign and symptomless complication of diabetes, but our data showed that neuropathy negatively affects all subscales of the EuroQol-5D instrument, including pain and anxiety / depression. This association of neuropathy with a lower quality of life has also been reported in earlier studies ${ }^{18,20,21}$. In particular, Ahroni et al. ${ }^{21}$, who diagnosed PNP by the use of monofilaments, found in patients with PNP a lower score on all scales of the SF-36, except on mental health. The present study is the first population based study showing that neuropathy is one of the most important factors determining quality of life.

Using the EuroQol-5D instrument in the multivariate analyses we did not observe an independent effect of a diabetic ulcer on HRQOL. The decrease in quality of life was mainly associated with neuropathy, macrovascular disease, insulin treatment, and obesity. Almost all of our patients with an ulcer had neuropathy, which could have masked an effect of the ulcer per se. Furthermore, the EuroQol-5D instrument is not disease specific and could be too insensitive to measure relatively small changes in quality of life ${ }^{22}$. On the other hand, disease specific scales are unable to make comparisons across different disease states and are unable to assess quality of life effects for individuals suffering from more than one condition. As described earlier ${ }^{3}$ and shown in the present study (see table 6.1), diabetic foot ulcers are closely associated with multiple microvascular and macrovascular complications.

In conclusion, diabetic neuropathy was a major determinant of a poor quality of life in Dutch Type 2 diabetic patients with and without foot ulcers. Diabetic patients with an active foot ulcer reported a markedly lower HRQOL in comparison to patients without foot ulcers and this poor quality of life was closely associated with the presence of other diabetic complications. 


\section{References}

1. Rubin RR, Peyrot M. Quality of life and diabetes. Diaberes Metab Res Rew 1999, 15:205 -18.

2. Apelqvist J, Larsson J. What is the most effective way to reduce incidence of amputation in the diabetic foot? Diabetes Metab Res Rev 2000;16:51:575-83.

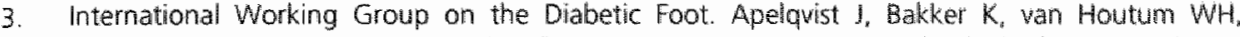
Nabuurs-Franssen MH, Schaper NC (ed). International Consensus on the Diabetic Foot. Schaper NC. Maastricht, 1999.

4. Meijer JW, Trip /, Jaegers SM, Links TP, Smits AJ, Groothoff $W^{2}$, et al. Quality of life in patients with diabetic foot ulcers. Disabil Rehabil $2001 ; 23: 336-40$.

5. Hux M. Milcovinch $N$, Torrance $G$, Gibbald $G$. Health-related quality of life related to chronic foot ulcers in diabetics. Qual Life Res $1998,8: 655$.

6. Ragnarson Tennvall $G$. Apelqvist J. Health-related quality of life in patients with diabetes mellitus and foot ulcers. NDiabetes Complications 2000; 14:235-41.

7. Brod M. Quality of Iffe issues in patients with diabetes and lower extremity ulcers: patients and Care givers. Qual the Res 1998;7:365-72.

8. Carrington AL, Mawdsley SK, Morley M, Kincey J, Boulton AJ. Psychological status of diabetic people with or without lower limb disalbility. Diabetes Res Clin Pract 1996;32:19-25.

9. Kind $P$, Dolan P, Gudex C. Willams A. Variations in population health status: resulis from a United Kingdom national questionnaire survey. BMH1998;316:73641.

10. Jonsson B. Revealing the cost of type 2 diabetes in Europe. Diabetologia 2002:45:55-12.

11. Redekop WK, Koopmanschap MA, Stolk RP, Rutten GE, Wolffenbuttel BH, Niessen LW. Health. related quality of iffe and treatment satislaction in Dutch patients with type 2 diabetes. Diabetes Care $2002: 25: 458-63$.

12. Redekop W. Koopmanschap $M$. Rutten G, Wolffenbuttel $B$, Stolk $\mathbb{R}$, Niessen L. Resource consumption and costs in Dutch patients with Type 2 Diabetes mellitus. Results from 29 general practices. Diabetes Med Mar 2002;19:246-53.

13. Van Agt HM, Essink-Bot ML, Krabbe PF, Bonsel GJ. Test-retest reliability of health state waluations collected with the EuroQol questionnaire. Soc Sci Med 1994;39:1537-44.

14. Quality of life in type 2 diabetic patients is affected by complications but not by intensive policies to improve blood glucase or blood pressure control (UKPDS 37). U.K. Prospective Diabetes Study Group. Diabetes Care 1999; 22:1125-36.

15. Greiner W, Graf won der Schulenberg JM, Bergmann KC. Quality of life of adult asthma patients. Pneumologie 1999;53:283-8.

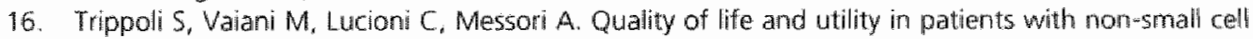
lung cancer. Quality-of-life Study Group of the Master 2 Project in Pharmacoeconomics. Pharmacoeconomics 2001:19:855-63.

17. Glasgow RE, Ruggiero L, Eakin EG, Dryfoos J, Chobanian L. Quality of life and associated characteristics in a large national sample of adults with diabetes. Diaberes Care 1997;20:562-7.

18. Klein BE, Klein R. MosS SE. Self-rated health and diabetes of long duration. The Wisconsin Epidemiologic Study of Diabetic Retinopathy. Diabetes Care 1998:21:236-40.

19. Kandrack MA, Grant KR, Segall A. Gender differences in health related behaviour: some unanswered questions. SoC SC Med 1991;32:579-90.

20. Jacobson AM, de Groot M. Samson JA. The evaluation of two measures of quality of life in patients with type I and type II diabetes. Diabetes Care 1994:17:267-74.

21. Ahroni JH, Boyko El, Davignom DR, Pecoraro RE. The health and functional status of weterans with diabetes. Diabetes Care 1994;17:318-21.

22. Eiser C. Tooke JE. Quality of life in type II diabetes: evailuation and applications Pharmacoeconomics 1995;8:17-22. 
Chapter

Health-Related-Quality of Life of diabetic foot ulcer patients and their caregivers

MH Nabuurs-Franssen, MSP Huijberts, AC Nieuwenhuijzen Kruseman, J Willems, NC Schaper

Diabetologia 2005, in press 


\section{Abstract}

\section{Aims}

The effect of a foot ulcer on Health-Related-Quality of Life (HRQOL) of patients with diabetes mellitus and their caregivers is unclear, and was, therefore, prospectively evaluated in this multicenter study.

\section{Methods}

HRQOL (SF-36 questionnaire) of 294 patients (ulcer duration $\geq 4$ weeks) and 153 caregivers was analysed at baseline (TO), once the ulcer was healed or after 20 weeks (T1), and 3 months later (T2). Patients with severe ischemia were excluded.

\section{Results}

The mean age of the patients were $60 \mathrm{yrs}, 72 \%$ was male and the time since diagnosis of diabetes was 17 years. Patients reported a low HRQOL on all SF-36 subscales. At T1, HRQOL scores in physical and social functioning were higher in patients with a healed vs a non-healed ulcer $(p<0.05)$. At $T 2$, these differences were larger, with higher scores for physical and social functioning, role physical and the physical summary score (all $p<0.05$ ). Within group analysis revealed that HRQoL improved in different subscales in HU and worsened in PU patients from TO to $\mathrm{T} 2$ (all $p<0.05$ ). The most marked difference between both groups was observed in items related to mobility. The caregivers of the patients with a persisting ulcer had markedly more emotional difficulties at $T 2$.

\section{Conclusion}

Diabetic patients with a healed foot ulcer had a higher HRQoL than patients with a persisting ulcer. Healing of a foot ulcer resulted in a marked improvement of several SF-36 subscales three months after healing (TO $\rightarrow$ T2). HRQOL progressively declined when the ulcer did not heal. A diabetic foot ulcer appeared to be a large emotional burden on the patients' surrounding as well. 


\section{Introduction}

Diabetic foot ulcers are one of the major complications of diabetes mellitus and have a large impact on the health status of the affected patients'. These ulcers heal slowly usually within 2 to 5 months, require intensive treatment ${ }^{2}$, and are associated with major health care consumption and high costs ${ }^{3}$. In the last decades the understanding of the pathogenesis, treatment, and prevention has improved". in contrast, our knowledge of the impact of a foot ulcer on the quality of life of a diabetic patient and his immediate environment is limited. A few cross-sectional studies, with a small sample size ${ }^{5-7}$ or a selected group ${ }^{8}$ of patients, reported a lower quality of life ${ }^{5-9}$. However, as these patients usually have ather diabetic complications influencing Health-Related-Quality of Life (HRQOL) ${ }^{1,10,11}$, the effect of an ulcer per se on HRQOL is still unclear. In addition, a diabetic foot ulcer probably is a major burden for the (non-paid) individuals from the patients" immediate surrounding, as these caregivers frequently assist in wound care, and support the patient in coping with the physical disabilities and emotional distress ${ }^{6}$. Therefore, the aim of the present study was to determine the impact of healing of a foot ulcer on HRQOL of diabetic patients and their caregivers.

\section{Subject, materials and methods}

\section{Methods}

This study was part of a prospective, randomised, double-blind, placebo-controlled trial testing the efficacy and safety of recombinant human platelet-derived growth factor-BB (becaplermin). Eighty-one centres in the United States, the UK and Europe participated. Both patients and caregivers were asked to fill our the SF-36 questionnaire at 3 time points; study entry (TO), once the ulcer was healed or after 20 weeks (whichever occurred first) (T1), and subsequently 12 weeks later (T2). The difference in HRQOL at T2 between the subjects with a healed ulcer and the subjects with a persisting ulcer was defined as the primary endpoint.

The $5 F-36^{12,13}$ is a short, 36-item questionnaire which measures eight multi-item general health scales, ranging from 0 (worst possible health status) to 100 (best possible health status). The scores on the eight subscales can be aggregated in two distinct summary scores: Physical Component Summary, PCS (Physical Functioning, Role Physical, Bodily Pain, General Health) and the Mental Component Summary, MCS (Vitality, Social Functioning, Role Emotional, Mental Health). In the Physical Functioning scale, physical impairments are assessed; in the Role Physical the burden of these impairment in daily life is addressed. In the Role Emotional scale, the subject is questioned about impairments in daily life due to emotional problems. The investigators were instructed not to help the patients in interpreting 
or answering any question. Data were also obtained on patient demographics, relevant medical details and foot ulcer severity according to clinical criteria. All participants gave written informed consent and the hospital's medical-ethics committee approved the study, which was carried out in accordance with the Declaration of Helsinki as revised in 2000.

\section{Patients / Caregivers}

Diabetic patients with a chronic (ulcer duration at least 4 weeks), full thickness lower extremity ulcer, ranging from 0.5 to $30 \mathrm{~cm}^{2}$ post-debridement, were included. Patients were $\geq 18$ years of age and had Type 1 or Type 2 diabetes. Patients with more than 3 foot ulcers, with ulcers not related to diabetes, or with poor metabolic control $(\mathrm{HbA} 1 \mathrm{C}>11.0 \%$ ) were excluded. In addition, patients with severe peripheral ischemia ( $\mathrm{tcpO} \mathrm{O}_{2}$ dorsum foot $<30 \mathrm{mmHg}$, any malignancy, connective tissue diseases, chronic alcohol or drug abuse, or signs of infection and/or osteomyelitis at study entry were excluded. The caregiver was defined as a significant, non-paid person who had regular contact with the subject and was responsible for and/or engages in caregiving activities with the subject (e.g., health care, housekeeping, shopping, transportation). No information about clinical characteristics of the caregiver was obtained.

The study population is shown in the flow chart (figure 7.1). HRQOL data were obtained in 486 patients at baseline, 32 were excluded from the analyses since they developed a major disease during the study or were hospitalised during completion of the SF-36 questionnaire. At T1 the ulcer was still present in 230 patients and was healed in 224 patients. Between $T 1$ and $T 2$ the ulcer healed or recurred in 81 patients, and 79 were lost to follow-up. For all analyses, we used the HRQOL data of the 132 patients with a persisting ulcer (PU) during the course of the study $(T O \rightarrow T 2$ ) and of the 162 patients with a healed ulcer ( $\mathrm{HU}$ ) at both $\mathrm{T1}$ and T2 (in total 294 subjects). Since numbers were too small, we excluded patients from the analyses in whom the ulcer healed or recurred between T1 and T2. No differences in clinical characteristics were observed between the included patients and the excluded patients. HRQoL data of 153 caregivers was obtained. This number was smaller than the number of patients $(n=294)$, as many did not have a caregiver or the caregiver was not interested in participating.

\section{Statistics}

The data were entered using a double-entry validation technique and are presented as means (95\% confidence intervais). As some of the data were not normally distributed, non-parametric tests were used. In the primary analyses we compared the HRQOL at each time point between the two groups (PU vs HU Kruskal-Wallis test and the Mann-Whitney $U$ test). Changes over time within each 
group were analysed using the Wilcoxon rank-sum test, correlations were calculated using the Spearman-test. Statistical analyses were performed with the SPSS statistical package (SPSS Inc. Chicago, III., USA). Statistical significance was considered as $\mathrm{p} \leq \mathrm{s} 0.05$.

Figure 7.1 Flow chart study population

Total

$n=486$

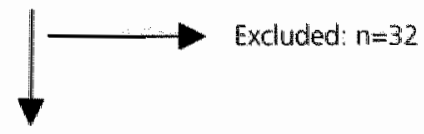

TO

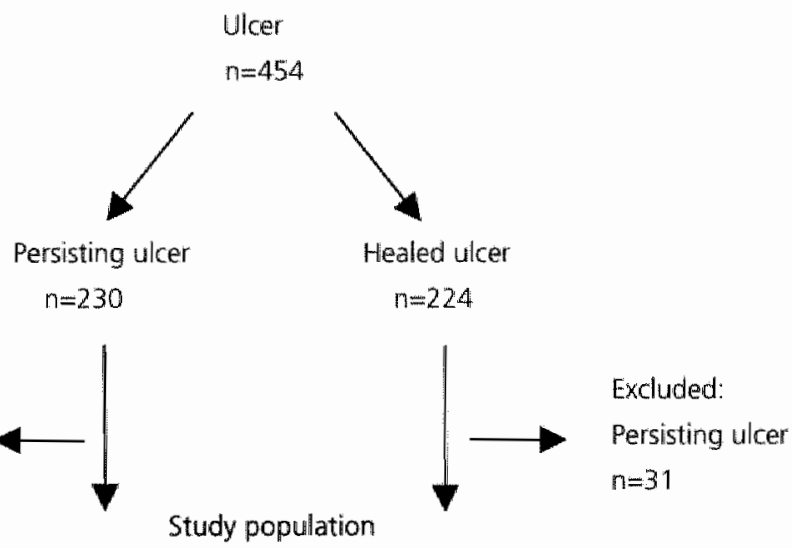

Excluded:

Healed ulcer

$n=50$

Study population

12

$$
\begin{aligned}
& \text { Persisting ulcer Healed ulcer } \\
& n=132^{\circ}
\end{aligned}
$$$$
n=162^{i}
$$

TO = study entry, $T 1=$ time-point at which ulcer was healed or persisting ulcer at 20 weeks, $T 2=12$ weeks after T1. "48 patients lost to follow-up." 31 patients lost to follow-up.

\section{Results}

\section{Patients}

Seventy-one percent of the subjects with a healed ulcer (HU) anf $76 \%$ of the subjects with a persisting ulcer (PU) were males (ns). No differences were observed between the patients with a healed ulcer ( $\mathrm{HU})$ and patients with a persisting ulcer (PU) with respect to age: $61(95 \%$ CI 59-62) vs 60 (59-62) years, duration of 
diabetes: $16(15-18)$ vs $17(15-19)$ years and HbAlc (mean To and T1): 8.7 (8.5$9.0)$ v5 $8.8(8.6-9.1) \%$. The mean $\mathrm{tcpO}_{2}$ was $54 \mathrm{mmHg}$ in both groups. HU patients had a lower BMI than PU patients, 28.2 (27.5-28.9) vs 29.6 (28.8-30.3) $\mathrm{kg} / \mathrm{m}^{2}$, and had at baseline smaller ulcers, $3.7 \mathrm{vs} 5.8 \mathrm{vs} \mathrm{cm}^{2}$, with a shorter duration, 32 vs 73 weeks (all $p<0.01$ ).

At baseline (TO), no differences were observed in the HRQOL data between the HU and PU patients (between group analyses, table 7.1).

Table 7.1 SF-36 score at three measure points

\begin{tabular}{|c|c|c|c|c|c|c|}
\hline $5 F-36$ & TO & & $\mathrm{T1}$ & & 12 & \\
\hline Patient & PU & $\mathrm{HU}$ & PU & $H U$ & PU & HU \\
\hline puf & 39.2 & 44.7 & 38.3 & $47.5^{\mathrm{e}}$ & $35,0^{\circ}$ & 51.1 \\
\hline st & 63.8 & 60.5 & 63.5 & $65.5^{\text {\#,e }}$ & $58.0^{\circ}$ & $71.0 \mathrm{c}$ \\
\hline Rp & 38.0 & 26.7 & 35.7 & 32.3 & $29.6^{d}$ & $43.4^{c e}$ \\
\hline Ree & 59.2 & 47.9 & 55.6 & 48.1 & $50.0^{d}$ & $55.5^{\text {व }}$ \\
\hline Mh & 70.1 & 65.9 & 67.9 & 66.4 & 67.9 & 68.7 \\
\hline$V t$ & 53.11 & 51.8 & 51.1 & 52.1 & $49.5^{d}$ & 53.3 \\
\hline $\mathrm{Bp}$ & 60.9 & 58.4 & 61.0 & 63.3 & 58.9 & $64.4^{d}$ \\
\hline Gh & 52.0 & 53.1 & 51.1 & 53.1 & 48.8 & 52.8 \\
\hline pcsi & 34.6 & 350 & 34.7 & 38.8 & $33.3^{b}$ & $38.3^{\circ}$ \\
\hline mos & 49.5 & 46.5 & 48.7 & 48.8 & 47.9 & 48.5 \\
\hline Caregiver & $\mathrm{CPU}$ & $\mathrm{CHU}$ & CPU & $\mathrm{CHU}$ & CPU & $\mathrm{CHU}$ \\
\hline $\mathrm{pf}$ & 77.0 & 65.1 & 76.4 & 60.0 & 67.0 & 65.9 \\
\hline $5 f$ & 78.7 & 74.1 & 74.7 & 70.7 & 73.0 & 73.5 \\
\hline $\mathbb{R p}$ & 68.6 & 57.9 & 62.1 & 56.9 & 56.2 & 64.8 \\
\hline $\operatorname{Re}$ & 72.4 & $\therefore 63.6$ & 70.5 & 64.9 & $54.3^{6}$ & $77.0^{60}$ \\
\hline Mh & 70.7 & 67.4 & 71.2 & 69.2 & 70.6 & 70.9 \\
\hline Wt: & 62.4 & 54.6 & 62.7 & 57.0 & 58.9 & 57.8 \\
\hline $\mathrm{Bp}$ & 77.4 & 65.2 & 74.3 & 650 & 690 & 65.1 \\
\hline Gh & 66.8 & 64.7 & 63.2 & 61.4 & 61.7 & 62.6 \\
\hline pess & 48.5 & 44.6 & 46.2 & 42.8 & 44.2 & 4.4 .0 \\
\hline mes & 48.8 & 47.8 & 490 & 48.2 & 46.6 & $50.9^{\mathrm{d}}$ \\
\hline
\end{tabular}

Data shown as mean values: $p \leq 0.05$ (T1 ws T0), ${ }^{\circ} p \leq 0.05$ (T2 vs. TI), $p \leq 0.05$ (T2 ws T1 and To), "p 50.05 (n2 ws TO). p $\leq 0.05$ (HU ws PU). $5 F-36$ = short form 36-item Health-Related-Quality of Life questionnaire, $\mathrm{PU}=$ persisting ulcer patients, $\mathrm{HU}=$ healed ulcer patients, $\mathrm{CPU}=$ caregiver of persisting ulcer patients, $\mathrm{CH}$ = caregiver of healed ulcer patients. pf = physical functioning, $\mathrm{sf}=$ social functioning, $r p=$ role physical, $r e=$ role emotional, $m h=$ mental health, $v t=$ vitality, $b p=$ bodily pain, gh = general health, pes = physical component score, mes = mental component score.

$T 0=$ study entry, $T 1=$ timepoint at which ulcer was healed or persisted ulcer at 20 weeks, $T 2=12$ weeks after $T 1$.

HU patients had, compared to PU patients, higher HRQoL scores at T1 for both physical and social functioning $(p<0.05)$. At $T 2$, these differences were more 
prominent, with higher scores for physical and social functioning, role physical and the physical summary score (all $p<0.05$ ). The changes over time within each group are also depicted in table 7.1 , and in figure 7.2 (within group analyses). In general, HRQoL improved in the different subscales in the HU and worsened in the PU patients. In the HU patients only social functioning was improved at T1 (T1 vs TO, $p<0.05)$. At T2, in these HU patients, social and physical functioning, role physical and the physical summary score were improved ( $T 2$ ws $T 1$ and $T 0$, both $p \leq 0.05$ ). In addition, the role emotional improved and these HU patients experienced less problems with bodily pain relative to baseline ( $T 2$ vs $T 0, p<0.05$ ). In the PU patients no differences were observed at $T 1$ compared to baseline, but at $T 2$ social functioning ( $T 2$ vs T1 and T0, both $\mathrm{p} \leq 0.05$ ), role physical and role emotional ( $T 2$ vs TO, $p \leq 0.05)$ were worsened. The PU patients reported more problems with vitality at $T 2$ compared to baseline $(p<0.05)$. Analysing the 36 questions separately, the most marked difference between both groups was observed in questions related to mobility: HU patients experienced fewer problems with walking, and with performing moderate or vigorous activities compared to PU patients.

Figure 7.2 Change in SF-36 scores between patients and caregivers with a healed and persisting ulcer at baseline and final wisit.

Patient
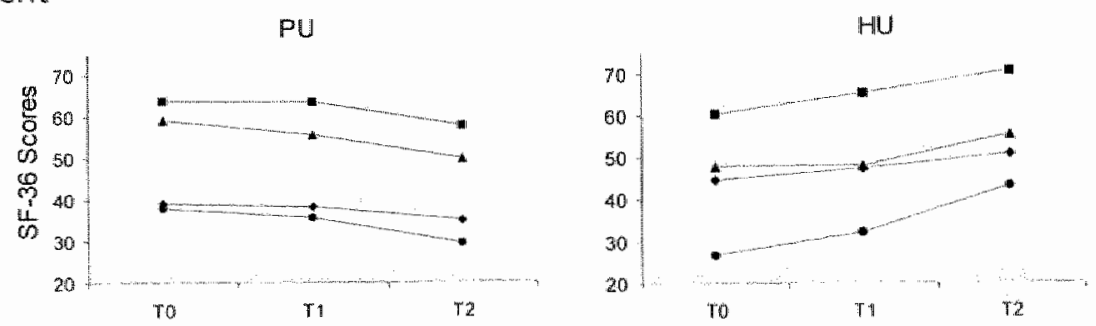

Caregiver
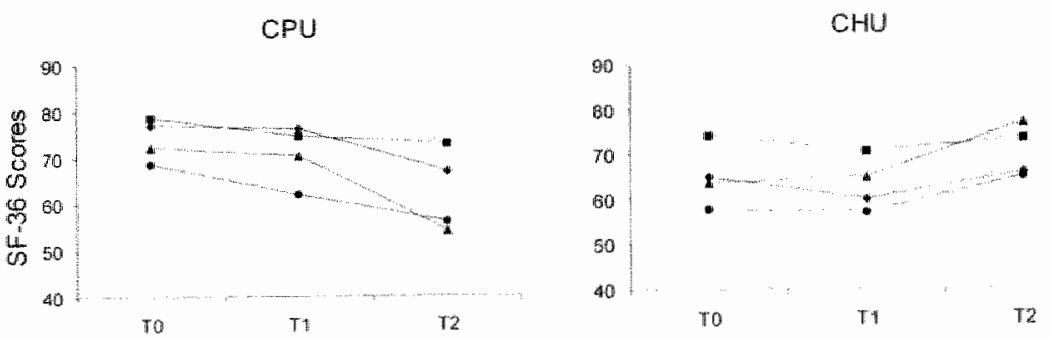

SF 36 = short form 36-item Health-Related-Quality of Life questionnaire, Pu=persisting ulcer patients, $H U=$ healed Ulcer patients, $C P U=$ caregiver of persisting ulcer patients, $C H U=$ caregiver of healled ulcer patients. $*$ physical functioning, $\mathbf{a}=$ social functioning, $\bullet=$ role physical, $\iota=$ role emotional 


\section{Caregiver}

Between the caregivers of the HU and PU patients no differences were observed in the reported quality of life at study entry. At $T 2$, the subscale role emotional was markedly higher in the HU caregivers compared to the PU caregivers $(p \leq 0.05)$. Analysing the changes over time (within group analyses), the subscalle role emotional improved in the HU caregivers and worsened in the PU caregivers (T2 Vs TO and $T 1 \quad p \leq 0.05$ ). In addition, the mental summary score was improved in the HU caregivers at $T 2$ compared to baseline $(p \leq 0.05)$

\section{Correlations}

Correlations (spearman correlation coefficient) were found between the reported HRQOL of the patients and the caregivers, for the following scales and summary scores: physical functioning 0.21 , social functioning 0.46 , role physical 0.35 , role emotional 0.46 and mental surnmary score 0.55 (all $p<0.03$ ).

\section{Discussion}

Neuropathic foot ulcers are characterised by loss of sensation and usually patients have very few specific complaints ${ }^{2}$. However, we demonstrated in this study that Health-Related-Quality of Life (HRQOL) of patients with chronic neuropathic and neuro-ischemic foot ulcers, without critical limb ischemia, is poor and comparable to, for instance, the HRQoL of patients with recurrent (breast) cancer ${ }^{14}$. At T2, patients with a healed ulcer had a higher HRQoL than patients with a persisting ulcer. Analyses over time revealed that this poor HRQoL improved after healing of the ulcer but deteriorated amongst the patients with a non-healing ulcer as well as their caregivers. We used the SF-36, which is a generic and not disease specific instrument, to measure quality of life ${ }^{15}$. Ideally, both a generic and a foot ulcer specific instrument should be used, but the latter, such as the NeuroQol, was not available at the time of the study't. Despite these limitations the SF-36 has several advantages. It can be used in the caregivers as well, and changes in HRQOL can be interpreted clinically". The smallest relevant change in the physical component summary and mental component summary is approximately $2-2.5$ points ${ }^{18}$. In our study, healing was associated with an improvement of 4.6 points in the physical summary score and 11 to 25 points in the various subscales, underlying the large impact of a diabetic foot ulcer on different dimensions of HRQOL.

A foot ulcer is frequently a sign of a poor health status and cross-sectional studies suggest that at least part of the loss of HRQoL in these patients is related to diabetic complications such as neuropathy ${ }^{19-21}$. This study indicates that the presence of an ulcer has an independent and relatively large effect on HRQOL, of 
both patients and caregivers. The largest loss of HRQOL was observed in the scores and specific items related to mobility. For example the low scores on the physical functioning scale indicate impairments in walking or climbing stairs. In addition. there was deterioration in the scale "role physical" in patients with persisting ulcers $(T O \rightarrow T 2)$. This part of the SF-36 questionnaire reports how patients experience the physical impairments, suggesting that the longer an ulcer is present, the greater the burden to the patient. In parallel, our patients seemed to become more socially isolated, given the loss in the social functioning scale.

In comparison to baseline, we found a moderate improvement of HRQOL as soon as the ulcer was healed (T1) and further improvement was observed 3 months after healing (T2). The relative small improvement at $\mathrm{T} 1$ could be related to the design of the SF-36 instrument, since many questions are related to the health status of the patient in the last 4 weeks. During this period most patients were still treated with an off-loading device, which was not specified in our study. However, off loading devices ${ }^{22.23}$, such as a cast or half-shoe, can result in loss of physical functioning, in particular mobility, as observed in the majority of our patients. After healing of the ulcer these devices are usually discontinued, which could have contributed to the improvement in mobility and HRQoL 3 months after healing. Various off-loading devices are currently used, with possibly different impact on mobility and HRQOL. This needs, however, further exploration.

The treatment of diabetic foot ulcers not only poses a great burden on the patient but also on the patients' surrounding $s^{6}$. in particular, healing was associated with a large improvement in the subscale related to emotional difficulties of the caregivers. Moreover, HRQoL of the caregivers were correlated with the HRQOL of the patients. Several factors are probably responsible for the loss of HRQoL of the caregivers, such as wound care, impaired mobility, frequent hospital visits and fear of amputation. A limitation of our study was the relatively small number of caregivers $(n=153)$ compared with the number of patients $(n=294)$, this may be due to social isolation or to unwillingness to fill out the questionnaire. We cannot exclude the possibility that the HRQoL of these possible non-participants was less affected by taking care of a diabetic patient with a foot ulcer. However, in the busy foot clinics, time and attention should be offered to these caregivers given their important role in treatment and the large emotional burden foot ulcers pose on the patients' immediate surrounding. 


\section{References}

1. Rubin RR, Peyrot M. Quality of life and diabetes. Diabetes Metab Res Rev 1999,15:205-118

2. International Working Group on the Diabetic Foot. Apelquist J, Bakker K, Wan Houtum WH, Mabuurs-Franssen MH, Schaper NC (ed). International Consensus on the Diabetic Foot. Schaper MC. Maastricht. 1999.

3. Apellqust J. Larsson \. What is the most effective way to reduce ncidence of amputation in the diabetic foot? Diabetes Metab Res Rev 2000,16 $51: 575-83$.

4. Jeficoate WI, Harding $\mathrm{KG}$. Diabetic foot ulcers. Lancet $2003: 361: 1545-51$.

5. Hux M, Mlcovinch N, Torrance $G$, Gibbald G. Healthwrelated quality of life related to chronic foot ulcers in diabetics. Qual Life Res 1998;8:655.

6. Brod M. Quality of life issises in patients with diabetes and lower extremity ulcers: patients and care givers. Qual Life Res 1998;7:365-72.

7. Carrington AL, Mawdsley SK, Morley M, Kincey J, Boulton A. Psychological status of diabetic people with or without lower limb disability. Diabetes Res Clin Pract 1996;32:19-25.

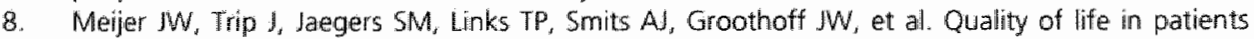
with diabetic foot ulcers. Disabil Rehabi/2001:23:336-40.

9. Ragnarson Tennvall $G$, Apelquist J. Health-rellated quality of life in patients with diabetes mellitus and foot ulcers. I Diabetes Complications 2000:14:235-41.

10. U.K. Prospective Diabetes Study Group. Quality of life in type 2 diabetic patients is affected by complications but not by intensive policies to improve blood glucose or blood pressure control (UKMDS 37). Diabetes Care 1999;22:1125-36.

11. Coffey JT, Brandle $M_{\text {, }}$ Zhow $H$, Marriott D, Burke $R$, Tabaei BP, et al. Valuing health-related quality of life in diabetes. Drabetes Care 2002;25:2238-43.

12. Mchorney CA, Ware IE Jr Raczek AE. The MOS 36-Item Short-Form Health Survey (SF-36): II. Psychometric and clinical tests of validity in measuring physical and mental health constructs. Med Gare 1993;31:247-63:

13. Ware JE Jr, Sherboume CD. The MOS 36-item short-form health survey (SF-36). I. Conceptual framework and tem selection. Med Care 1992;30:473-83.

14. Northouse LI, Mood D, Kershaw T, Schafenacker A, Mellon $S_{*}$ Walker J, et al. Quality of life of women with recurrent breast cancer and their family members. $J$ Clin Onco/2002;20:4050-64

15. Anderson RM, Fitzgerald IT, Wisdom K, Davis WK. Hiss RG. A comparison of global versus disease-specific quality-of-life measures in patients with NIDDM. Diabetes Care 1997;20:299-305.

16. Vileikyte $L_{,}$Peyrot M, Bundy $C$, Rubin RR, Leventhal $H$, Mora $\mathrm{P}_{r}$ el al. Development and validation of a neuropathy- and foot ulcer-specific quallity of life instrument. Diabetes Care 2003;26: $2549-55$.

17. Edelman D. Olsen $M$, Duddley $T$. Harris A, Oddone EZ. Impact of diabetes screening on quality of life. Diabetes Care 2002,25:1022-6.

18. Samsa G, Edelman D, Rothman ML, Williams GR, Lipscomb J, Matchar D. Determining elinically important differences in health status measures: a general approach with illustration to the Health Utilities Index Mark III. Pharmacoeconomics 1999;15:141-55

19. Klein BE, Klein R. Moss SE. Self-rated health and diabetes of long duration. The Wisconsin Epidemiologic Study of Diabetic Retinopathy. Diabetes Care 1998:21:236 40

20. Jacobson $A M$, de Groot $M$, Samson JA. The evaluation of two measures of quality of life in patients with type I and type ll diabetes. Diabetes Care 1994;17:267-74.

21. Ahroni $J H$, Boyko El, Davignon DR, Pecoraro RE. The health and functional status of veterans with diabetes. Diabetes Care 1994:17:318-21.

22. Cawanah PR. Therapeutic footwear for people with diabetes. Diabetes Metab Res Rev 2004;20 $\$ 1: 551-5$.

23. Armstrong DG, Lavery LA. Evidence-based options for off-loading diabetic wounds. Chin Podratr Med Surg 1998;15:95-104 


\section{Chapter 8}

\section{Summary and conclusions}

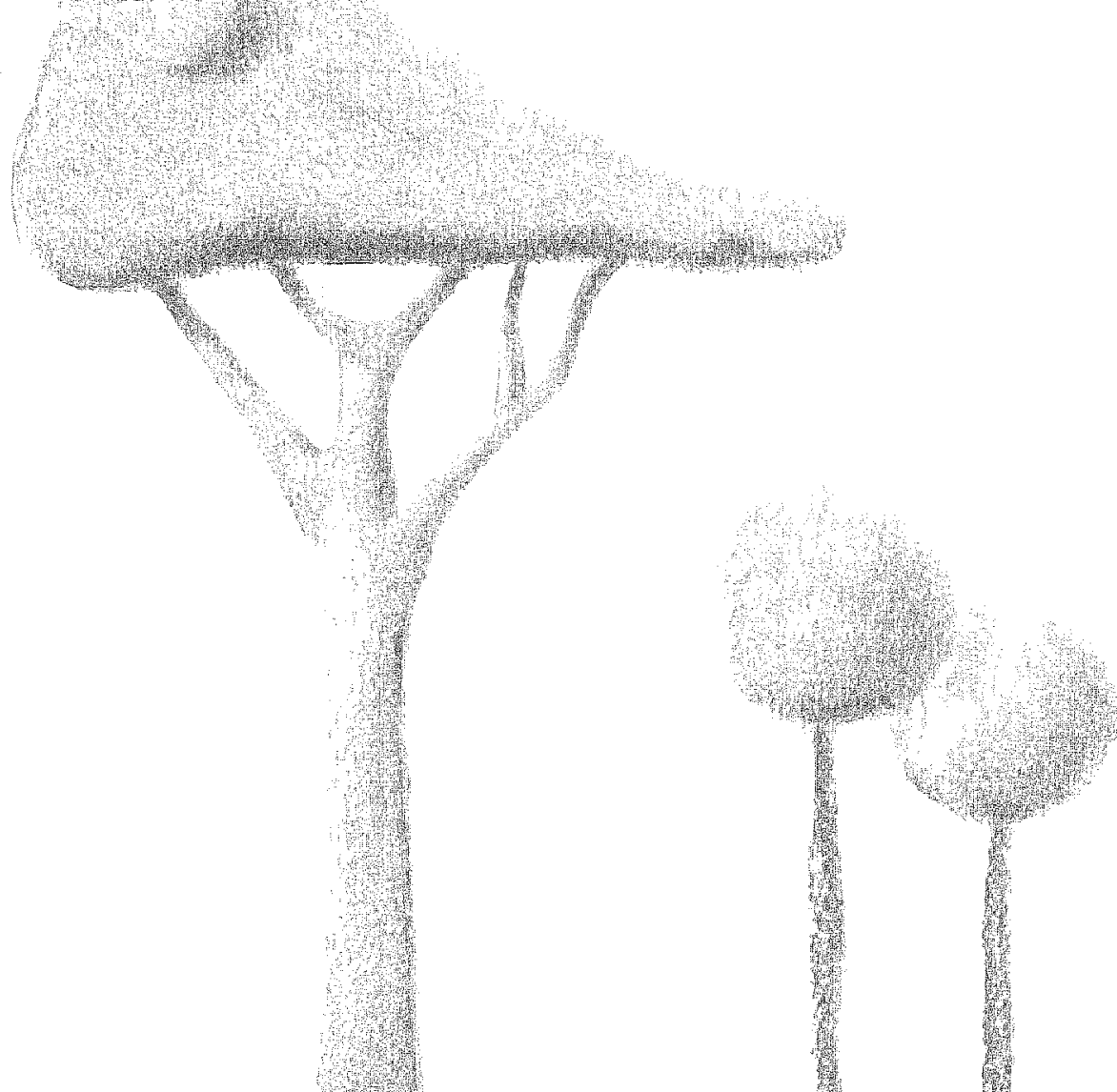


Chaper 


\section{Summary and conclusions}

The foot in diabetic patients is the cross-road of several pathological processes, in which almost all components of the lower extremity are involved: skin. subcutaneous tissue, muscles, bones, joints, blood vessels and nerves'. Furthermore, wound healing is impaire ${ }^{2}$ and the foot is vulnerable to infection ${ }^{3}$. which may lead to long-term hospitalisation and/or (partial) amputation of the foot and/or leg ${ }^{4}$. In chapter 2, the pathogenesis and the pathways to diabetic foot problems are summarised, and a systematic evaluation of a diabetic patient with a foot ulcer is described. Distal symmetrical polyneuropathy appeares to be a major factor in the pathogenesis of foot ulceration, , usually with loss of sensory, motor and autonomic functions. Muscle imbalance, due to motor loss, abnormalities in skin and subcutaneous tissues, which in part are related to autonomic neuropathy. in combination with limited joint mobility, all result in an abnormal loading of the foot $^{5}$. Due to the sensory loss the patient does not react adequately to this increased biomechanical stress, with subsequent damage of the skin and subcutaneous tissues?. In other patients a more acute trauma, which is not sensed, plays a more central role in the development of these so-called neuropathic ulcers. In one study the triad of neuropathy, foot deformity and minor trauma was present in more than $60 \%$ of the patients, illustrating that a foot of a diabetic patient does not ulcerate spontaneously ${ }^{8}$. In neuro-ischemic or the relatively rare "pure" ischemic ulcers", peripheral arterial disease (PAD) is an important pathogenic factor and a major factor determining outcome. Once a neuro(ischemic) ulcer has occurred, these wounds tend to heal poorly, if the wound is not properly off-loaded ${ }^{10}$ and, if severe PAD is present and the impaired blood flow is not restored". Finally, several studies suggest that diabetic patients with foot ulcers have an intrinsic defect in wound healing. Glycation of skin collagen and possibly of other matrix components may impair matrix degradation ${ }^{12}$. In addition, leukocyte function and recruitment of leukocytes ${ }^{13}$ is impaired in diabetic patients with poor metabolic control, resulting in defective chemotaxis, phagocytosis, and intracellular killing ${ }^{14 \cdot 16}$. The defect in intracellular killing may be due to shunting of glucose through the polyol pathway ${ }^{17}$. Abnormalities have also been observed in the proliferative capacity of fibroblasts of diabetic patients, derived from normal skin and from foot ulcers ${ }^{18,19}$. The mechanism of this decreased fibroblast proliferation is unclear, but may be caused by impaired cellular responsiveness to one or more growth factors, as recently suggested by Loots et al (unpublished data). In daily clinical practice, before treatment is started, a proper clinical evaluation of the foot ulcer is essential to guide further diagnostic work-up and treatment 20 . The clinician should evaluate the ulcer characteristics (site, size and depth), the cause of the ulcer (biomechanical evaluation), the underlying pathology (ischemia, neuropathy) and the possible complications of the ulcer (infection). 
As stated above, vascular abnormalities play an important role in the pathogenesis and course of many diabetic foot ulcers. In approximately $45 \%{ }^{20}$ of diabetic patients with a foot ulcer, PAD is involved ${ }^{21}$. In many patients the disease has no or few symptoms and runs a relative benign course, but in others it leads to gangrene or impaired healing of neuro-ischemic foot ulcers". Moreover, in comparison with non-diabetic patients. PAD has a more distal distribution in the legs ${ }^{22.23}$ and has a more aggressive course ${ }^{24}$. In contrast to macrovascular disease, diabetic microangiopathy is not considered an important pathogenic factor in the development of a diabetic foot ulcer ${ }^{20}$. However, several abnormalities can be observed in the skin microcirculation of diabetic patients, which might increase the vulnerability of the skin and thereby contribute to impaired wound healing.

In the human skin, the microcirculation is organized in two functional subdivisions. One part consists of the superficial capillaries in the dermal papillae, supplying nutrition to the skin dermal tissue and the basal cell layers of the epidermis. The second element are the sub-papillary arteriolar and venular plexus, interconnected by arteriolo-venular (AVA) anastomoses. These are mainly involved in the regulation of body temperature (thermoregulation) and are controlled by sympathetic nerve endings, in contrast to the capillaries, which have no nerve supply. Several studies suppose that total skin blood flow in diabetic neuropathy is increased, as a result of an increase in shunt flow through sympathetic denervated arteriovenous anastomoses (AVA). With laser doppler fluxmetry ${ }^{25}$, an increased skin blood flow in the toe pulp, a site were AVA are numerous, is reported. Under conditions of normal environmental temperature the majority (80-90\%) of skin blood flow passes through these anastomoses. Sympathetic stimulation results in vasoconstriction of the anastomoses, reducing total skin blood flow markedly ${ }^{26}$. On the other hand in pathological circumstances, for example after sympathetic denervation (which is the case in diabetic polyneuropathy), baseline skin blood flow increases and sympathetic stimulation does no longer induce a decrease in skin blood flow ${ }^{37}$. This can be an explanation for the warm feet in patients with diabetes mellitus and polyneuropathy. One may question whether there is besides an increase in AVA flow a parallel increase in nutritive capillary flow, or whether nutritive capillary flow is unchanged resulting in underperfusion of the skin. Therefore, in chapter 3, we assessed the effect of peripheral polyneuropathy (PNP) on skin microcirculation of patients with Type 2 diabetes, both supine and during dependency of the feet. As expected, foot skin temperature, which is mainly determined by thermo-regulatory skin blood flow, was elevated in the patients with PNP, probably due to auto-sympathectomy with opening of A-V shunts ${ }^{28.29}$. In healthy subjects acute denervation of a limb is associated with a parallel increase in both thermo-regulatory and capillary blood flow ${ }^{28}$, suggesting a close association between these two vascular beds. Indeed, we found a marked correlation between skin temperature and capillary blood cell velocity (CBV) in our Type 2 diabetic 
patients without PNP. In contrast, supine CBV was lower in the patients with PNP in comparison to the patients without PNP. Moreover, CBV was inversely correlated with the Valk score, which is a clinical measure of PNP severity ${ }^{30}$. These data suggest that increased denervation is associated with a rise in thermoregulatory blood flow and a progressive decline of nutritive skin blood flow in patients with Type 2 diabetes. This capillary steal may be related to the impaired vasodilator capacity in Type 2 diabetes: the loss in sympathetic vasoconstrictor tone would result in a decline in vascular resistance in the thermoreulatory vascular bed with subsequent shunting of blood from the nutritive vascular bed. This relative hypoperfusion may contribute to impaired wound healing in Type 2 diabetic patients with polyneuropathy.

Clinical studies suggest that edema is a contributing factor in the pathogenesis ${ }^{8}$ and clinical outcome ${ }^{31}$ of diabetic foot ulcers. During lowering of the limb, venous hydrostatic pressure increases, which results in vasoconstriction of the precapillary sphincters. This veno-arterial reflex limits the rise in capillary hydrostatic pressure, fluid filtration and subsequent edema formation. In patients with Type 1 diabetes an increased capillary pressure ${ }^{32}$ and increased capillary filtration rate of water ${ }^{33}$ have been observed. In patients with Type 2 diabetes both capillary pressure ${ }^{34}$ and filtration ${ }^{35}$ do not seem to be altered, although in one study a reduced capillary filtration was observed ${ }^{36}$. Data on the effect of polyneuropathy, however, are lacking. Therefore, in chapter 3, in addition to the microcirculatory parameters, also foot swelling rate was measured during dependency. After changing from the supine to the sitting position, foot swelling rate during the first 10 minutes of dependency was lower in the patients with polyneuropathy compared to the healthy subjects. Moreover, fluid filtration during this period correlated inversely with the Valk score, indicating that the severity of neuropathy contributes to this phenomenon. The attenuated swelling rate in our neuropathic patients could be due to the enhanced postural vasoconstrictor response which also observed in these patients at the same time-point, using continuous laser Doppler fluxmetry. The mechanism of the enhanced acute postural constrictor response is unclear, but could be related to hyperresponsiveness of the veno-arterial reflex, due to chronic denervation. An alternative explanation for the attenuated foot swelling rate could be that the interstitial hydraulic pressure was increased in the patients with neuropathy already at the start of the study. Indeed in one earlier study increased interstitial pressures ${ }^{37}$ were observed in patients with neuropathy, which could have limited capillary filtration during dependency. Finally, both MRI and autopsy studies have shown that polyneuropathy is associated with marked qualitative and quantative changes in soft tissues within the diabetic foot ${ }^{38}$. These structural changes could clearly have affected the rate of foot swelling. Additionall studies are needed to explore this. 
In conclusion, our study in chapter 3 support the view that PNP in Type 2 diabetes is associated with multiple abnormalities in the (skin) microcirculation of the foot, characterised by reduced capil ary blood flow, an acute enhanced vasoconstriction and impaired fluid filtration after sitting up. We observed the most severe abnormalities in patients with a history of foot ulceration, suggesting that such disturbances in the skin microcirculation may contribute to the impaired healing capacity of diabetic foot ulcers. The most marked effect of PNP on skin microculation was observed in the supine position. These data imply that bedrest in neuropathic Type 2 diabetic patients might have negative effects on nutritive skin blood flow. Indeed, in clinical practice some ulcers respond very well to restoration of ambulation, if properly off-loaded.

Total contact casting is seen as the golden standard treatment in patients with superficial, non-infected, non-ischemic, plantar neuropathic ulcers. Recent studies show that approximately $55 \%$ of all ulcers are purely neuropathic ${ }^{20}$, and that about half of these ulcers are infected. Therefore, less than $30 \%$ of our patients in daily clinical practice will fulfil these criteria. For this reason the prospective followup study in chapter 4 on the efficacy and safety of casting in a relatively wide variety of patients was performed. All consecutive patients visiting the casting clinic were included in this study. As also observed in earlier studies ${ }^{35-41}$, good healing rates ( $90 \%$ of the patients) were observed in patients with pure neuropathic ulcers. A striking finding was the remarkably fast healing in the latter patients, with a median time-to-heal of 18 days. A new finding was that patients with infection or moderate PAD can also be treated effectively and safely with casting. Superficial infection did not affect healing in this study and moderate PAD resulted in a slightly decreased, but still substantial healing rate $(69 \%)$. However, patients with the combination of moderate PAD and superficial infection had a poor outcome. For this type of patients alternatives to casting are probably indicated. Few studies ${ }^{42,43}$ have been performed yet on the effect of infection on the outcome (neuro-)ischemic diabetic foot ulcers. Armstrong et al. ${ }^{44}$ showed that patients with PAD and infection had a higher amputation rate, but in this study patients with more severe PAD and more severe infection were included. In an earlier study we showed that relatively mild impairment of perfusiom may contribute to a poor penetration of antibiotics, which can impair the efficacy of antibiotic treatment ${ }^{415}$. According to (inter)national guidelines, patients with superficial infection are treated in the University Hospital Maastricht with oral small spectrum antibiotics. Perhaps in this patient group (patients with a superficial infection and $P A D$ ) higher doses or broader spectrum antibiotics should be prescribed. Also in patients with heel ulcers poor healing rates were observed and in these patients alternative strategies should be sought for, such as a cast with extra depth around the heel. Unfortunately, the contours of such a cast will impair walking capacity. 
Three different casting modalities were used in our studies. To our surprise, a nonremovable shoe-model cast seemed as effective as a non-removable total contact cast (TCC) up to the knee. However, the current study was not a randomized controlled trial and additional studies are needed to determine whether this relative patient-friendly shoe-model cast is in fact equally effective as the classic TCC. Several explanations are given in the literature ${ }^{39.40}$ for the effectiveness of a TCC, including an increase in loading surface, transfer of pressure from the foot to the shaft of the cast and immobilisation of the ankle joint. As shown in an earlier study ${ }^{46}$, the forced compliance to a TCC is probably one of the most important determinants of success and indeed we found that the removable cast had poorer results in patients treated longer than 4 weeks. In conclusion, total contact casting has been shown to be very effective in a wide range of patients. Nevertheless, relatively few centers use this technique, probably due to fear of complications and lack of trained personnel. Indeed, we found a high incidence of pre-ulcerative lesions, but serious complications were rarely observed. The low complication rate is probably related to the close monitoring of the patients.

Unfortunately, with each leg saved, the number of legs at risk for ulceration increases and as a consequence, the recurrent foot is becoming a major burden for both the patient and the health care system $\mathrm{m}^{47-49}$. Recurrence rates of approximately $70 \%$ over five years have been reported in patients with neuropathic or neuroischemic foot ulcers ${ }^{50}$. In chapter 5 we evaluated if patients with foot ulcers can be treated repeatedly with total contact casting for recurrent ulceration, without loss of efficacy or safety. No differences were observed in healing rate and healing velocity with repeated casting. In total $88 \%$ of all ulcers healed with this off-loading modality. Repeated casting was not associated with an increase in complications, but rather a decrease in the number of complications. However, it should be noted that selection bias could have contributed to the relatively low number of complications observed in our study. Patients in which (serious) complications did occur, were possibly no longer treated with total contact casting and patients with good results were probably repeatedly treated with casting. In addition, we did not study the effects of casting on mobility, muscle wasting and quality of life.

One remarkable finding was that during follow-up $75 \%$ of the patients had ulcers on different locations of the foot and $25 \%$ had only 1 region with recurrences, illustrating that once an ulcer has occurred the whole foot is at risk. An additional finding was that PAD seemed to be associated with recurrent ulceration, as has been found by other investigators as well ${ }^{49}$. As shown by Edmonds et al. ${ }^{51}$. increased plantar foot pressures can also be observed in patients with neuroischemia. Moderate PAD probably renders the skin more susceptible to this elevated biomechanical stress but once a cast is applied healing rates are 
acceptable. In almost all patients customised shoes were prescribed. Unfortunately these measures were not able to prevent re-ulceration in a subset of patients. As discussed in this thesis, new techniques are needed for the development and evaluation of more effective shoe-wear. In addition, more effective education programmes should be developed to prevent re-ulceration. Finally, long-term studies are urgently needed in which the cost-effectiveness and re-ulceration rate are compared between repeated conservative casting treatment, surgical procedures, aimed to reduce the increased biomechanical stress, and revascularisation procedures. Until these data are available, our data imply that patients with neuropathic and neuro-ischemic foot ulcers should be treated for recurrent ulceration with total contact casting.

Diabetic foot ulcers pose a great burden on the patient and his or her immediate surrounding. Although the ulcer itself is associated with few symptoms ${ }^{52}$, the consequences are dire. In most centers treatment usually takes 11 weeks on average and during this phase mobility is impaired. In approximately $50 \%$ of the patients wound infection occurs ${ }^{53}$ and hospitalisation is often indicated. During hospitalisation invasive therapies as revascullarisation procedures (PTCA or bypasses), free-flap transplantations or orthopedic surgical procedures, are often necessary. In addition, diabetic foot ulcers are closely associated with multiple microvascular and macrovascular complications, as described in chapters 2 and 4 . Foot ulcers in diabetic patients are therefore a sign of extensive disease, are associated with a poor prognosis and 5 year mortality rates up to $70 \%$ have been reported ${ }^{54}$. Therefore, quality of life in these patients can be affected by the ulcer and its complications and/or the treatment of the uicer and the diabetes treatment and/or the presence of comorbidity. There are several instruments to measure Health-Related-Quality of Life (HRQoL). Ideally, a generic instrument should be used along with a disease specific instrument to determine HRQoL ${ }^{55}$. The generic instrument should make comparisons between different disease states possible and should take the underlying pathology and extensive comorbidity into account. The disease specific instrument should take the consequences of the ulcer and its treatment into account. Unfortunately, at the time of our studies no such instrument was available. Our studies in chapter 6 and 7 for the measurement of HRQOL of diabetic foot ulcer patients were therefore done with two generic instruments. The first study was performed with the EQ-5D ${ }^{56}$, which is an easy to use generic instrument to measure HRQoL that can be completed by the patient himself in only a few minutes. This instrument was used because of the practical advantages of this instrument in comparison to the more extensive SF-36 questionnaire ${ }^{57.58}$ which was used in our second study. Besides that, with the EQ5D quality-of-life-adjusted-live-years (qualy's) can be calculated, which can be used in health economic studies. Our second study on HRQoL was part of a prospective, randomised, double-blind, placebo-controlled trial testing the efficacy and safety 
of recombinant human platelet-derived growth factor-BB (becaplermin). Eightyone centres in the United States, the UK and Europe participated.

in the first study, chapter 6 , we determined the impact of a diabetic foot ulcer and other diabetic complications on the HRQOL. Three different cohorts were studied: patients without and patients with a foot ulcer treated by a diabetologist and patients without a foot ulcer treated by the general practitioner. Patients with a diabetic foot ulcer reported a marked reduction in HRQOL, determined with the EQ-5D, but this reduction was mainly related to the underlying pathology and other diabetic complications. Multivariate analyses revealed that neuropathy was one of the most important independent determinants of HRQOL. As almost all patients with a foot ulcer also had neuropathy, an independent effect of an ulcer could not be determined cross-sectionally. In daily practice neuropathy is seen as a relative mild and asymptomatic complication of diabetes ${ }^{20}$. Only a few studies have been performed on the impact of neuropathy on HRQOL ${ }^{59}$. Clearly, more information is needed on both the physical and mental consequences of neuropathy, and additional strategies should be developed to relieve the burden of this complication. In the second part of this study, no changes were observed in HRQOL after healing of the ulcer and the low HRQOL, as determined with the EQ5D, can therefore be seen as a sigm of a poor general health status. On the other hand, the lack of an effect of healing on HRQoL could also be explained by the choice of the instrument used, as the scaling of the individual EQ-5D questions seems inappropriate and too narrow to capture important changes in foot ulcer patients. For example, for mobility, the two extreme categories are 'no problems' and 'confined to bed'. Since almost no patients will be in the 'unable' category, the only movement that can be detected will be between 'no problems' and the presence of 'problems'. Finally the number of patients could have been too low to see any effect of the ulcer per se.

For this reason, we performed a second study with a more sensitive instrument (SF-36) to determine the effect of an active foot ulcer on the HRQOL of diabetic patients. This study is reported in chapter 7 and the HRQOL of diabetic foot ulcer patients and their caregivers was prospectively evaluated. The SF-36 is a generic instrument with, relative to the EuroQol-5D instrument, a more extended scaling. Prospective studies have revealed that this instrument may be more effective in detecting changes over time ${ }^{60}$. Diabetic patients with a foot ulcer reported a markedly low HRQoL on all SF-36 subscales and their quality of life was comparable to the HRQoL of patients with lung cancer. Furthermore, the presence of an ulcer seemed to have an independent and relatively large effect on HRQOL of both patients and caregivers ${ }^{61}$. Healing of the foot ulcer resulted in a marked improvement in quality of life and in contrast HRQOL declined progressively in case the ulcer did not heal in both patients and caregivers. Diabetic foot ulcer patients experienced the biggest problems with the physical scales of the SF-36 
questionnaire. The largest loss in HRQOL was observed in the scores and specific items related to mobility. After healing of the ulcer these off-loading devices are usually discontinued, which could have contributed to the improvement in mobility and HRQOL after healing. Little data are available on the impact of the different off-loading devices on the HRQoL of the patient. Additional studies are needed to explore this. In contrast, the caregivers experienced the biggest problems with scales related to emotional problems. During the time the ulcer of the patient was present, the HRQOL of the caregiver progressively declined. On the other hand, healing of the ulcer of the patient was associated with a large improvement in the subscale related to emotional difficulties. Finally, there was a high correlation between the HRQOL of the patient and his caregiver, suggesting that changes in HRQOL of the caregivers are presumably caused by the effect of the ulcer of the patient. These data stresses the importance of making the time to heal of an ulcer as short as possible. As stated above as long as the ulcer is present, there is a risk for infection, a risk for amputation and a progressive decline in the Health-RelatedQuality of Life of the patient, as shown by the study described in Chapter 7 . Therefore, more effective strategies should be developed to shorten the time to heal. HRQoL of the caregiver also deteriorated progressively over time as long as the ulcer was present. These caregivers play an essential role in the life of diabetic foot patients. In the modern time where we are living in, reduction in the costs of the health care system is a hot topic on the list of the policy makers and these caregivers (unavoidably) play an increasingly important role. Therefore, time and attention should be offered to these caregivers during the busy foot clinics, given their important role in the treatment of the foot ulcer and the large emotional burden these foot ulcers pose on the patients' immediate surrounding.

In view of the continuously growing population of patients with diabetes, diabetic foot problems will remain a major health care problem. The increasing number of patients with Type 2 diabetes at a relatively young age will predispose to the development of neuropathy in the course of their disease and may augment the number of patients that are confronted with neuropathic foot ulcers in a phase of their life in which they are still active and part of the working population. On the other hand, the ageing of the general population will also predispose to PAD with the subsequent development of (neurow) ischemic foot ulcers in elderly individuals. Therefore continued efforts are needed to develop new therapies to prevent foot ulceration and to improve the outcome of diabetic individuals with foot ulcers. The results of the studies reported in this thesis have of number of implications for the care of patients with diabetic foot disease. We have shown that in patients with polyneuropathy a number of microcirculatory abnormalities exist that correlate with the severity of the nerve dysfunction, these disturbances are most prominent in patients with a previous foot ulcer. Further research is needed to clarify the role of this microvascular impairment in wound healing and to investigate if these 
abnormalities can be restored with specific therapies. Our studies on casting treatment of plantar foot ulcers stress the good results of this therapy in a wide range of patients. A recent European survey among diabetic foot centers indicated that this therapy is not used in many centers of expertise (the Eurodiale group. unpublished data). Efforts should be made to make this treatment available for more patients by creating casting facilities in more centers worldwide. Alternatively, studies should be performed to evaluate the effects of other offloading modalities such as ready to use inflatable and non-removable casts or shoe-models as developed in our clinic. Despite multiple preventive measures recurrent ulceration could not be prevented in several patients, and although patients can be treated with repetative casting, clearly more effective preventive strategies are needed. Such preventive efforts are usually aimed at improving the biomechanical loading of the foot. However, as the majority of our patients had $P A D$, strategies should also be developed to improve tissue perfusion in these patients. This thesis demonstrates the important effects of foot ulcers and their treatment on quality of life of both patients and caregivers; effects on quality of life should therefore be taken into account in the evaluation of new treatments. The poor quality of life is in part related to the ulcer per se and in part to the underlying pathology, in particular neuropathy. Clearly more research is needed to determine the factors responsible for this loss of quality of life in diabetic neuropathy, with the development of new treatment madalities. Finally, mortality is high and strategies should be sought for to improve the poor prognosis of diabetic patients with a foot ulcer. 


\section{References}

1. Jeffcoate WJ, Harding KG. Diabetic foot ucers. Lancet 2003;361:1545*51.

2. Jeffcoate $W I_{s}$ Price $P$. Harding $K G$. Wound healing and treatments for people with diabetic foot ulcers. Diabetes Metab Res Rev 200420 $51578-89$

3. Lipsky $B A$. A report from the international consensus on diagnosing and treating the infected diabetic foot. Diabetes Metab Res Rev 2004;20 51:568-77.

4. Eneroth $M$, Apelqvist $J$, Stenstrom A. Clinical characteristics and outcome in 223 diabetic patients with deep loot infections. Foot Ankle /nt 1997;18:716-22.

5. Boulton As. The pathogenesis of diabetic foot problems: an overview. Diaber Med 1996;13 $\$ 1: \$ 12-6$.

6. Frykberg RG, Lavery LA, Pham H. Harvey C, Harkless L. Vewes A. Role of neuropathy and high foot pressures in diabetic foot ukeration. Diabetes Care 1998:21:1714-9.

7. Ziegler D. Diagnosis and management of diabetic peripheral meuropathy. Diabet Meo $1996 ; 13: 534-8$.

8. Reiber GE, Vileikyte $L_{\text {s }}$ Boyko EJ, del Aguila M, Smith DG, Lavery LA, Boulton A. Causal pathways for incident lower-extremity ulcers in patients with diabetes from two settings. Diabetes Care $1999 ; 22: 157-62$

9. Rauwerda JA. Surgical treatment of the infected diabetic foot. Diabetes Metab Res Rev 2004:20 $51: 541-4$

10. Cavanagh PR. Therapeutic footwear for people with diabetes. Diabetes Metab Res Rev 2004;20 $51: 551-5$

11. Andros G. Diagnostic and therapeutic arterial interventions in the ulcerated diabetic foot. Diabetes Metab Res Rev 2004,20 51:529-33.

12. Dyer DG, Dunn JA, Thorpe SR, Bailie KE, Lyons TJ, McCance DR, Bayres JW. Accumulation of Maillard reaction products in skin collagen in diabetes and aging. $/$ Clin lowest 1993,91:2463-9.

13. Fahey TJ, 3rd, Sadaty A, Jones WG, 2nd, Barber A, Smoller $\mathbb{B}$, Shires GT. Diabetes impairs the late inflammatory response to wound healing. / Surg Res 1991:50:308-13.

14. Mowat A, Baum J. Chemotaxis of polymorphonuclear leukocytes from patients with diabetes mellitus. N Eng/ / Med 1971:284:621-7.

15. Davidson NJ. Sowden $\mathrm{IM}$, Fletcher J. Defective phagocytosis in insulin controlled diabetics: evidence for a reaction between glucose and opsonising proteins. $/$ Clin Patho/ 1984;37:783-6.

16. Repine JE, Clawson CC, Goetz FC. Bactericidal function of neutrophils from patients with acute bacterial infections and from diabetics. Infect Dis 1980;142:869-75.

17. Boland OM, Blackwell CC. Clarke BF, Ewing DJ. Effects of ponalrestat, an aldose reductase inhibitor, on neutrophil killing of Escherichia coli and autonomic function in patients with diabetes mellitus. Dabetes 1993;42:336-40.

18. Rowe DW, Starman BI, Fujimoto WY, Williams RH. Abnormalities in proliferation and protein synthesis in skin fibroblast cultures from patients with diabetes mellitus. Diabetes 1977;26: 284.90 .

19. Loots MA, Lamme EN, Mekkes JP, Bos JD, Middelkoop E. Cultured fibroblasts from chronic diabetic wounds on the lower extremity (non-insulin-dependent diabetes mellitus) show disturbed proliferation. Arch Dermatol Res 1999;291:93-9.

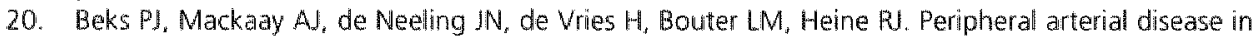
relation to glycaemic level in an elderly Caucasian population: the Hoom study. Diabetologia $1995 ; 38: 86-96$.

21. International Working Group on the Diabetic Foot. Apelqvist 1 , Bakker K, Van Houtum WH, Nabuurs-Franssen MH- Schaper NC (ed). International Consensus on the Diabetic Foot. Schaper NC, Maastricht, 1999.

22. Strandness DE JT, Priest RE, Gibbons GE. Combined Clinical and Pathologic Study of Diabetic and Nondiabetic Peripheral Arterial Disease. Diabetes 1964;13:366-72.

23. Stemmer E.A. Influence of diabetes on patterns of peripheral vascular disease. Surg rounds $1990 ; 13: 43-53$.

24. Management of peripheral arterial disease (PAD). TransAtlantic lnter-Society Consensus (TASC). Eur f Vasc Endovasc Surg 2000;19 Suppl A.Si-xxvili, S1-250. 
25. Rayman $G$, Hassan $A$, Tooke $J E$. Blood flow in the skin of the foot related to posture in diabetes mellitus. BrMed / (Cin Res Ed) 1986:292:87-90.

26. Coffman JD. Total and nutritional blood flow in the finger. Clim $5 / 1972,42: 243-50$.

27. Cronenwett $\mathrm{L}$, Lindenauer SM. Direct measurement of arteriovenous anastomotic blood flow after lumbar sympathectomy. Surgery $1977,82: 82-9$.

28. Netten PM, Wollersheim H. Thien T. Lutterman JA. Skin microcirculation of the foot in diabetic neuropathy. Clin Soi (Lond) 1995;91:559-65

29. Flynn MD, Tooke IE. Diabetic neuropathy and the microcirculation. Diabet Med $1995: 12: 298-301$.

30. Valk GD. Nauta 14 , Sitrijers RL, Bertelsmann FW. Clinical examination versus neuro-physiological examination in the diagnosis of diabetic polyneuropathy. Diabet $M$ ed 1992:9:716-21

31. Apelquist J, Larsson J, Aglardh CD. Medical risk factors in diabetic patients with foot ulcers and severe peripheral vascular disease and their influence on outcome. J Diabetes complications $\pi 992 ; 6: 167-74$.

32. Sandeman DO, Shore AC, Tooke JE. Relation of skin capillary pressure in patients with insulindependent diabetes mellitus to complications and metabolic control. $N$ Eng/ $/ \mathrm{Med}$ 1992;327: $760-4$.

33. Jaap AJ, Shore AC. Gartside IB, Gamble J, Tooke IE. Increased microvascular fluid permeability in young type 1 (insulin-dependent) diabetic patients. Diabetologia 1993;36:648-52.

34. Shore $A C_{\text {. Jap }}$ AJ. Tooke JE. Capillary pressure in patients with NIDDM. Diabetes 1994,43: $1198-202$.

35. Jaap AI, Shore AC, Gamble ), Gartside IB, Tooke JE. Capillary filtration coefficient in type ll (noninsulin-dependent) diabetes. J Diabetes Complications 1994:8:111-6.

36. Katz MA, Janjan $N$. Forearm hemodynamics and responses to exercise in middle-aged adult-onset diabetic patients. Diabetes 1978:27:726-31.

37. Lower RF, Kenzora JE. The diabetic neuropathic foot: a triple crush syndrome--measurement of compartmental pressures of normal and diabetic feet. Orthopedics 1994:17:241-8.

38. Brash PD. Foster $J_{*}$ Vennart $W$, Anthony $P$, Tooke JE. Magnetic resonance imaging techniques demonstrate soft tissue damage in the diabetic foot. Diabet Med 1999;16:55-61.

39. Armstrong DG, Nguyen $H C$, Lavery LA, van Schie $C H$, Boulton AJ, Harkless $L B$. Off-loading the diabetic foot wound: a randomized clinical trial. Diabetes Care 2001;24:1019-22.

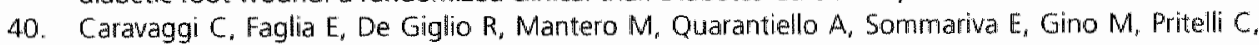
Miorabito A: Effectiveness and safety of a nonremowable fiberglass off-bearing cast versus $a$ therapeutic shoe in the treatment of neuropathic foot ulcers: a randomized study. Diabetes Care 2000:23:1746-51.

41. Mueller MI, Diamond JE, Sinacore DR, Delitto A, Blair VP, 3rd, Drury DA, Rose SI. Total contact casting in treatment of diabetic plantar ulcers. Controlled clinical trial. Diabetes Care 1989:12:384-8.

42. Sinacore DR. Mueller MJ, Diamond JE, Blair VP, 3rd, Drury D, Rose 5J. Diabetic plantar ulicers treated by total contact casting. A clinical report. Phys Ther 1987;67:1543-9.

43. Borssen $B$, Lithner $F$. Plaster casts in the management of advanced ischaemic and neuropathic diabetic foot lesions. Diabet Med 1989;6:720-3

44. Armstrong DG, Lavery LA, Harkles5 LB. Validation of a diabetic wound classification system. The contribution of depth, infection, and ischemia to risk of amputation. Diabefes Care 1998;21: $855=9$.

45. Raymaker's JTF, Houben Al, Van der Heyden J). Tordoir JHM, Kitslaar PJEHM, Schaper NC. The effect of diabetes and severe ischemia on the penetration of ceflazidime into tissues of the limb. Diabet Med 2001:18:229-34.

46. Armstrong DG, Lavery LA, Kimbriel HR, Nixon BP, Boulton Al. Activity patterns of patients with diabetic foot ulceration: patients with active ulceration may not adhere to a standard pressure off-loading regimen. Diabetes Care 2003;26:2595-7

47. Connor $\mathrm{H}$, Mahdi $O Z$. Repetitive ulceration in neuropathic patients. Diabetes Metab Res Rev 2004;20 51:523-8.

48. Mantey I. Foster AV, Spencer S, Edmonds ME. Why do foot ulcers recur in diabetic patients? Diabet Med 1999;16:245-9.

49. Peters El. Risk assessment of diabetic foot complications, Thesis, VU Amsterdam, 2002 
50. Apelowist $\mathrm{J}_{\text {; }}$ Larsson J. Mgardh CD. Long-tem progniosis for diabetic patients with foot ulcers. Intern Med 1993:233:485-91

51. Pitei DL, Lord M, Foster A, Wilson S, Watkins PI, Edmonds ME. Plantar pressures are elevated in the neuroischemic and the neuropathic diabetic foot. Diabetes Care 1999:22:1966-70

52. Jude EB, Boulton AJ. Peripheral neuropathy. Clin Podiatr Med Surg 1999:16:81-916.

53. Lpsky $B A$, Berendt $A R$, Embil 1 , De Lalla F. Diagniosing and treating diabetic foot infections. Olabetes Metab Res Rev 2004,20 51:556-64.

54. Boyko E. Ahroni JH. Smith DG, Davigmon D. Increased mortality associated with diabetic foot ulcer. Diabet Med 1996;13:967-72.

55. Eiser C, Tooke JE. Quality of life in type II diabetes: evaluation and applications Pharmacaeconomics 1995;8:17-22

56. Kind P, Dolan P, Gudex C, Williams A. Variations in population health status: results from a United Kingdom national questionnaite survey. BM/1998;316:736-41.

57. MCHorney CA, Ware JE, Jr, Raczek AE. The MOS 36-ltem Short-Form Health Survey (SF-36): II. Psychometric and clinical tests of validity in measuring physical and mental health constructs. Med Care 1993,31:247.63.

58. Ware JE, Jr., Sherbourne CD. The MOS 36-item short-form health survey (SF-36). I. Conceptual framewark and item selection. Med Care 1992;30:473-83

59. Ahroni $\mathrm{JH}$, Boyko EJ, Davignon DR, Pecoraro RE. The health and functional status of veterans with diabetes. Diabetes Care 1994;17:318-21.

60. Ahronil $J H_{*}$ Boyko EJ. Responsiveness of the SF-36 among veterans with diabetes mellitus I Diabetes Complications 2000:14:31-9.

61. Nonthouse LL, Mood D, Kershaw T, Schafenacker A, Mellon S, Walker J. Galwin E, Decker V. Quality of liffe of women with recurrent breast cancer and their familly members. It Clin Oncol $2002: 20: 4050-64$ 
Nederlandse samenvatting 


\section{Samenvatting}

De diabetische voet is het gevolg van het samengaan van verschillende pathologische processen, waarbij bijna alle componenten van de onderste extremiteiten zijn betrokken: huid, subcutaan weefsel, spieren, botten, pezen, bloedvaten en zenuwen. Bovendien is de wondgenezing gestoord en is de voet gevoelig voor infecties, die kunnen leiden tot langdurige ziekenhuisopnames en/of (gedeeltelijke) amputatie van de voet en/of onderste extremiteit. In hoofdstuk 2 wordt een samenvatting gegeven van de verschillende factoren en hun interactie die leiden tot het onstaan van een voetulcus en wordt er een beschrijving gegeven van een systematische evaluatie van een patiënt met diabetes mellitus en een voetulcus. Distale symmetrische polyneuropathie is een belangrijke factor in de pathogenese van het ontstaan van een voetulcus en gaat meestal gepaard met verlies van sensorische, motorische en autonome functies.

Spierzwakte, als gevolg van de motorische neuropathie, afwijkingen in de huid en het onderliggend weefsel, die voor een gedeelte gerelateerd zijn aan autonome dysfunctie, en verminderde beweeglijkheid van de gewrichten resulteren allemal in een abnormale drukbelasting van de voet. Tengevolge van de sensorische neuropathie reageert de patiënt niet adequaat op deze toegenomen biomechanische belasting, wat resulteert in schade aan de huid en het subcutane weefsel. Bij andere patiënten speelt een acuut trauma, dat niet gevoeld wordt door de patiënt, een centrale rol in de antwikkeling van het neuropathische ulcus. In én studie was de trias neuropathie, voet deformiteiten en een klein trauma in meer dan $60 \%$ van de patiënten aanwezig. waaruit blijkt dat er niet spontaan wonden aan de voeten van patiënten met diabetes mellitus ontstaan. In het neuroischemische of het relatief zeldzame "pure" ischemische ulcus, speelt perifeer arterieel vaatlijden (PAV) een belangrijke rol in het ontstaan van ulcera en is het een belangrijke determinant van de uitkomst van het ulcus. Als er een neuro(ischemisch) ulcus is ontstaan, genezen deze wonden langzaam, indien er geen goede drukontlasting van de wond platsvindt. Als ernstig perifeer vaatlijden aanwezig is genezen de wonden langzaam indien de gestoorde doorbloeding niet is verbeterd. Tenslotte veronderstellen verschillende studies dat er bij diabetes patiënten een intrinsiek defect in de wondgenezing aanwezig is. Glycosylering van het huidcollageen en mogelijk ook van andere matrixcomponenten leiden waarschijnlijk tot stoornissen in de afbraak van de matrix. Bovendien is de leukocytenfunctie (influx van leucocyten) verminderd bij mensen met diabetes en een slechte metabole controle, resulterend in onvoldoende chemotaxis, phagocytose en bactericide activiteit. De verminderde bactericide activiteit is mogelijke veroorzaakt door een toegenomen shunting van glucose door de "polyol pathway". Het is ook waargenomen dat de proliferatiecapaciteit van fibroblasten van diabetes patiënten, verkregen uilt zowel gezonde huid als uit huid 
ter plaatse van thet ulcus, is verminderd. Het mechanisme van deze verminderde fibroblasten proliferatie is onduidelijk, maar berust mogelijk op een verminderde cellulaire respons op een of meer groeifactoren, zoals recent werd verondersteld door Loots et al (ongepubliceerde data).

In de dageijkse klinische praktijk is het essentieel, dat woordat de behandeling wordt gestart, er een volledige evaluatie van het voetulcus plaatsvindt voor een goed verloop van het diagnostische proces en behandeling ${ }^{20}$. De clinicus zou de ulcus karakteristieken (plaats, grootte en diepte), de oorzaak van het ulcus (biomechanische evaluatie), de onderliggende pathologie (ischemie, neuropathie) en de mogelijke complicaties van het ulcus (infectie) moeten evalueren.

Zoals hierboven beschreven spelen vasculaire stoornissen een belangrijke rol in de pathogenese en het verloop van veel diabetische voetulcera. In ongeveer $45 \%$ van de diabetes patiënten met een voetulcus is perifeer vaatlijden aanwezig. Bij veel patiënten gaat de ziekte gepaard met weinig symptomen en heeft het een relatief mild beloop, maar bij andere leidt het tot gestoorde wondgenezing of zelfs progressief weefselverlies. Bovendien is het perifeer vaatlijden, in vergelijking met patiënten zonder diabetes mellitus, meer distaal in de benen gelokaliseerd en heeft het vaak een aggressiever verloop. In tegenstelling tot macrovasculaire afwijkingen wordt diabetische micro-angiopathie niet gezien als een belangrijke pathogenetische factor in het ontstaan van voetulcera. Daarentegen worden er stoornissen in de microcirculatie van de huid van diabetes patiënten gevonden, die mogelijk well leiden tot een toegenomen gevoeligheid van de huid en die bovendien zouden kunnen bijdragen aan de gestoorde wondgenezing.

In de menselijke huid is de microcirculatie opgebouwd uit twee verschillende functionele eenheden. Eén deel bestaat uit de oppervlakkige capillairen in de dermale papilla, die de voeding van de huid en de basale cellagen van de epidermis verzorgen. Het tweede element bestaat uit de sub-papillaire arteriolen en veneuze plexus, die met elkaar verbonden zijn door arteria-veneuze anastomoses (AVA). Deze zijn met name betrokken bij regulering van de lichaamstemperatuur (thermoregulering) en worden geïnnerveerd door sympatische zenuwen, in tegenstelling tot de capillairen die niet zijn geïnnerveerd. Verschillende studies hebben aangetoond dat de totale huiddoorbloeding is toegenomen bij diabetische polyneuropathie, ten gevolge van een toegenomen shunt flow door de sympatisch geïnnerveerde arterioveneuze anastomoses (AVA). Met de laser doppler fluxmetrie werd een toegenomen huiddoorbloeding gevonden in de top van de teen, een plaats waar veel AVA aanwezig zijn. Bij normale omgevingstemperatuur stroomt de meerderheid (80-90\%) van de huiddoorbloeding door deze anastomoses. Sympatische stimulatie resulteert in vasoconstrictie van de anastomoses, waardoor de totale huiddoorbloeding 
aanzienlijk daalt. Aan de andere kant, in pathologische omstandigheden, bijvoorbeeld na sympatische denervatie (wat het geval is bij diabetische polyneuropathie), neemt de basale huiddoorbloeding toe en leidt sympatische stimulatie niet langer tot een afname in huiddoorbloeding. Dit kan een verklaring zijn voor de warme en rode voeten bij patiënten met diabetes mellitus en polyneuropathie. Bij patienten met Type "I diabetes mellitus gaat polyneuropathie gepaard met een parallelle toename van zowel AVA flow als nutritieve capillaire flow, bij patienten met Type 2 diabetes is het effect van polyneuropathie op de microcirculatie onbekend. Daarom hebben wij in hoofdstuk 3 het effect van perifere polyneuropathie (PNP) op de microcirculatie van de huid van patiënten met Type 2 diabetes bestudeerd, in zowel de liggende houding als gedurende het afhangen wan de benen. Zoals verwacht was de huidtemperatuur van de voet, die met name wordt bepaald door de thermoregulatoire huiddoorbloeding. toegenomen in patiënten met PNP, waarschijnlijk tengevolge van de autosympathectomie met opening van de AV-shunts. In gezonde personen gaat acute denervatie van een extremiteit gepaard met cen paralelle toename van zowel de thermo-regulatoire als de capillaire huiddoorbloeding, wat impliceert dat er een nauwe associatie is tussen deze twee vaatbedden. Inderdaad vonden wij een correlatie tussen huidtemperatuur en capillaire doorbloeding (Capillary Blood flow Velocity, CBV) in patiënten met Type 2 diabetes mellitus zonder PNP. Daarentegen was de CBV liggend gemeten lager in patiënten met PNP in vergelijking met patiënten zonder PNP. Bovendien was de CBV omgekeerd gecorreleerd aan de Valk score, wat een klinische maat is voor de ernst van de PNP. Deze data duiden erop dat een toegenomen denervatie is geassocieerd met een toename in thermoregulatoire huiddoorbloeding en een progressieve afname van nutritieve huiddoorbloeding in patiënten met Type 2 diabetes. Deze "capillary steal" zou gerelateerd kunnen zijn aan een gestoorde vasodilatoire capaciteit in patiënten met Type 2 diabetes: het verlies aan sympatische wasoconstrictoire capaciteit zou kunnen resulteren in een afname in vasculaire weerstand in het thermoregulatoire vasculaire bed met daardoor shunting van bloed weg van het nutritieve vaatbed. Deze relatieve hypoperfusie in de nutritieve microcirculatie zou bij kunnen dragen aan de gestoorde wondgenezing bij patiënten met Type 2 diabetes mellitus en polyneuropathie.

Klinische studies veronderstellen dat oedeem een belangrijke factor is in de pathogenese en het resultaat van de behandeling van diabetische voet ulcera. Tijdens afhangen van het been stijgt de veneuze hydrostatische druk, wat resulteert in een vasoconstrictie van de precapillaire sfincters. Deze veno-arteriële reflex beperkt de toename in capillaire hydrostatische druk, de extravasatie van water en vervolgens vorming van weefseloedeem. Bij patiënten met ongecompliceerde Type 1 diabetes mellitus is de capillaire druk en de capillaire filtratie van water toegenomen. Biij patiënten met (ongecompliceerde) Type 2 
diabetes wordt door de meeste onderzoekers een onveranderde capillaire druk en capillaire permeabiliteit voor water gevonden, hoewel in één (oudere) studie een afgenomen capillaire permeabiliteit van water werd gerapporteerd ${ }^{35}$. Gegevens over de invloed van polyneuropathie onbreken echter. Daarom wordt in hoofdstuk 3 in aanvulling op de microcirculatoire parameters, ook de "foot swelling rate" gemeten tijdens afhangen van de benen. Na verandering van de zittende houding naar een houding met afhangende benen, is de 'foot swelling rate' in de eerste 10 minuten na afhangen lager bij patiënten met polyneuropathie dan bij gezonde controle personen. Bovendien is de capillaire permeabiliteit van water gedurende deze periode omgekeerd gecorreleerd aan de Valk score, wat aangeeft dat de ernst van de neuropathie bijdraagt aan dit fenomeen. De verminderde 'swelling rate' in onze neuropatische patiënten zou veroorzaakt kunnen zijn door een toegenomen arteriolaire vasoconstrictoire respons in de voet na afhangen van de benen, wat bij deze patiënten op hetzelfde moment werd aangetoond met de laser doppler fluxmetrie. Het mechanisme van deze toegenomen arteriolaire vasocontrictie is onduidulijk, maar zou gerelateerd kunnen zijn aan de toegenomen gevoeligheid van de veno-arteriolaire reflex, die is ontstaan door chronische denervatie. Een alternatieve verklaring zou kunnen zijn dat reeds in het begin van de studie de interstitiële hydrostatische druk verhoogd was. Inderdaad werd in één eerdere studie een verhoogde interstitiële druk gevonden in patiënten met neuropathie, wat geleid zou kunnen hebben tot een verminderde capillaire permeabiliteit van water tijdens afhangen van het been. Tenslotte werd in zowel MRI als obductie studies gevonden dat polyneuropathie geassocieerd is met kwalitatieve en kwantitatieve verandering in de weke delen van de voet. Deze structurele veranderingen zouden de "foot swelling rate" beinvloed kunnen hebben. Additionele studies zijn nodig om meer inzicht te krijgen in deze processen.

Concluderend bevestigde de studie in hoofdstuk 3 dat PNP in Type 2 diabetes samenhangt met verschillende afwijkingen in de microcirculatie van de huid van de voet, gekenmerkt door een verminderde capillaire bloeddoorstroming, een toegenomen acute vasoconstrictie en een verminderde extravasatie van water nadat men rechtop is gaan zitten. Wij vonden de meest uitgesproken afwijkingen in patiënten met in de voorgeschiedenis een voetulcus, wat suggereert dat stoormissen in de microcirculatie van de huid kunnen bijdragen aan de gestoorde wondgenezing bij patiënten met diabetes mellitus en ulcera aan de voeten. De meest uitgesproken effecten van PNP op de microcirculatie van de huid werden gevonden in de zittende positie. Deze data impliceren dat bedrust in patiënten met Type 2 diabetes en neuropathie een negatief effect zou kunnen hebben op de nutritieve doorbloeding van de huid. Inderdaad vonden wij in de dagelijkse klinische praktijk dat sommige ulcera goed reageerde op het hervatten van 
mobilisatie, onder voorwaarde dat er een goede drukontlasting van de wond plaatsvindt.

'Totall contact casting' (gipstherapie) wordt gezien als de gouden standaard in de behandeling van patiënten met een oppervlakkig, niet geïnfecteerd, niet ischemisch plantair meuropathisch woetulcus. Recente studies hebben aangetoond dat ongeveer $55 \%$ van alle ulcera puur neuropatisch zijn, en dat ongeveer de helft van deze ulcera geinfecteerd zijn. Daardoor voldoen minder dan $30 \%$ van de patiënten in de dagelijkse klinische praktijk aan deze criteria. Om die reden hebben wij, zoals beschreven in hoofdstuk 4 , een prospectieve follow-up studie verricht maar de effectiviteit en veiligheid van gipstherapie in een breed scala aan patiënten. Alle opeenvolgende patiënten die de gipspoli bezachten, werden geincludeerd in deze studie. Zoals ook in andere studies werd aangetoond, bereikten wij goede helingspercentages ( $90 \%$ van de patiënten) biij patiënten met puur neuropatische ulcera. Een opmerkelijke bevinding was de zeer korte helingstijd bij deze laatste groep patiënten, met een mediane tijd-tot-genezing van 18 dagen. Een nieuwe bevinding was dat ook patiënten met een oppervlakkige infectie of matig perifeer vaatlijden effectief en veilig behandeld kunnen worden met gipstherapie. Een oppervlakkige infectie had geen effect op het genezingspercentage in deze studie en milid perifeer vaatlijden ging gepaard met een lichte daling, maar nog steeds goede genezingspercentages (69\%). Maar bij patiënten met zowel mild perifeer vaatlijden als een oppervlakkige infectie werden slechte genezingspercentages bereikt. Voor deze patiëntengroep is gipstherapie ongeschikt en zal voor een andere vorm van drukontlasting gekozen dienen te worden. Er zijn slechts weinig studies verricht naar het effect van infectie op de uitkomst van (neuro-) ischemische diabetische voetulcera. Armstrong et al. toonden aan dat bij patiënten met zowel PAV als infectie meer amputaties werden verricht, maar in deze studie werden patiënten met ernstigere vormen van ischemie en ernstigere infecties geïncludeerd. In een eerdere Maastrichtse studie werd gevonden dat relatief milde stoornissen in de perfusie kunnen bijdrage aan een matige penetratie van antibiotica, met daardoor een verminderde effectiviteit van de antibiotische therapie. In overeenstemming met (inter)nationale richtlijnen, worden patiënten met een oppervlakkige infectie in het academisch ziekenhuis Maastricht behandeld met een smal spectrum antibioticum. Wellicht zou in deze patiëntengroep (patiënten met een oppervlakkige infectie en PAV) een zo hoog mogelijke dosis antibioticum toegediend moeten worden. Ook werden bij patiënten met hielulcera slechte genezingspercentages waargenomen. Voor deze groep dient daarom gezocht te worden naar een alternatieve vorm van drukontlasting van de wond, bijvoorbeeld een gipsmodel met extra ruimte rondom de hiel. Helaas worden de loopmogelijkheden door een dergelijk gipsmodel enorm beperkt. 
In onze studie werden drie verschillende gipsmodellen gebruikt. Enigszins verrassend lijkt een niet-afneembare gipsenschoen even effectief als een nietafneembare corventionele "total contact cast" (TCC) tot onder de knie. Aangezien onze studie niet gerandomiseerd was, zijn additionele studies nodig om te bepalen of dit patiënturiendelijke schoenmodel even effectief is als de klassieke TCC. In de literatuur worden verschillende verklaringen gegeven voor het werkingsmechanisme van gipstherapie, zoals een verplaatsing van de druk van de voet naar de schacht van het gips en immobilisatie van het enkelgewricht. Zoals aangetoond in én eerdere studie, is het gedwongen gebruik van de TCC waarschijnlijk één van de belangrijkste determinanten van succes en inderdaad vonden wij met de afneembare gipsmodellen minder goede resultaten indien de patiënten meer dan 4 weken hiermee behandeld werden. Concluderend bleek 'total contact casting' een zeer effectieve behandeling te zijn bij een brede groep patiënten. Ondanks deze goede resultaten wordt deze therapie nog in zeer weinig centra toegepast, waarschijnlijk door de angst voor complicaties of door het tekort aan gekwalificeerd personeel. Wij vonden inderdaad een hoge incidentie van preulcera (drukplekken), maar ernstige complicaties kwamen zelden voor. De lage complicatie ratio hangt mogelijk samen met de frequente controles van de patiënten.

Helaas neemt met ieder been dat behouden wordt, het aantal benen dat zou kunnen ulcereren toe en is het recidief ulcus een groot probleem geworden voor zowel de patiënt als het zorgsysteem. Recidief percentages van ongeveer $70 \%$ in 5 jaar zijn gerapporteerd in patiënten met neuropatische en neuro-ischemische voetulcera. ledere ulcus episode gaat gepaard met aanzienlijke schade aan huid en onderliggende weefsels en met vorming van littekenweefsel na genezing. Dergelijke veranderingen zouden kunnen leiden tot een toenemende gestoorde wondgenezing met een afname van effectivitiet van de gipstherapie. In hoofdstuk 5 onderzochten we of patiënten met voetulcera herhaaldelijk met gipstherapie behandeld kunnen worden voor een recidief ulcus, zonder verlies van effectiviteit en/of veiligheid van de gipsbehandeling. Er werden geen verschillen in genezingspercentage en genezingssnelheid gevonden bij herhaaldelijk gipsen. Een genezingspercentage van $88 \%$ van alle ulcera werd bereikt met deze drukontlastende therapie. Er werd geen samenhang geconstateerd tussen herhaaldelijke toepassing van gipstherapie en een toename van complicaties; er werd een afname van het aantal complicaties gevonden. Daarbij dient wel te worden opgemerkt dat een selectie bias bijgedragen zou kunnen hebben aan het lage aantal complicaties in ons onderzoek. Het is mogelijk dat patiënten waarbij (serieuze) complicaties optraden niet langer behandeld werden met gipstherapie en dat patiënten waarbij goede resultaten werden behaald herhaaldelijk met gips behandeld werden. Bovendien hebben wij in onze studie niet het effect van gips op de mobiliteit, het spierverlies en de kwaliteit van leven bestudeerd. 
Een opmerkelijke bevinding tijdens de follow-up periode was dat in $75 \%$ van de patiënten de ulcera op verschillende locaties op de voet optraden en dat slechts $25 \%$ van de patiënten éen specifieke regio op de voet had waar de recidief ulcera optraden, wat impliceert dat indien er eenmaal een ulcus op een voet is ontstaan de gehele voet gevaar loopt. Een additionele bevinding was dat PAV geassocieerd leek te zijn met het krijgen van een recidief ulcus. Dit werd eerder door andere onderzoekers ook aangetoond. Edmonds et al. vonden toegenomen plantaire voetdrukken bij patiënten met neuro-ischemie. Mild PAV maakt waarschijniijk de huid gevoeliger voor deze toegenomen biomechanische stress, maar indien een TCC is aangebracht zijn de genezingspercentages acceptabel. In bijna al onze patiënten werd na genezing van het ulcus aangepast schoeisel voorgeschreven. Desondanks kon in een te grote groep patiënten niet voorkomen worden dat er een recidief ulcus ontstond. Zoals beschreven in dit proefschrift zijn nieuwe technieken nodig voor de evaluatie en ontwikkeling van effectiever schoeisel. Daarnaast zouden effectieve educatie programma's ontwikkeld dienen te worden ter preventie van ulcus recidieven. Tenslotte zijn lange termijn studies nodig waarin de (kosten-) effectiviteit en recidiefpercentages van herhaaldelijke conservatieve gipstherapie, van chirurgische interventies voor reductie van biomechanische stress en revascularisatie procedures vergeleken worden. Totdat we kunnen beschikken over deze gegevens, impliceren onze data dat patiënten met neuropatische en neuro-ischemische voetulcera voor recidief ukera behandeld dienen te worden met gipstherapie.

Diabetisch voetulcera zijn een zware belasting voor zowel de patiënt als zijn of haar omgeving. Ondanks het feit dat het ulcus op zichzelf vaak weinig symptomen geeft, zijn de consequenties van het ulcus zeer ingrijpend. In de meeste centra duurt het gemiddeld 11 weken totdat het ulcus genezen is, waarbij gedurende deze periode de mobiliteit sterk beperkt is. In ongeveer $50 \%$ van de patienten treedt een infectie van het ulcus op en is een ziekenhuisopname vaak nodig voor optimale behandeling van deze infectie. Gedurende een ziekenhuisopname worden ook vaak invasieve therapiën, zoals een revascularisatie procedure (PTCA of bypass), een huidtransplantatie of een orthopedische (chirurgische) interventie toegepast. Daarnaast zijn diabetische voetulcera vaak geassocieerd met verschillende microvasculaire en macrovasculaire complicaties, zoals beschreven in hoofdstuk 2 en 4 . Een voetulcus bij een patiënt met diabetes mellitus is vaak een teken dat door de ziekte diverse organen zijn aangedaan, is geassocieerd met een matige prognose, en met een mortaliteit tot $70 \%$ in de eerste 5 jaar. De kwaliteit van leven van deze patiënten kan beinvloed worden door het ulcus, de complicaties van het ulcus, de behandeling van het ulcus, de behandeling van de diabetes en/of de aanwezigheid van comorbiditeit. Er zijn verschillende instrumenten om 'Health-Related-Quality of Life (HRQOL)' te meten. Het meest optimale is om zowel een generiek instrument als een ziekte specifiek instrument 
te gebruiken om HRQoL te meten. Een generiek instrument maakt de vergelijking tussen verschillende ziekten mogelijk en houdt daarbij rekening met onderliggende pathologie en de aanwezigheid van comorbiditeit. Een ziekte specifiek instrument laat zowel de consequenties van het ulcus als ook de behandeling van het ulcus zien. Helaas was ten tijde van onze studie een ziekte-specifiek instrument niet beschikbaar. Onze studies in hoofdstuk 6 en 7 naar de HRQoL van diabetische voet patiënten zijn daarom uitgevoerd met twee verschillende generieke instrumenten. In de eerste studie werd de EQ-5D gebruikt. Dit is een zeer gebruikersvriendelijk generiek instrument om HRQOL te meten en kan door de patiënt zelf in een paar minuten worden ingevuld. We hebben voor dit instrument gekozen omdat het beter toepasbaar is bij grootschalig onderzoek in een grote groep patiënten dan de uitgebreidere SF-36 vragenlijst, die werd gebruikt in onze tweede studie. Bovendien is het met de EQ-5D mogelijk om zogenaamde "quality-of-life-adjustedlive-years (qualy's)' te berekenen, die gebruikt kunnen worden in kosteneffectiviteit studies. Onze tweede HRQoL studie was onderdeel van een prospectieve, gerandomiseerde, placebo-gecontroleerde trial naar de effectiviteit en veiligheid van recombinant 'human platelet-derived growth factor-BB (becaplermin)". Een-en-tachtig verschillende centra in de Verenigde Staten en Europa deden mee aan deze studie.

In onze eerste studie, hoofdstuk 6 , onderzochten wij de invloed van een ulcus en andere diabetes complicaties op de HRQOL van een patiënt met diabetes mellitus. Er werden drie groepen bestudeerd: patiënten met diabetes mellitus zonder en met een voetulcus behandeld door de diabetoloog en diabetespatiënten zonder voetulcera onder behandeling bij de huisarts. Diabetespatiënten met een voetulcus hadden een sterk verlaagde HRQoL, gemeten met de EQ-5D, maar deze afname was onder andere gecorreleerd aan onderliggende pathologie en overige diabetes complicaties. Multivariaat analyse liet zien dat neuropathie éen van de meest belangrijke onafhankelijke determinanten van HRQoL was in de totale patiëntengroep. Omdat bijna alle patiënten met een voetulcus ook neuropathie hadden, was het niet mogelijk om cross-sectioneel het onafhankelijk effect van het ulcus te bepalen. In de dagelijkse klinische praktijk wordt neuropathie gezien als een relatief milde en asymptomatische diabetes complicatie. Er zijn slechts enkele studies verricht naar het effect van neuropathie op HRQOL. Ons inziens is er meer informatie nodig over zowel de fysieke als mentale consequenties van neuropathie en zouden additionele therapiën ontwikkeld dienen te worden om het ongemak van deze complicatie te verminderen. In het tweede gedeelte van deze studie werden er geen veranderingen in HRQoL gevonden na genezing van het ulcus, en de lage HRQOL, gemeten met de EQ-5D, kan daarom gezien worden als een uiting van een matige algehele gezondheidstoestand. Aan de andere kant zou de afwezigheid van een effect van genezing van het ulcus op de HRQOL verklaard kunnen worden door de keuze van het instrument, want de schaal van de 
verschillende vragen van de EQ-5D lijkt ongeschikt en te beperkt om belangrijke veranderingen bij voetpatiënten op te vangen. Een voorbeeld is de schaall mobiliteit waarin de keuzemogelijkheden zich beperken tot "geen problemen", 'aanwezigheid van problemen' en 'gekluisterd aan bed'. Omdat er bijna geen patiënten in de laatste categorie zullen vallen is de enige verandering in die schaal mogelijk van 'geen problemen' naar de 'aanwezigheid van problemen'. Tenslotte zou het aantal patiënten dat in deze studies in geindudeerd te klein kunnen zijn om een effect van het uicus te vinden.

Om toch de invloed van een actief voetulcus op de HRQoL van een diabetespatiënt te onderzoeken, hebben wij een tweede studie uitgevoerd met een sensitiever instrument (SF-36). Deze studie, waarin de HRQoL van diabetische voetpatiënten en hun verzorgers wordt gemeten, wordt beschreven in hoofdstuk 7. De SF-36 is een generiek instrument met een uitgebreidere scoringsschaal in vergelijking met de EQ-5D. Prospectieve studies hebben aangetoond dat dit instrument beter is om veranderingen in de loop van de tijd op te sporen. Diabetes mellitus patiënten met een voetulcus rapporteren een opvallend lage HRQOL op alle subschalen van de SF-36 en hun kwaliteit van leven is te vergelijken met patiënten met longkanker. Verder lijkt het voetulcus een onafhankelijk en relatief groot effect te hebben op de HRQoL van zowel de patiënt als zijn verzorger. Genezing van het ulcus resulteert in een sterke toename van de HRQOL in vergelijking met een een progressieve afname van de HRQoL indien het ullcus blijt bestaan, bij zowel de patiènt als de verzorger van de patiënt. Patiënten met diabetische voetulcera ervaren de meeste problemen met de fysieke subschalen van de SF-36 vragenlijst. Het grootste verlies in HRQOL werd gevonden in schalen en items gerelateerd aan mobiliteit. Na genezing van het ulcus zijn de drukontlastende therapiën (hulpmiddelen) niet meer nodig en worden deze maatregelen gestaakt. Dit zou bijgedragen kunnen hebben aan de verbetering van de mobiliteit en aan de toename in HRQOL na genezing van het ulcus. Er zijn weinig data beschikbaar over de invloed van de verschilende drukontlastende therapiën op de HRQOL van de patient. Aanvullende studies zijn hiervoor nodig. In tegenstelling tot de patiënten, rapporteren de verzorgers de meeste problemen op schalen die betrekking hebben op de aanwezigheid van emotionele problemen bij de verzorger. Gedurende de tijd dat het ulcus van de patiënt aanwezig is, is er een progressief verlies in $\mathrm{HRQOL}$ bij de verzorger. Aan de andere kant trad er een sterke verbetering op in de subschaal die betrekking heeft op emotionele problemen, na genezing van het ulcus. Tenslatte was er een sterke correlatie tussen de HRQoL van de patiënt en zijn verzorger, implicerend dat veranderingen in de HRQOL van de verzorger waarschijnlijk zijn veroorzaakt door het ulcus van de patiènt. Deze data benadrukken dat het belangrijk is om de tijd tot genezing van het ulcus zo kort mogelijk te houden. Zoals eerder beschreven is er gedurende de aanwezigheid van het ulcus een risico op een infectie, een risico op een amputatie en is er een 
progressief verlies in 'Health-Related-Quality of Life' van de patiënt, zoals aangetoond in onze studie beschreven in hoofdstuk 7. Daarom zouden er effectievere therapiën ontwikkeld dienen te worden die de genezingstijd zo kort mogelijk maken. Zolang het ulcus aanwezig is, is er ook een progressief verlies in HRQoL bij de verzorger van de patient. Deze verzorgers spelen een essentiele rol in het leven van diabetische voetpatiênten. In de moderne tijd waarin wij leven, staan kostenbesparingen in de gezondheidszorg hoog op de agenda van politici, derhalve zijn deze (onbetaalde) verzorgers ook vanuit kosteneffectiviteit zeer belangrijk. Daarom zou er, tijdens de drukke voetenpoli's, meer tijd en aandacht gegeven dienen de worden aan de rol die de verzorgers spelen bij de behandeling van de voetulcera van de patiènt, en aan de zware emotionele last die deze zorg met zich meebrengt.

In het licht van de continue groeiende groep mensen met diabetes mellitus, blijven voetproblemen een groot probleem in de zorg. Het aantal patiënten dat op een relatief jonge leeftijd Type 2 diabetes mellitus ontwikkelt, zal stijgen en daardoor zullen zij tijdens het verloop van hun ziekte vaker geconfronteerd worden met de aanwezigheid van neuropathie. Hierdoor zal het aantal patiënten toenemen dat neuropathische voetulcera ontwikkelt in een fase in hun leven waarin zij nog zeer actief zijn en vaak deelnemen aan de arbeidsmarkt. Aan de andere kant worden wij gemiddeld steeds ouder en neemt met deze veroudering de kans op het ontwikkelen van perifeer vaatlijden toe, waardoor er in de toekomst meer patiënten met (neuro-) ischemische voetulcera zullen zijn. Daarom is het zeer belangrijk om te blijven werken aan het ontwikkelen van nieuwe therapieën die voetulcera voorkomen en de uitkomst van een voetulcus verbeteren. De resultaten van de studies die in dit proefschrift beschreven worden hebben een aantal implicaties voor de dagelijkse zorg van diabetespatiënten met voetproblemen. We hebben aangetoond dat in patienten met polyneuropathie een aantal afwijkingen in de microcirculatie aanwezig zijn die gecorreleerd zijn aan de ernst van de zenuwschade, en dat deze stoornissen het meest uitgesproken zijn in patiënten met een voetulcus in de medische voorgeschiedenis. Aanvullend onderzoek is nodig om het effect van deze microcirculatoire stoornissen op de wondgenezing te onderzoeken en om te onderzoeken of deze stoornissen verholpen kunnen worden met specifieke therapieen. Onze studies over gipstherapie bij plantaire voetuicera benadrukken de goede resultaten van deze therapie bij een gevarieerde groep patiënten. In een recent Europees onderzoek bij gespecialiseerde voetklinieken bleek dat ook in deze centra gipstherapie niet vaak werd toegepast (the Eurodiale group, ongepubliceerde data). We zullen moeten proberen om gipsbehandeling voor meer patiënten mogelijk te maken door wereldwijd meer gipspoliklinieken te starten. Daarnaast zullen er aanvullende studies verricht dienen te worden naar het effect van alternatieve drukontlastende therapieën, zoals opblaasbare niet-afneembare casts en de gipsenschoen, zoals ontwikkeld in ons 
centrum. Ondanks vele preventieve maatregelen kunnen recidief ulcera waak niet voorkomen worden, en ondanks het feit dat deze patiënten steeds met gipstherapie behandeld zouden kunnen worden; zijn effectievere preventieve therapiën nodig. Zulke preventieve inspanningen zijn meestal gericht op verbetering van de biomechanische drukbelasting van de voet. Echter, aangezien het merendeel van onze patiënten met recidief ulcera ook leed aan perifeer vaatlijden zullen er strategiën ontwikkeld moeten worden om de weefsel perfusie bij deze patiënten te verbeteren. Dit proefschrift laat zien dat voetulcera en de behandeling van het ulcus een grote invloed hebben op de kwaliteit van leven van zowel de patiënt als zijn verzorger: deze effecten op kwaliteit van leven dienen in acht genomen te worden bij de ontwikkeling van nieuwe therapiën. De slechte kwaliteit van leven van patiënten met een diabetisch voetulcus wordt deels verklaard door het ulcus zelf en deels door de onderliggende pathologie, met name neuropathie. Er is duidelijk aanvullend onderzoek nodig om te bepalen welke factoren verantwoordelijk zijn voor het verlies van kwaliteit van leven bij diabetische neuropathie en daarna zouden nieuwe behandelingstechnieken ontworpen dienen te worden. Tenslotte is de mortaliteit onder deze patiënten zeer hoog en is het wenselijk om nieuwe strategieën te ontwikkelen om de prognose van deze patiëntengroep te verbeteren. 


\section{Dankwoord}




\section{Dankwoord}

De klus is geklaard, een spreekwoordelijke boom is tot bloei en volwassenheid gekomen. Dit was niet mogelijk geweest door de inzet en thulp van velen. Een dankwoord is nooit compleet, enkelen zou ik willen noemen.

Om een boom te laten groeien zijn voedingsstoffen noodzakelijk, zonder patiënten en vrijwilligers is het onmogelijk om enige groei mogelijk te maken. Daarom wil ik de vele patiënten en vrijwilligers danken voor de medewerking aan de onderzoeken. Zonder hun steun was het niet mogelijk geweest om de onderzoeken uit te woeren en nieuwe inzichten en behandeltechnieken te ontwikkelen.

Prof. dr. AC Nieuwenhuijzen Kruseman, beste Arie. Onder jouw leiding ontstond er, zoals jij dat zo mooi verwoordt, een "promotieteam". Onze afzonderlijke kwaliteiten werden gebundeld in een gezamenlijke groei. Ik will je graag bedanken voor het vertrouwen in het manuscript. Tevens heb ik jouw hulp bij het verbeteren van de teksten, het "time-management" en de begeleiding van het totale proces zeer gewaardeerd.

Dr. NC Schaper, beste Nicolaas. Dank voor jouw enthousiasme en onuitputtelijke wetenschappelijke interesse, die ertoe leidde dat we menigmaal een boom hebben opgezet over nieuwe mogelijkheden voor ons onderzoek. Jij leerde mij de kneepjes van het wetenschappelijke onderzoek, zowel als de finesses bij de behandeling van de diabetische voet. Het bijschaven van teksten, snoeien in verkeerde uitlopers van het onderzoek en het enten van nieuwe loten aan deze onderzoeksboom. Daarnaast maakte jij het mogelijk om mee te werken aan de 'internationale consensus'. We hebben vele intensieve weekenden gehad, waar ik met veel plezier aan terug denk.

Dr. MSP Huijberts, beste Maya. Op jou heb ik de laatste jaren kunnen steunen. Als ik een voetje nodig thad om hogerop te komen, dan kon ik op jouw hulp rekenen. Van jou hoorde ik hoe het spel in het wetenschappelijke woud gespeeld wordt. Maar jij hebt ook een belangrijke bijdrage geleverd aan het verbeteren van de teksten en het duidelijker en overzichtelijker presenteren van onderzoek en conclusies. Met andere woorden, jij zorgde voor meer kleur en variatie in mijn onderzoeksboom. Als 'room-mate' hebben we een aantal goede congressen meegemaakt en hebben we er ook een gezellige tijd van kunnen maken.

Aan het einde van het groeiproces was het aan de beoordelingscommissie om het resultaat in al haar facetten te beoordelen. Graag wil ik Prof, dr. PJEHM Kitslaar, 
Prof. dr. JM Apelquist, Prof. dr. C Spreeuwenberg en Prof. dr. CDA Stehouwer, bedanken voor het positieve commentaar en de goedkeuring van het manuscript.

Daarnaast wil ik de leden van het "Voetenteam", Jean Willems, Jolanda ClaessensVersprille, Peter Kitslaar, Jan Tordoir, Luc v.d. Akker, Joep Veraart, Antal Sanders, Michael Brouwers, Marjon van Eysden, Joop Ruygrok, Hans Emmen, Thijs Smeets, Thomas Kaidijk, Kitty Daemen, Geerd Walenkamp, Nick Guldemond, Mia Munnix, Fieke Damoiseaux en Ludo Penninger heel hartelijk danken voor de prettige samenwerking. Zoals wij inmiddels weten is een aanpak vanuit verschillende disciplines essentieel om tot een goede behandeling te komen, een boom moet zowel gesnoeid, bemest, beschermd en ondersteund worden. ik denk dan ook met veel plezier terug aan de vaste ronde op donderdagochtend en de voetenpoli's.

Ook wil ik de gipsmeesters: Sven Iser, Ludo Opsteyn, Chris Ottenbros, Eugène Rüth, Ron Sleegers en Wiel Wijnen bedanken. Gebleken is dat sommige takken beter herstellen als zij op een goede wijze ingepakt worden totdat zij hersteld zijn. Jullie onuitputtelijke inzet en secure manier van data verzameling heeft er mede voor gezorgd dat we deze mooie resultaten hebben bereikt. Ik zal de gezelligheid van de gipskamer missen!

De vele (internationale) contacten van Dr. NC Schaper, Nicolaas, maakte het mogelijk om met verschillende centra onderzoek te verrichten, andere werkbijen die zorgden voor kruisbestuiving, bevestiging of versterking van ons onderzoek. Prof. de JM Apelqvist en het Öresund Diabetes Team: many thanks for the nice working together. Dr. $K$ Bakker: bedankt voor de fijne samenwerking in de internationale consensus en de organisatie van het congres in Noordwijkerhout. Dr. K Redekop: wij hebben veel contact gehad via email en telefoon. Veel dank voor de bereidwilligheid om te helpen als ik daarom vroeg, zowel inhoudelijk als voor vertalingen. Dr. I Sijbrandij: vele uren hebben wij gepuzzeld om tot de juiste statistische analyse te komen. Veel dank voor jouw hulp!

Verder wil ik ieder werkzaam op het Circulatielaboratorium, Esther Beeks, Jörgen ten Berge, Karin Franken, Eric Keulen, Marieke van Onna, Wilco Spiering, Kim van der Zander, Boy Houben, Dorien Bleeker, Stella Brand, Monique Fuss en de studenten Boukje van Casteren, Iris Debats, Jolanda Dennert en Anniek Peters, heel hartelijk danken. Het lab was als een broeikas in het begin van mijn onderzoek, daar ontstonden de gegevens, die de basis vormden voor mijn onderzoeken. Ook wil ik Claudia de Haan bedanken voor de ondersteuning van de lab-studies en de waardevolle vriendschap die daaruit voortgekomen is. 
De werkgroep endocrinologie, de natuurlijke omgeving, waarin deze wetenschappelijke boom tot bloei is gekomen: Marion Graal, Caroline Heijckmann, Frank Huvers, Melanie van der Klauw, Sabine Landewé-Cleuren, Ronald van Schelven. Jean-Pierre Sels, Bruce Wolffenbuttel, Leonne Prompers, Marcel Bruijsten, Lianne Daemen, Els Denis, Annemie van Haarlem, Yvonne Hermans-Brassé, Bea Jöbses, Sylvia Martens, Hannie Bouchoms, Christine Coenen, Wilke Ellenbroek, Ingrid Hogenboom, Bertie Janssen, Annie Peeters en Marion Wijnandts, wil ik bedanken. En uiteraard dank ik Tiny Wouters voor de lay-out van het boekje.

Mijn begeleiders en mede-assistenten in het Maasland Ziekenhuis in Sittard hebben mij gelukkig de vrijheid gegeven om het onderzoek af te ronden. Een boom moet ruimte hebben om te groeien. Ik wil hen graag van harte danken voor de ruimte die mij geboden is.

Lieve mam en pap, jullie hebben de basis, de bodem gecreëerd, waaruit alles voortgekomen is. Lieve mam, jij was en bent er altijd als ik je nodig heb en jij hebt mij altijd ondersteund en geïnspireerd om dit resultaat te bereiken. Jouw studie tijdens onze kleuterjaren, leerde ons dat het leuk is om jezelf te ontplooien. Jij hebt het zaadje geplant en al die jaren goed verzorgd, daaruit ontstond het begin, waaruit dit mooie eindresultaat gegroeid is.

De vele hulptroepen, met name Dory en Ria, die in wilde springen om het thuisfront ook bij zwaar weer te beschermen tegen natuurlijke of andere invloeden, wil ik ook van harte danken. Zonder jullie was het niet mogelijk geweest.

Lieve Tjebbe, door jouw continue ondersteuning hebben wij samen deze boom tot bloei kunnen brengen. De vele kopjes thee, de zorg voor de kinderen en vooral je onuitputtelijke vertrouwen in mij, maken het mogelijk om alles wat wij graag willen te kunnen realiseren. Tenslotte onze lieve kleine mannetjes, het mooiste wat ons is geschonken en de basis van ons geluk. 
Curriculum vitae 


\section{Curriculum vitae}

Marrigje Hubertine Nabuurs-Franssen werd op 6 maart $197 \|$ geboren in Nijmegen. $\mathrm{Na}$ het behalen van het WWO diploma aan het Elshof College in Nijmegen, startte zij in 1989 met de studie Gezondheidswetenschappen aan de Universiteit van Maastricht. Na een jaar werd de propedeuse behaald en slaagde zij ook voor het VWO certificaat natuurkunde, waardoor het mogelijk werd om in 1990 te starten met de studie geneeskunde, eveneens aan de Universiteit van Maastricht. Tijdens haar studie kwam zij reeds in aanraking met wetenschappelijk onderzoek. Eerst bij de vakgroep huisartsgeneeskunde onder begeleiding van Prof. dr. HFJM Crebolder en later bij de vakgroep interne geneeskunde, werkgroep endocrinologie onder begeleiding van Dr. NC Schaper. Na het behalen van het artsexamen in 1997 werd zij aangesteld als arts-onderzoeker binnen de werkgroep endocrinologie met als aandachtspunt 'de diabetische voet'. In 1998 begon zij als AlO (Assistent-InOpleiding) aan het onderzoek 'The Diabetic Foot'. De resultaten van dit onderzoek heeft $u$ kunnen lezen in dit proefschrift. In oktober 2003 is zij gestart met de opleiding interne geneeskunde in het Maasland ziekenhuis te Sittard (opleider Dr. BJ Looij). Vanaf augustus 2005 zal de opleiding worden voortgezet in het Canisius Wilhelmina ziekenhuis te Nijmegen (opleider Dr. ASM Dofferhoff). Zij is getrouwd met Tjebbe Nabuurs en samen hebben zij drie prachtige zonen, Tjielke (2001), Jouke (2003) en Doeke (2005). 